\title{
Fatigue and psychological distress in the working population : the role of work and lifestyle
}

Citation for published version (APA):

Bultmann, U. (2002). Fatigue and psychological distress in the working population : the role of work and lifestyle. [Doctoral Thesis, Maastricht University]. Datawyse / Universitaire Pers Maastricht. https://doi.org/10.26481/dis.20020412ub

Document status and date:

Published: 01/01/2002

DOI:

10.26481/dis.20020412ub

Document Version:

Publisher's PDF, also known as Version of record

\section{Please check the document version of this publication:}

- A submitted manuscript is the version of the article upon submission and before peer-review. There can be important differences between the submitted version and the official published version of record.

People interested in the research are advised to contact the author for the final version of the publication, or visit the DOI to the publisher's website.

- The final author version and the galley proof are versions of the publication after peer review.

- The final published version features the final layout of the paper including the volume, issue and page numbers.

Link to publication

\footnotetext{
General rights rights.

- You may freely distribute the URL identifying the publication in the public portal. please follow below link for the End User Agreement:

www.umlib.nl/taverne-license

Take down policy

If you believe that this document breaches copyright please contact us at:

repository@maastrichtuniversity.nl

providing details and we will investigate your claim.
}

Copyright and moral rights for the publications made accessible in the public portal are retained by the authors and/or other copyright owners and it is a condition of accessing publications that users recognise and abide by the legal requirements associated with these

- Users may download and print one copy of any publication from the public portal for the purpose of private study or research.

- You may not further distribute the material or use it for any profit-making activity or commercial gain

If the publication is distributed under the terms of Article $25 \mathrm{fa}$ of the Dutch Copyright Act, indicated by the "Taverne" license above, 
Fatigue and Psychological Distress in the Working Population:

The Role of Work and Lifestyle 
ISBN 9052783403

Lay-out: Cobie Martens, Ute Bültmann, UM Epidemiologie, Maastricht

Cover: Artwork by courtesy of KEYKEY Company, Leiden

Printing: Datawyse / Universitaire Pers Maastricht

Q 2002, U. Bültmann

All rights reserved. No part of this thesis may be reproduced or transmitted in any form or by any means, electronic or mechanical, including photocopying, recording or any information storage or retrieval system, without permission in writing from the author, or, when appropriate, from the publishers of the publications. 


\title{
Fatigue and Psychological Distress in the Working Population: The Role of Work and Lifestyle
}

\author{
PROEFSCHR\|FT \\ ter verkrijging van de graad van doctor aan \\ de Universiteit Maastricht, \\ op gezag van de Rector Magnificus, \\ Prof. dr. A.C. Nieuwenhuijzen Kruseman, \\ volgens het besluit van het College van Decanen, \\ in het openbaar te verdedigen \\ op vrijdag 12 april 2002 om 14.00 uur \\ door
}

Ute Bültmann

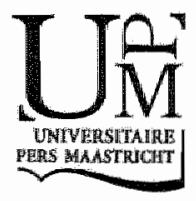




\section{Promotores}

Prof. dr. ir. P.A. van den Brandt

Prot. dr. S.V. Kasl (Yale University School of Medicine, New Haven, CT, USA)

\section{Co-promotor}

Dr. ing. I.J. Kant

\section{Beoordelingscommissle}

Prof. dr. J.A. Knottnerus (voorzitter)

Prof dr. F.J.N. Nijhuils

Prof. dr. W.B. Schaufeli (Universiteit Utrecht)

Prof. dr. F. Sturmans

Prof: dir. Ch.J. de Wolff (Katholieke Universiteit Nijmegen)

The Maastricht Cohort Study is part of the Netherlands concerted research action on "Fatigue at Work" granted by the Netheriands Organization for Scientific Research (NWO). The study presented in this thesis was supported by the Netherlands Organization for Scientific Research (NWO grant no. 580-02.251).

The study presented in this thesis was conducted at the Maastricht Health Research Institute for Prevention and Care (HEALTH), Universiteit Maastricht, the Netherlands. HEALTH participates in the Netherlands School of Primary Care Research (CaRe), which was acknowledged in 1995 by the Royal Netherlands Academy of Arts and Sciences (KNAW). 


\section{CONTENTS}

1 Introduction

2 Measurement of prolonged fatigue in the working population:

Determination of a cutoff point for the Checklist Individual Strength

3 Fatigue and psychological distress in the working population:

Psychometrics, prevalence, and correlates

4 The relationship between psychosocial work characteristics and fatigue and psychological distress

5 Psychosocial work characteristics as risk factors for the onsel of fatigue and psychological distress:

Prospective results from the Maastricht Cohort Study

6 Differences in fatigue and psychological distress across occupations:

Results from the Maastricht Cohort Study of Fatigue at Work

7 Lifestyle factors as risk factors for fatigue and psychollogical distress in the working population:

Prospective results from the Malastricht Cohort Study

8 Epilogue

Summary

Samenvatting

Appendix: Fatigue among working people: validity of a questionnaire measure

Acknowledgements

About the author 


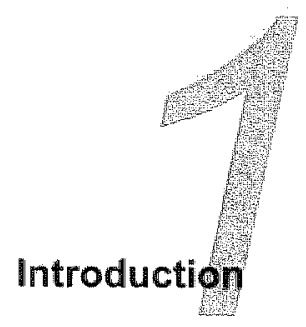


In recent years, fatigue in the working population has attracted renewed attention in occupational (mental) health research. ${ }^{1-4}$ In the Netherlands, the increasing awareness of the impact of fatigue on the individual employee, the employer and the society has led to the recognition that there is little information about the magnitude of fatigue in the working population and about the risk factors involved in the etiology of fatigue in the working population. The absence of these data and the need for preventive measures has prompted the establishment of the Netherlands' concerted research action on "Fatigue at Work", granted by the Netherlands Organization for Scientific Research (NWO). This multidisciplinary, 6-year national research program was initiated in 1996, and includes medical and psychological research on acute and prolonged fatigue in the working population.

In 1998, as part of the Netherlands' concerted research action, the large-scale epidemiological Maastricht Cohort Study of "Fatigue at Work" was set up (1) to gain insight into the prevalence and incidence of prolonged fatigue in the working population, (2) to identify risk factors involved in the onset and natural course of fatigue in the working population, and (3) to investigate the effectiveness of different treatments of fatigue. The purpose of the study presented in this thesis was to determine the prevalence and incidence of prolonged fatigue and psychological distress in the working population, and to identify possible risk factors for the onset of fatigue and psychological distress in the working population.

\section{Fatigue}

Numerous studies have repeatedlly shown that fatigue is a common complaint. ${ }^{5-12}$ in a review on the epidemiology of fatigue in both the community and primary care settings, Lewis \& Wessely ${ }^{13}$ reported prevalence rates varying from $7 \%$ to $45 \%$. Although different definitions of fatigue, different settings, different response rates, the different measurement of fatigue, and different duration criteria for fatigue hinder a direct comparison " the prevalence of fatigue was $14.3 \%$ in men and $20.4 \%$ in women in the US Health and Nutrition Examination Survey, ${ }^{5}$ $22 \%$ ( $11 \%$ for 6 month or longer) in the general Norwegian population, ${ }^{11} 25 \%$ (at least 2 weeks duration) in an Australian primary care study, ${ }^{10}$ and $38 \%$ ( $18 \%$ for 6 month or longer) in a UK community survey.

The definition and the assessment of fatigue have been subjects of controversy for many years. ${ }^{13.16}$ Even though an extensive body of literature on this complex subject was helpful in advancing the understanding of the concept of fatigue, some issues remain largely unresolved. For example, What is the relationship between the mild, frequent complaints of fatigue seen in the community and the severe, disabling fatigue characteristics of chronic fatigue syndrome? ${ }^{13.17}$ At present, we do know that fatigue is a common complaint, is difficult to measure, and that fatigue as a concept is best vieved as a continuum. Several studies in the community and in primary care settings have shown that fatigue is continuously distributed, with some degree of fatigue in nearly all of the population. ${ }^{6.5 .11}$ In Wessely's words "Fatigue is not something that one has or does not have. We all experience fatigue. but some have it for longer periods or at a greater intensity than another", ${ }^{17}$

While fatigue that occurs as a normal, everyday phenomenon is usually relieved by a period of rest prolonged fatigue is not easily reversible in the short term, ${ }^{3.16}$ may accompany 
physical ithessest and psychiatric disorders, ${ }^{1,5,8,0,11,49}$ and may also affect the individualis performance and ability to function in the accupational and home settings. Moreover, prolonged fatigue may lead to sickness absence and (work) disability. ${ }^{20}$ In the Netherlands, about one in every three work disability benefit recipients is classified as disabied for work on mental grounds. ${ }^{21}$ It is generally assumed that prolonged fatigue is a major symptom in this kind of work disability. Since prolonged fatigue not only affects the individuals" performance and ability to function, but also may have consequences in terms of sickness absence and (work) disability, it is a pressing social and economic problem calling for preventive action.

Fatigue is thought to have a multifactorial etiology. ${ }^{13.17}$ Over the years, fatigue was found to be associated with a wide range of factors, such as demographic, social, behavioral, physical, and psychological factors. ${ }^{5,8,0,11,22}$ For example, in a UK population-based study. psychosocial reasons were most often mentioned as explanation for feeling fatigued. ${ }^{2}$ With regard to the working population, Hardy and colleagues " reported in a cross-sectional study using specific occupational groups in the workforce of the UK National Health Service Trusts, that high work demands and role conflict were related to high levels of fatigue. Another cross-sectional study among Israeli industrial employees revealed that "not being active during leisure time" and smoking ten or more cigarettes per day were associated with more complaints of severe fatigue. ${ }^{23}$ Obviously, there is a variety of factors, such as work-related factors, individual characteristics, but presumably also domestic and social factors, eg. demands in home life, which may be involved in the onset of fatigue in the working population. Given the cross-sectional nature of most previous studies of factors related to fatigue, it is important to note that a secure interpretation concerning cause and effect is not possible. For the development of effective preventive measures for fatigue, it is however highly desirable to learn as much as possible about the etiological role of putative risk. factors. To begin to disentangle which factors may play a role in the onset of fatigue. longitudinal analyses are invaluable. The epidemiological Maastricht Cohort Study contributes to this research field with a large-scale, prospective study of prolonged fatigue in the working population.

\section{THE MAASTRIGHT COHORT STUDY OF "FATIGUE AT WORK"}

\section{Design}

The epidemiological Maastricht Cohort Study of "Fatigue at Work" was established (1) to determine the prevalence and incidence of prolonged fatigue in the working population, (2) to identify possible risk factors for the onset and natural course of fatigue in the working population. and (3) to investigate the effectiveness of different treatments of fatigue. The design of the prospective Maastricht Cohort Study stems from the understanding of fatigue as a continuum, ranging from mild, frequent complaints - experienced by everybody - to severe, disabling fatigue characteristics, with a likely multifactorial etiology, including complex interactions between risk factors and (mental) health outcomes.

To explore the onset and natural course of fatigue, al prospective cohort design was used with a 3-year follow-up period. Because fatigue can range from mild, frequent complaints to severe, disabling fatigue characteristics, different (mental) health outcomes were assessed. That were: need for recovery (or unwinding), fatigue, and burnout on the one hand, and 
consequences in terms of sickness absence and work disability on the other. Psychological distress was measured as well, since various studies have shown that fatigue is associated with psychological distress.,8.10,24-20 However, hardly any studies have examined the relationship between fatigue and psychological distress in the working population, and addressed the question as to whether fatigue is etiologically distinct from psychological distress.

To identify the possible risk factors involved in the onset and natural course of fatigue, three domains of exposure, comprising a variety of work-related factors, domestic and social factors, as well as individual characteristics, were assessed. Table 1 shows an overview of the risk factors that were measured within the Maastricht Cohort Study of "Fatigue at Work".

Table 1 Overview of risk factors included in the Maasticht Cohot Study of "Fatigua at Work"

\begin{tabular}{|c|c|c|}
\hline Domain & Calagory & Aspect \\
\hline \multirow[t]{7}{*}{ Work-related factors } & Wok content & $\begin{array}{l}\text { Psycholongical job demands } \\
\text { Decision authority } \\
\text { Skill discretion } \\
\text { Role ambiguity } \\
\text { Job tille I lass }\end{array}$ \\
\hline & Work relations & $\begin{array}{l}\text { Supervisor social support } \\
\text { Coworker social support } \\
\text { Conflict with supentersor } \\
\text { Confllict with coworker }\end{array}$ \\
\hline & Conditions of employment & $\begin{array}{l}\text { Working hours } \\
\text { Job insecurity } \\
\text { Career opportunities } \\
\text { Job history }\end{array}$ \\
\hline & Wark conditions & $\begin{array}{l}\text { Physical demands } \\
\text { Emotional demands } \\
\text { Mental demands }\end{array}$ \\
\hline & Perception of work & $\begin{array}{l}\text { Effortreward balance } \\
\text { Faimess } \\
\text { Commitherit } \\
\text { Jób satusfactor }\end{array}$ \\
\hline & Organization & Culture \\
\hline & Professional suppont & $\begin{array}{l}\text { Occupalional Health Service } \\
\text { Primary heath care }\end{array}$ \\
\hline Domestic \& social factors & & $\begin{array}{l}\text { Priwate situalion } \\
\text { Leisure activilies } \\
\text { Daily hassies } \\
\text { Life events }\end{array}$ \\
\hline \multirow[t]{3}{*}{ Individual characteristics, } & Demographics & Age, gender, aducaional level \\
\hline & Health \& Well-being & $\begin{array}{l}\text { Health status } \\
\text { Lifestyle } \\
\text { Chroric disease }\end{array}$ \\
\hline & Personal charticteristics & $\begin{array}{l}\text { Coping } \\
\text { Negative affectiwity }\end{array}$ \\
\hline
\end{tabular}


In order to investigate the wide variety of risk factors, to ensure variation in the risk factors, and to obtain sufficient incident cases during the period of follow-up, a large, heterogeneous occupational study population was required. In the Maastricht Cohort Study, a total of 26,978 employees were asked to participate, of which 12,161 employees completed and returned the baseline questionnaire.

In the work stress literature, it has been argued that different exposure variables may follow different exposure time courses, ranging from few month for short term effects (initial impact) to one or more years for long term effecis (time exposure concept) ${ }^{27}$ Since not only different exposure variables but also different (mental) health outcomes may follow different time courses, repeated measurements were strongly required. In the Maastricht Cohort Study. (changes of) exposure variables and (mental) health outcomes were frequently measured. that means every 4 month (Table 2). This frequent sampling also allows to examine the complex interactions between exposure variables and (mental) health outcomes, such as leedback mechanisms and reverse causation. ${ }^{23}$

Table 2 Measurement of exposure variables and health outcames in the Maastricht Cohort Sudy of "Fatigue ai Work"

\begin{tabular}{|c|c|c|c|}
\hline \multirow[t]{2}{*}{ Tïne: } & \multicolumn{2}{|c|}{ Exposure measurement } & \multirow[t]{2}{*}{ Outcome measurement } \\
\hline & Extensive questionnaire & Short questionnaire & \\
\hline May 1998 (Baseline) & - & & - \\
\hline September 1998 & & $\bullet$ & $\bullet$ \\
\hline January 1999 & & $\cdot$ & $\bullet$ \\
\hline May 1999 & - & & $\bullet$ \\
\hline September 1999 & & 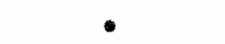 & 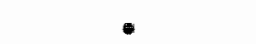 \\
\hline January 2000 & & $\bullet$ & - \\
\hline May 2000 & * & & - \\
\hline September 2000 & & 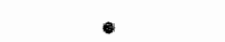 & 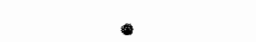 \\
\hline January 2001 & & - & - \\
\hline
\end{tabular}

During the 3-year follow-up period from May 1998 until January 2001, data on demographics, work-related factors, domestic and social factors (eg. home life, leisure time activities), individual characteristics, and (mental) health outcomes were obtained yearly by means of an extensive, mailed selfadministered questionnaire. In addition to the yearly collection, follow-up data on (mental) health outcomes were gathered twice a year by a short. mailed self-administered questionnaire. Additional data on sickness absence were obtained by record linkages to company sickness absence and work disability registry systems and by subsequent telephone interviews.

\section{Study population}

In May 1998, 26,978 male and female employees, aged 18 to 65 years, from 45 Dutch companies and organizations received an introductory letter at home inviting participation and the baseline questionnaire. The letter explained the purpose and the general outline of the cohort study, described how the data would be used, and guaranteed anonymity of responses. The voluntary mature of participation was emphasized. A total of 12,161 
employees completed and retumed the baseline questionnaire. The overall response rate was $45 \%$. Written consent was obtained from all participants. Sixty-six questionnaires were excluded from the analysis because the age criterion was not met or due to technical reasons. The baseline cohort consisted of 12,095 employees: 8840 men ( $73 \%$ ) and 3255 women $(27 \%)$.

In May 1999, those employees $(n=11,272)$ who had completed the baseline questioninaire and at least one of the two short questionnaires, which were sent in September 1998 and January 1999, were approached again to complete the 1-year follow-up questionnaire. A totall of 9625 employees, 7025 men $(73 \%)$ and 2600 women $(27 \%)$, completed and returned the 1-year follow-up questionnaire (response rate of $80 \%$ ). In May 2000, those employees (n = 9200) who had completed the 1-year follow-up questionnaire in May 1999 and at least one of the two short questionnaires, which were sent in September 1999 and January 2000, were asked to complete the 2-year follow-up questionnaire. A total of 8007 employees, 5814 men $(73 \%)$ and 2193 women $(27 \%)$, completed and returned the 2-year follow-up questionnaire (response rate of $66.2 \%$ with respect to baseline population).

\section{THE PURPOSE OF THIS STUDY}

The purpose of the study presented in this thesis is (1) to determine the prevalence and incidence of fatigue and psychological distress in the working population, and (2) to identify the possible risk factors for the onset of fatigue and psychological distress in the working population. The study evaluates primarily the etiological role of work and lifestyle in the onset of fatigue and psychological distress in the working population. Beyond that, the study aims to cast light on the concepts of fatigue and psychological distress; not only by addressing operational and conceptual issues, but also by investigating differential etiological factors regarding fatigue and psychological distress in the working population.

\section{OUTLINE OF THE THESIS}

A prerequilite of a study of the magnitude and etiology of fatigue is, of course, valid instrument to measure fatigue. In the Maastricht Cohort Study of "Fatigue at Work", fatigue is measured with the Checklist Individuall Strength. Chapter 2 describes the results of a pilot study conducted to determine a cutoff point for fatigue for use in the working population. Additional information on the validation of the Checklist Individual Strength in the working population is presented in the Appendix.

In Chapter 3 , the relationship between fatigue and psychological distress is addressed. Next to the prevalence of fatigue and psychological distress in the working population, the chapter describes the psychometric properties of the Checklist Individual Strength and the General Health Questionnaire, and the associations with demographic and health factors. The following chapters deal with possible risk factors, such as work and lifestyle, for the onset of fatigue and psychological distress in the working population. Chapter 4 and 5 address associations between a wide range of work-related factors and fatigue and psychological distress in the working population. In Chapter 4 "the results of cross-sectional analyses with baseline data are illustrated and discussed. Chapter 5 presents the longitudinal findings 
regarding possible associations between work-related factors at baseline and the onset of fatigue and psychological distress after 1-year of follow-up. In Chapter 6, differences in fatigue and psychological distress are described across occupations. The chapter focuses on the use of occupation, as a proxy index for the objective work environment, supplemented with work characteristics as perceived by job occupants, to explain occupational differences in fatigue and psychological distress.

Beyond the influence of the work environment, the role of lifestyle in the development of fatigue and psychological distress is explored. In Chapter 7, longitudinal findings regarding possible associations between lifestyle factors at baseline and the onset of fatigue and psychological distress after 1-year of follow-up are presented. Finally, in the epilogue (Chapter 3 ). the findings described in this thesis are discussed, the implications for occupational (mental) health are addressed, and recommendations for further research are presented.

\section{REFERENCES}

1. Hardy GE, Shapiro DA, Borrill CS. Fatigue in the workforce of National Health Service Trusts: levels of symptomatology and links with minor psychiatric disorder, demographic, occupational and work role factors. J Psychosom Res 1997:43:83-92.

2. Mounstephen $A$, Sharpe M. Chronic fatigue syndrome and occupational health. Occup Med Oxf $1997: 47: 217-27$.

3. Meijman T, Schaufeli W. Psychische vermoeidheid en arbeid. Ontwikkelingen in de A\&Osychologie [Fatigue at work. Developments in $1 \& O$ psychology]. De Psycholoog 1996; June:23641.

4. Ahsberg E. Dimensions of fatigue in different working populations. Scand J Psychol 2000,41:231. 241.

5. Chen MK. The epidemiology of self-perceived fatigue among adults. Prev Med 1986;15:74-81.

6. David A. Pelosi A, McDonald E, Stephens D, Ledger D. Rathbone R, et al. Tired, weak, or in need of rest: fatigue among general practice attenders. BMJ 1990;301:1199-202.

7. Cathebras PJ, Robbins JM, Kirmayer LJ, Hayton BC. Fatigue in primary care: prevalence, psychiatric comorbidity, illness behavior, and outcome. J Gen Intern Med 1992;7:276-86.

8. Pawlikowska $T$, Chalder $T$, Hirsch SR, Wallace P, Wright DJ, Wessely SC. Population based study of fatigue and psychological distress. BMJ 1994;308:763-6.

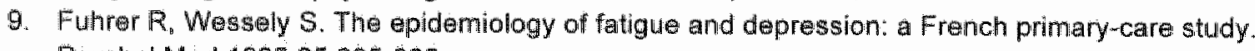
Psychol Mod 1995;25:895-905.

10. Hickie 13. Hooker AW. Hadzi Pavlovic D, Bennett BK, Wilson AJ, Lloyd AR. Fatigue in selected primary care settings: sociodemographic and psychiatric correlates. Med J Aust 1996;164:585-8.

11. Loge $\mathrm{JH}$, Ekeberg $\mathrm{O}$, Kaasa S. Fatigue in the general Norwegian population: normative data and associations. J Psychosom Res 1998,45(1 Spec No) 53-65.

12. Addington AM, Gallo JJ, Ford DE, Eaton WW. Epidemiology of unexplained fatigue and major depression in the community: the Baltimore ECA follow-up, 198\% 1994. Psychol Med $200131: 1037-44$

13. Lewis $G$, Wessely $S$. The epidamiology of fatigue: more questions than answers. J Epidemiol Community Health 1992;46:92-7

1.4. Barofsky 1, Legro MW. Definition and measurement of fatigue. Rev Infect Dis 1991;13 (Suppl 1:594-7.

15. Chaldler T, Berelowitz $G$, Pawlikowska T, Watts L, Wessely S, Wright D, al Development of a fatigue scale. J Psychosom Res $1993 ; 37: 147-53$.

16. Taylor RR, Jason LA, Torres A. Fatigue rating scales: An empirical comparison. Psychol Med $2000 ; 30: 849-856$ 
17. Wessely S. Chronic fatigue: symptom and syndrome. Ann Intern Med 2001:134:838-43.18. Meliman TF. Over vermoeidheid: arbeidspsychologische studies naar beleving van belastingseffecten. [Fatigue: studies of the perception of workload effects]. Amsterdam: Universily of Amsterdam; 1991.

19. Kroenke $K$, Wood DR, Mangelsdorf AD, Meier NJ, Powell JB. Chronic fatigue in primary cane. Prevalence, patient characteristics, and outcome. JAMA 1988;260:929-34

20. Schröer CAP. De toename van arbeidsongeschiktheid wegens psychische aandoeningen [The increase of work disability due to mental disorders]. Tijdschrift voor Bedrijfs- en Verzekeringsgeneeskunde 1997:5:16-23.

21. Houtman I. Feiten en fabels op een mij. Werkdruk in cijfers [Work pace in numbers]. Arbeidsomstandigheden 1999;75:2-5.

22. Chalder T, Power MJ. Wessely S. Chronic fatigue in the community: "A question of attribution". Psycholl Med 1996;26:791-800.

23. Kristal Boneh E, Froom P, Harari $G$, Ribak J. Fatigue among Israelli industrial employoes. J Occup Environ Med 1996;38:1145-50.

24. Hickie I, Koschera A, Hadzi-Pavlovic D. Bennett B, Lloyd A. The temporal stability and comorbidity of prollonged fatigue: a longitudinal study in primary care. Psychol Med 1999;29:855-61.

25. Van der Lindien $G$, Chalder $T$, Hickie I, Koschera $A$, Sham $P$, Wessely $S$. Fatigue and psychiatric disorder: different or the same? Psychol Med 1999;29:863-8.

26. Koschera $A$, Hickie I, Hadzi-Pavlovic D, Wilson A, Lloyd A. Prolonged fatigue, anxiety and depression: exploring relationships in a primary care sample. Aust $N Z$ J Psychiatry $1999 ; 33: 545$. 52.

27. Frese M, Zapf D. Methodological issues in the study of work stress: Objective vs subjective measurement of work stress and the question of longitudinal studies. In: Cooper CL. Payne R, editors. Causes, Coping and Consequences of Stress at Work. Chichester: Wiley; 1988: p. 375 411.

28. Zapf D, Dormann $C_{\text {: }}$ Frese M. Longitudinal studies in organizational stress research: A reviewof the literature with reference to methodological issues. J Occup Health Psychol 1996;1:145-69. 
Measurement of prolonged fatigue in the working population:

Determination of a cutoff point for the Checklist Individual Strength

Ute Bültmann ${ }^{a}$, Maaike de Vries ${ }^{b}$, Anna J.H.M. Beurskens ${ }^{a}$, Gijs Bleijenberg ${ }^{b}$, Jan H.M.M. Vercoulen ${ }^{\text {, }}$, IJmert Kant ${ }^{\mathrm{a}}$

${ }^{a}$ Department of Epidemiology, Maastricht University, Maastricht, the Netherlands

${ }^{b}$ Department of Medical Psychology. University Hospital Nijmegen, Nijmegen, the Netherlands.

Journal of Occupational Health Psychology 2000:5:411-416 


\section{ABSTRACT}

In the Netherlands, a large-scalle prospective cohort study was started on prolonged fatigue in the working population. The 1st issue that had to be addressed was the determination of a cutoff point for fatigue for use in the working population. Fatigue is measured with the Checklist Individual Strength (CIS), a 20-item self-report questionnaire. This article demonstrates the process of decision making in the determination of the cutoff point. Total CIS scores were calculated, sensitivity and specificity were compared for potential cutoff points, and receiver operating characteristics analysis was conducted. A CIS totall cutoff point for fatigue of $>76$ was determined, with a specificity of $90 \%$ and a sensitivity of $73 \%$. Limitations regarding the use of cutoff points are discussed. It is concluded that the defined cutoff point seems to be appropriate for use in the working population. 


\section{INTRODUCTION}

In the Netherlands, about one in every three work disability benefit recipients is classified as disabled for work on mental grounds. 1.2 The majority of this kind of work disability benefit recipients (approximately 90\%) suffer from an "exogenous reaction".3. the official diagnostic label that includes chronic job stress, overstrain and burnout - mental states that involve prolonged fatigue as a major symptom. Because prolonged fatigue may lead to sick leave and work disability, ${ }^{4}$ it is not only a pressing social problem but also an economic problem urging for preventive action.

In 1998, a large-scale epidemiologicall study on "Fatigue at Work" was started in the Netherlands. The Maastricht Cohort Study was set up (a) to examine the psychosocial risk factors in the etiology and natural course of prolonged fatigue among employees, (b) to gain insight into the prevalence and incidence of prolonged fatigue, and (c) to investigate the effectiveness of different treatments of fatigue. The general objective of the study is to develop preventive measures and actions that can be used in the workplace. The Maastricht Cohort Study surveys 12,000 employees from 45 companies and organizations and follows them for 3 years. The data on work-related factors, non-work-related factors (e.g., home situation and leisure activities), individual characteristics, and health outcomes are gathered annually by means of a mailled self-administered questionnaire. Follow-up data on fatigue are collected twice a year by a short, mailed questionnaire. Additional data on sick leave are obtained by record linkages to company sick leave and work disability registry systems and by subsequent telephone interviews. The Maastricht Cohort Study is part of the Netherlands' concerted research action on "Fatigue at Work" granted by The Netherlands Organization for Scientific Research (NWO). This multidisciplinary, 6-year national research program was initiated in 1996 and includes medical and psychological research on acute and prolonged fatigue among employees.

Acute fatigue is a normal phenomenon that disappears after a period of rest. when tasks are switched, or when particular compensation strategies are used (e.g., working at a slower pace). In contrast, prolonged fatigue is not easily reversible in the short term and is not taskspecific; the compensating mechanisms that are useful in reducing acute fatigue are no longer effective. ${ }^{5}$ According to Meijman and Schaufeli, ${ }^{\circ}$ prolonged fatigue manifests itself in: inefficient action patterns; declining interest, involvement, and commitment; reduced concentration and motivation; and negative emotions. Moreover, prolonged fatigue may affect the individual's performance and functioning in the occupational as well as in the home setting. The Maastricht Cohort Study focuses on prolonged fatigue among employees; we simply use the term fatigue.

Fatigue is measured with the Checklist Individual Strength (CIS), " a 20-item self-report instrument (see the Appendix). The CIS covers severall aspects of fatigue, such as severity, motivation, concentration, and physical activity level, which fit in with the concept of prolonged fatigue. To compare the prevalence of fatigue within demographic and occupational subgroups, using the CIS as an estimator of fatigue, we first have to determine a cutoff point for use in the working population during the preparation phase of the cohort study. The cutoff point should be regarded as a score indicating a fatigue level that puts the individual "at risk" for sick leave or work disability. Defined in this way, it can be used as a tool for monitoring employees. Moreover, in specific research projects within the Maastricht Cohort Study such as the studies investigating the natural course of fatigue or the effectiveness of treatment, the cutoff point can be used as one criterion among others to 
classify casses of to select cases for treatment. The objective of the present study was to define an "optimal" cutoff point for fatigue for use in studies on fatigue among employees.

\section{METHOD}

\section{Samples}

To determine a cutoff point for fatigue, we used six samples with expected differences in fatigue leval. Demographics for all samples are specified in Table 1. As most severely affected, a sample of 756 patients with chronic fatigue syndrome (CFS) referred to the outpatient"s clinic of the department of General Internal Medicine at the University Hospital Nijmegen ${ }^{3-10}$ was included. Assuming a less severe, but still considerable fatigue level, a sample of 59 "fatigued" employees wals used. Three company doctors and insurance dociors selected the fatigued employees. The doctors were asked to include fatigued employees without a somatic explanation for fatigue and to exclude employees with psychological morbidity and psychiatric disorder, because fatigue may accompany these conditions. For privacy reasons, the exact diagnoses of these employees are not known.

Moreover, lumbar disc surgery patients $(n=38)$ and pregnant, working women $(n=47)$ were included. It is assumed that they report fatigue, but less than the "fatigued" employees and the CFS patients. The lumbar disc surgery patients were recruited at the University Hospital of Maastricht. The physical therapists in attendance asked the patients to complete the questionnaire 5 to 7 days after surgery. The pregnant women were selected by three midwives and had a 27-week median duration of pregnancy. In addition, a sample of 1,700 Dutch veterans who had participated in the United Nations Transitional Authority for Cambodia (UNTAC) peacekeeping operation during 1992 and 1993 was used. "This sample was recruited from a study of symptoms in Cambodia veterans, which was initiated since unexplained symptoms of fatigue, concentration problems, and forgetfulness emerged from military personnel's reports. The vast majority $(93 \%)$ of the veterans was working. The sample was split, because $18 \%(n=311)$ of the veterans reported a moderate or bad health status. It is assumed that the veterans with a moderate or bad health status report more fatigue in contrast to the veterans who report a good or very good health status. Finally, a sample of 75 "healthy" working employees was included, and it was assumed that they represent the lowest fatigue level. Most of the healthy white-collar workers $(n=37)$ were working at a university; the healthy blue-collar workers $(n=38)$ were working in an iron foundry. None of these working employees was on sick leave.

\section{Fatigue questionnaire}

The CIS (see the Appendix) is a 20-item self-report questionnaire, developed for hospital studies of CFS. The CIS measures several aspects of fatigue: fatigue severity (8 items, e.g.. "I feel tired"), concentration ( 5 items, e.g. "I have trouble concentrating"), motivation (4 items, e.g." "I feel no desire to do anything"), and physical activity level ( 3 items, e.g. "l don"t do much during the day"). The items are scored on 7 -point Likert scales $(1=$ "Yes, that is true" to $7=$ "No, that is not true"). Participants are instructed to indicate how they felt during the last 2 weeks. Four factor scores can be calculated. The ranges of these factor scores are 8 56 (fatigue severity), 5-35 (concentration), 4-28 (motivation), and 3-21 (physical activity 
level). Higher scores indicate a higher degree of fatigue, more concentration problems, reduced motivation, or less activity. Moreover, a composite cls total score (ranging from 20 to 140 ) can be obtained by adding the individual's scores on the four factors. The CIS was tested thoroughly in the clinical

Table 1 Characteristics of the Samples

\begin{tabular}{lcccc}
\hline & & \multicolumn{2}{c}{ Age (years) } & Gendar \\
\cline { 2 - 5 } Siample & $n$ & $M$ & $S 0$ & \% Famale \\
\hline Healthy employees & $72^{\mathrm{a}}$ & 35.5 & 7.7 & 27 \\
Fatigued employees & 59 & 44.0 & 9.1 & 46 \\
Pregnani women & 47 & 30.9 & 2.7 & 100 \\
Lumbar disc surgery patients & $37^{7}$ & 43.4 & 7.4 & 37 \\
UNTAC welerans (very goodigood health) & 1,389 & 35.0 & 7.9 & 1 \\
UNTAC weterans (moderatelbad health) & 311 & 37.3 & 8.6 & 0.5 \\
Chronic Fatigue Syndrome patients & 756 & 37.5 & 10.4 & 77 \\
Total & 2.671 & 36.2 & 8.6 & 27 \\
\hline
\end{tabular}

Note. UNTAC $=$ Unithed Nations Transitional Authority for Cambodia

a Three cases were excluded from the analyses because of an invalid Checkilst Individual Strength (CIS) total score

- One case was excluded from the analyses because of an invalid CIS total score

setting among patients with CFS and has been frequently used in patients with CFS and other chronic illnesses. ${ }^{8.10}$ Furthermore, the CIS was used to determine the prevalence of symptoms in veterans who had been deployed in the UNTAC peacekeeping operation during 1992 and $4993^{11}$ In these studies, the CIS subsicale fatigue severity was used as one criterion among others to identify cases. The psychometric properties of the CIS are good: Cronbach"s alpha reliability coefficient for the entire CIS is 0.90 . The Cronbach's alphas for the scales are 0.88 (fatigue severity), 0.92 (concentration), 0.83 (motivation), and 0.87 (physical activity level). ${ }^{.8}$ in the present study, the cutoff point is based on the composite CIS total score.

\section{Statistics}

The CIS total scores "means, standard deviations, and percentile scores) were calculated for all of the samples. Considering the purpose of detecting fatigued employees in the working population, the determination of a CIS total cutoff point was based on the data of the healthy working employees and the fatigued employees. A receiver operator characteristic (ROC) analysis was used to define the Cis total cutoff point for fatigue. An ROC curve is obtained by plotting the true-positive rate (sensitivity) against the false-positive rate (1-specificity) for a range of cutoff values. ${ }^{2}$ The ROC curve shows how severe the trade-off between sensitivity and specificity is for a test and can be used to help decide where the "best" cutoff should be. Generally, the best cutoff is a point on the ROC curve that is closest to the upper lefthand corner of the plot. In a first step, the "best" cutoff point, with both high sensitivity and specificity, was derived. Considering the main studly, it is more important to restrict the number of false-positively classified healthy working employees. Therefore, in a second step 
the determination of the cutoff point was based on high specificity. The specificity was set at $90 \%$, assuming the presence of fatigued or less-functioning employes among the healthy working employees.

Table 2 Wean Scores, Standard Deviations, and Percentile Scores of the Checklist individual Strength (CIS) Totai

\begin{tabular}{|c|c|c|c|c|c|c|c|c|}
\hline \multirow[b]{2}{*}{ Sample } & \multirow[b]{2}{*}{$n$} & \multirow[b]{2}{*}{$M$} & \multirow[b]{2}{*}{$S D$} & \multicolumn{5}{|c|}{ CIS total Percentle } \\
\hline & & & & 5 & 25 & 50 & 75 & 95 \\
\hline Heallhy employeess & 72 & 47.3 & 19.2 & 22 & 32 & 44 & 61 & 81 \\
\hline UNTAC veterans (very goodigood health) & 1,389 & 47.9 & 23.7 & 20 & 31 & 43 & 62 & 88 \\
\hline Lumbar diss surgery patients & 37 & 67.7 & 23.5 & 32 & 45 & 73 & 80 & 112 \\
\hline Pregnant women & 47 & 707 & 24.9 & 33 & 52 & 66 & 87 & 116 \\
\hline UNTAC velerans (moderateibad health) & 311 & 86.1 & 21.5 & 42 & 73 & 88 & 102 & 122 \\
\hline Fatigued employees & 59 & 89.7 & 26.2 & 29 & 75 & 92 & 107 & 140 \\
\hline Chronic Fatigue Syndrome patierits & 756 & 113. & 14.6 & 86 & 105 & 1114 & 124 & 135 \\
\hline
\end{tabular}

Nole. UNTTAC = Unifed Nations Transitional Authority for Cambodia

\section{RESULTS}

Table 2 shows the means, standard deviations, and the percentile scores of CIS total for the different samples. As expected, the CFS patients scored highest on CIS total $(M=113.1, S D$ $=14.6$ ), followed by the "fatigued" employees and the UNTAC veterans reporting a moderate or bad health status. Low CIS total scores were found among the working UNTAC veterans. reporting a good or very good health status $(M=47.9, S D=23.7)$, and among the healthy working employees $(M=47.3, S D=19.2)$.

As can be seen from the ROC curve, the "best" cutoff was a Clls total score of $>70$ (see Figure 1). With this cutoff point 49 of the 59 fatigued employees were classified as fatigued, for a sensitivity of $83 \%$, whereas 62 of the 72 healthy working employees were classified as non fatigued, for a specificity of $86 \%$. Because of the $90 \%$ specificily demand, a cutoff point of $>76$ was defined in the second step (see Figure 1). With this cutoff point, 65 of the 72 healthy working employees were classified as non latigued and 43 of the 59 fatigued employees were classified as fatigued, for a sensitivity of $73 \%$. The CIS total scores in Table 2 show that in the working samples the defined cutoff is located close to the $95 \%$ percentile. In the CFS sample, almost all CFS patients scored above the CIS total cutoff point of $>76$, whereals in the samples of fatigued employees and UNTAC veterans with a moderate or bad health status, the cutoff point is located close to the $25 \%$ percentile. 
Figure 1 The receiver operating characteristic curve of the Checklist Individual Strength total scores representing potential cutoff points.

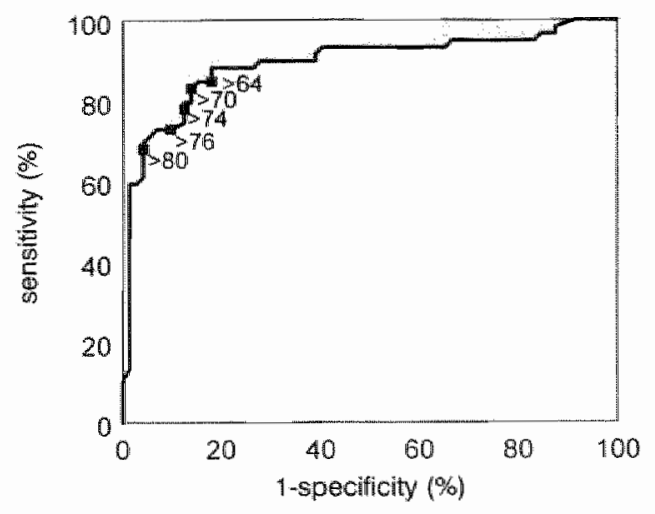

\section{Discussion}

In the present study, a cutoff point of $>76$ was determined for the cls. This cutoff point should be regarded as a score indicating a fatigue level that puts the individual "at risk" for subsequent sick leave or work disability.

The CIS was used to measure fatigue in the working population. The CIS is easy to administer and is a thoroughly tested fatigue instrument. Other instruments, such as the 11item Fatigue Questionnaire developed by Chalder et all. ${ }^{13}$ with a physical and mental fatigue component, are available. The CIS, however, was used because the components of this instrument fit in with our concept of fatigue.

A cutoff point with a sensitivity of $73 \%$ and a specificity of $90 \%$ was identified. From a statistical point of view, a cutoff point with both high sensitivity and high specificity is preferred. The determination of the cutoff point in this study, however, was not based on the "best" cutoff from the ROC curve but on considerations concerning an "optimal" cutoff point for use in the working population. Because no gold standard was avallable for the determination of a cutoff point for fatigue among employees, the determination was based on high specificity.

With respect to the setting of a cutoff point, Dwyer" noted "that cut scores always entail judgment" ( $p$. 361). This issue should be kept in mind when cutoff points are set or used, but it is also critical to clarify how the judgments are structured and to describe the process of decision making accurately. In this study we explicitly demonstrated the judgments on which. combined with descriptive and analytic data, the cutoff point was derived. Although it is difficult to sellect adequate samples, the cutoff was derived from defined samples with differences in fatigue levels rather than determined, for example, on the basis of baseline data from the cohort study. The percentile scores for CIS total in the different working and clinical samples confirmed the determination of the cutoff of $>76$ derived from the $R O C$ analysis.

Another issue addressed by Dwyer ${ }^{14}$ is that cut scores "inherently result in misclassification" (p. 360). In our study a false-positive rate of $10 \%$ in thealthy working employees is accepted and cannot be regarded as "true" misclassification (i.e. truly not fatigued), because in the 
sample of working employees, individuals can be fatigued or can be less functioning without seeing a company doctor or being on sick leave or disabled for work. Moreover, it should be noted that the sample of fatigued employees is rather more severely affected than the employees who have to be detected in the working population.

It should also be kept in mind that in Dwyer's" words, "cul scores impose an artificial dichotomy on an essentially continuous distribution of knowledge, skill or ability" (p. 360 ). Like many medical conditions, fatigue is best viewed as a continuum ${ }^{\text {ty }}$ as opposed to a dichotomy. When using a cutoff point, one may lose important information. For that reason, fatigue should be treated as a continuous variable whenever possible. If the purpose of a study is, for example. to examine the etiology of fatigue, it is more informative to describe the relation between exposure and fatigue in terms of a range of fatigue scores than in terms of fatigue cases versus non fatigue cases. A dichotomy, however, is useful when the prevalence of fatigue has to be compared in different subgroups or when employees have to be selected for treatment.

For future research on fatigue, it should be acknowledged that "no true cut score exists" ( $p$. 361). ${ }^{14}$ it can be assumed that different studies within working populations or different projects within the Maastricht Cohort Study may have different demands on the sensitivity and specificity of a cutoff point. Therefore, it cannot be ruled out that the defined cuttoff point might have to be adjusted. However, depending on the aim of a specific study, a suitable cutoff point can be determined by using the presented ROC curve and the percentile scores. It should also be noted that fatigue is reported to be associated with psychological morbidity and psychiatric disorder both in primary care and the general population. ${ }^{6,27}$ with these authors labeling the observed association as "moderate" or "high." In the present study. company and insurance doctors were asked to exclude fatigued employees with psychological morbidity and psychiatric disorder. In the working population as well as in the cohort study, however, we have to deal with these conditions. For that reason, a key issue that has to be addressed in future research is not only to examine whether our measure of fatigue is highly correlated with existing measures of psychological distress, but aiso to explore the relationship between fatigue and psychological morbidity in the working population.

In conclusion, a cIS total cutoff of $>76$ was defined. The delermination was based on high specificity, considering a minimum of false-positively classified healthy working employees. The defined CIS tolal cutoff point seemed to be appropriate for use in fatigue studies in the working population and for the Maastricht Cohort Study on fatigue among employees.

\section{ACKNOWLEDGEMENTS}

The present study is part of the Maastricht Cohort Study, which is supported by a grant from The Netherlands Organization for Scientific Research (NWO Grant No. 580-02.251). The Dutch Ministry of Defense supported the study on the United Nations Transitional Authority for Cambodia veterans. 


\section{REFERENCES}

1. Houtman, I. L. D. (1997). Trends in arbeid en gezondheid 1996 [Trends in work and health]. Amsterdam: NIATNO (Nlederlands Instituut voor Arbeidsomstandigheden/Nederlandse Organisatie voor Toegepast-natuunwetenschappelijk Onderzoek).

2. Houtman, 1. (1999). Feiten en fables op een rij]: Werkdruk in ciffers [Facts and myths: Workpace in numbers]. Arbeidsomstandigheden, $75,2-5$.

3. Van Eck. M. A. A. (1991). De diagnosestelling "Categorie V" [Diagnose "Category V"]. In R. Bijl \& D. Baudin (Eds.), Categorie V: Arbeidsongeschiktheid wegens psychische stoomissen [Cattegory W. Work disability due to mental disorders] (pp. 79-94), Utrecht, the Netherlands: Nederlands Centrum Geestelijke Volksgezondheid.

4. Schroer, C. A. P. (1997). De toename van arbeidsongeschiktheid wegens psychische aandoeningen [The increase of work disability due to mental disorders]. Tijdschrift voor bedriffsen verzekeringsgeneeskunde, 5, 16-23.

5. Meijman, T. F. (1991). Over vermoeidheid: Anbeidspsychologische studies naar beleving van belastingseffecten [Fatigue: Studies on the perception of workload effects]. Amsterdam, the Netherlands: University of Amsterdam, Studiecentrum Arbeid en Gezondheid.

6. Meijman, T. \& Schaufeli, W. (1996, June). Psychische vermoeidheid en arbeid: Ontwikkelingen in de A \& O-psychologie [Fatigue at work: Developments in 1 \& O psychology]. De Psycholoog, 236241.

7. Vercaulen, J.H. M. M., Alberts, M., \& Bleijenberg. G. (1999) De Checklist, Individuele Spankracht (CIS) [The Checklist Individual Strength (CIS)]. Gedragstherapie, 32, 131-136.

8. Vercoulen, J.H. M. M., Swanink, C. M. A., Fennis, J. F. M., Galama, J. M. D., Van der Meer, J. W. M., \& Bleijenberg, G. (1994). Dimensional assessment of chronic fatigue syndrome. Journal of Psychosomatic Research, 38, 383-392.

9. Vercoulen, J. H. M. M. Hommes, O. R., Swanink, C. M. A., Jongen, P. J. H., Fennis, J. F. M., Galama, J. M. D. Van der Meer, J. W. M., \& Blejenberg. G. (1996). The measurement of fatigue in patients with multiple sclerosis: A multidimensional comparison with patients with chronic fatigue syndrome and healthy subjects. Archives of Neurology, 53, 642-649.

10. Vercoulen, J. H. M. M., Swanink, C. M. A., Fennis, J. F. M., Galama, J. M. D., Van der Meer, J. W. M. \& Bleijenberg, G. (1996). Prognosis in chronic fatigue syndrome: A prospective study on the natural course. Journal of Neurology, Neurosurgery and Psychiatry, 60, 489-494.

11. De Vries, M., Soetekouw, P. M. M. B., Bleijenberg, G., \& Van der Meer, J. W. M. (1998). Het PostCambodja Klachten Onderzoek fase ll: Een inventariserend onderzoek naar aard, omvang en ontstaanswijze [The Post Cambodia Symptom Research Phase I: An inventory of the nature, the magnitude, and the etiology]. Nijmegen, the Netherlands: Academisch Ziekenhuis Nijmegen,

12. Fletcher, R. H. Fletcher, S. W. \& Wagner, E. H. (1996). Clinical epldemiology: The ssentials (3rd ed.). Baltimore: Williams \& Wilkins.

13. Chalder, T., Berelowitz, G., Pawlikowska, T., Watts, L., Wessely, S., Wright, D., \& Wallace E. P. (1993). Development of a fatigue scalle. Journal of Psychosomatic Research, 37. 147-153

14. Dwyer; C. A. (1996). Cut scores and lesting: Statistics, judgment, truth, and error. Psychological Assessment, $8,360-362$

15. Lewis, G. \& Wessely, S. (1992). The epidemiology of fatigue: More questions than answers. Journal of Epidemiology and Community Health, 46, 92-97.

16. Hickie, I. B. Hooker, A. W. Hadzi-Pavlovic, D. Bennett B. K., Wilson A. J., Lloyd, A. R. (1996) Fatigue in selected primary care settings: Sociodemographic and psychiatric correlates. Medical Journal of Australia, 164, 585-588.

17. Pawlikowska, T. Chalder, T., Hirsch, S. R., Wallace, P., Wright D. J. M., \& Wessely, S. C. (1994). Population based study of fatigue and psychological distress. British Medical Journal ${ }_{4} 308,763-$ 766. 


\section{APPENDIX}

Checklist Individual Strength

The Checklist Indivdual Strength (CIS), a 20-item self-report instrument is published by the University Hospital Nijmegen, Department of Medical Psychology, the Netherlands. The following is the list of the items:

\section{I feel thred}

2. Ifeel very active

3. Thinking requires effort

4. Physically $\|$ feel exhausted

5. I feel like doing all kind of nice things

6. I feel fit

7. I do quite a lot within a day

8. When I am doing something, I can concentrate quite well

9. If feel weak

10. I don't do much during the day

11. I can concentrate well

12. If feel rested

13. I have trouble concentrating

14. Physically I feel I am in a bad condition

15. I am full of plans

16. I am tired very quickly

17. I have a low output

18. I feel no desire to do anything

19. My thoughts easily wander

20. Physically If feel in a good shape

Note. Individuals were asked to indicate how they felt during the last 2 weeks by answering each statement "Yes, that is true" or "No, that is not true" on a 7-point Likert scale. The CIS with scoring is available from the authors of the questionnaire: Jan $H . M$. M. Vercoulen and Gijs Bleijenberg, Universify Hospital Nijmegen, P.O. Box 9101, 6500 HB Nijmegen, the Netherlands. 
Fatigue and psychological distress in the working population: Psychometrics, prevalence, and correlates

Ute Bültmann a, IJmert Kant ${ }^{a}$, Stanislav V. Kasl ${ }^{b}$, Anna J.H.M. Beurskens ${ }^{\mathrm{a}}{ }_{1}$ Piet A. van den Brandt ${ }^{a}$

a Department of Epidemiology, Maastricht University, Maastricht, the Netherlands

- Department of Epidemiology and Public Health, Yale University School of Medicine, New Haven, Connecticut, USA 


\section{ABSTRACT}

Objective: The purposes of this study were 1) to explore the relationship between fatigue and psychological distress in the working population; 2) to examine associations with demiographic and health factors; and 3) to determine the prevalence of fatigue and psychological distress. Methods: Data were taken from 12,095 employees. Fatigue was measured with the Checklist Individual Strength and the General Health Questionnaire was used to measure psychological distress. Results: Fatigue was fairly well associated with psychological distress. A separation between fatigue items and GHQ items was shown. No clear distinct pattern of associations was found for latigue versus psychological distress with respect to demographic factors. The prevalence was $22 \%$ for fatigue and $23 \%$ for psychological distress. Of the employees reporting fatigue, $43 \%$ had fatigue only, whereas $57 \%$ had fatigue and psychological distress. Conclusions: The results indicate that fatigue and psychological distress are common in the working population. Although closely associated, there is some evidence suggesting that fatigue and psychological distress are different conditions, which can be measured independently. 


\section{INTRODUCTION}

Community and primary care studies have repeatedly shown that fatigue is a common complaint, $^{t .6}$ and that fatigue may accompany physical as well as psychiatric disonders. ${ }^{1,5,7}$ Fatigue that becomes prolonged is reported to be associated with impairments comparable to chronic medical conditions, ${ }^{7}$ and may affect the individual's performance and functioning in the occupational as well as in the home setting.

The concept and the assessment of fatigue have been subjects of controversy for many years, and there are still more questions than answers with respect to the status of fatiguie. For example, is fatigue conceptually, operationally, and etiologically distinct from psychological distress, or is the overlap between the two constructs so large as to throw in doubt the usefulness of having two separate concepts? Is the natural history of the two different? Are different prevention and treatment strategies applicable? At present, these questions cannot be adequately answered. We do know that studies conducted in the general population ${ }^{3}$ and in the primary care setting. ${ }^{5}$ have shown that fatigue is associated with psychological distress, with observed correlations of 0.62 and 0.51 . However, the relationship between fatigue and psychological distress may vary across different populations. With respect to the working population, previous research of fatigue and psychological distress was restricted to a specific occupational setting, ${ }^{10}$ with an observed correlation of 0.54 . Hence, one key issue is whether the available measures of fatigue and the existing measures of psychological distress assess highly similar or sufficiently different underlying concepts in the generall working population.

The Maastricht Cohort Study of "Fatigue at work" contributes to this research field with a large-scale epidemiological study in a heterogeneous working sample, in which not only the etiological factors in the onset and natural history of fatigue and psychological distress will be investigated but also the measures of fatigue and psychological distress and the constructs themselves will be examined. Within the Maastricht Cohort Study, fatigue is measured with the self-report Checklist Individual Strength. ${ }^{11-43}$ The General Health Questionnaire (GHQ) is used to assess psychological distress. ${ }^{14,15}$

In the present study we used the baseline data from the Maastricht Cohort Study to describe the relationship between fatigue and psychological distress in the working population, to examine associations with demographic and health factors, and to determine the prevalence of fatigue and psychological distress.

\section{METHODS}

\section{Study population}

In May 1998, a total of 26,978 male and female employees, aged 18-65 years, from 45 Dutch companies and organizations received a letter at home inviting participation and the baseline questionnaire. The letter explained the purpose and the general outline of the cohort study. described how the data would be used, and guaranteed amonymity of responses. The voluntary nature of participation was emphasized. Nonrespondents received a written reminder 2 weeks later. After 6 weeks, a random sample of 600 persistent nonrespondents 
was asked to complete a brief questionnaire about the reasons for nonresponse; $168(30 \%)$ of the nonrespondents returned this questionnaire.

A total of 12,161 employees completed the baseline questionnaire. Written consent was obtained from all participants. The overall response rate was $45 \%$. Twenty-one questionnaires were discarded from the analysis because of technical reasons; another 45 questionnaires were excluded because an inclusion criterion was not met. The final study population at baseline consisted of 12,095 employees: $8840(73 \%)$ men and $3255(27 \%)$ women. The mean age of the total cohon was 41.0 years (S.D. 8.9) - 42.0 years (S.D. 8.8) in men and 38.0 years (S.D. 8.8) in women. Table 1 shows demographic and health factors for the total cohort at baseline.

In a nonresponse analysis, no significant differences were found between respondents and nonrespondents on demographic characteristics. Nonrespondents were less likely to report fatigue complaints ( $42 \%$ vs. $\left.55 \%, x^{2}=11.1, p<.05\right)$, sickness absence $\left(21 \%\right.$ vs. $39 \%, x^{2}=$ $21.5, p<.05)$, and difficulties in work execution due to health complaints ( $17 \%$ vs. $26 \%, x^{2}=$ $7.75, p<05)$. The main reason for nonresponse was "no time to complete the questionnaire" $(30 \%)$, followed by "nothing would be done with the results" $(18 \%)$, and "no interest in the study subject" (15\%).

\section{Fatigure}

Fatigue was measured with the 20-item self-report Checklist Individual Strength (CIS), which was originally developed for hospital studies of chronic fatigue syndrome. 11,12 The CIS was extensively tested in the clinical setting, ${ }^{18,17}$ and validated in the working population. ${ }^{13}$ if covers several aspects of fatigue , such as severity (elight items), concentration (five items). motivation (four items), and physical activity level (three items), which fit in with the concept of prolonged fatigue. Subjects are instructed to indicate how they felt during the last 2 weeks. The response to each statement is scored on a seven-point Liken scale ( $1={ }^{\text {"Yes, }}$, that is true" to $7=$ "No, that is not true"). Four factor scores can be calculated. Higher scores indicate a higher degree of fatigue, more concentration problems, reduced motivation or low levels of activity. Moreover, a composite CIS total score (ranging from 20 to 140) can be obtained by adding the individual's scores on the four factors. In the Maastricht Cohort Study, the composite CIS total score was used to measure fatigue. The cut-off point for case classification used in the present study was CIS total $>76$. This cut-off was established in a separate pilot study by means of defined samples with differences in fatigue levels. ${ }^{\text {}}{ }^{8}$ All those employees scoring $>76$ were considered to be probable fatigue cases

\section{Psychological distress}

Psychological distress was assessed with a Dutch translation of the General Health Questionnaire (GHQ-12). ${ }^{14,15}$ The GHQ-12 was developed as a screening instrument for detecting minor psychiatric disorders in the general population. Two scoring systems were used for the four-point response scale. The Likert scoring method $(0,1,2,3)$ summed the responses of the 12 items to give a continuous distribution of the scores ranging from 0 to 36 . The traditional GHQ scoring method $(0,0,1,1)$ is designed to identify individuals reporting sufficient psychologicall distress to be classified as probable cases of minor psychiatric disorder. Given a possible range of scores from 0 to 12 , the threshold for case classification 
used in the present study was four or higher. That means that all those employees scoring on four or more of the 12 GHQ items were considered to be cases of psychological distress. The threshold for case classification is high. but comparable to the threshold used in the few other studies in this research field and likely to predict very symptomatic patients.

\section{Demographic and health factors}

Demographic items comprised gender, age, educational level, living alone, and dependent children. The questionnaire further included items about the presence of diseases and the general health status. The health status item was adapted from the Dutch version of the SF$36^{19}$ and is scored on a five-point response scale ("excellent", "very good" "good", "moderate", "bad").

Table 1 Demographic and heallh factors for the total cohort $(N=12,095)$

\begin{tabular}{|c|c|c|c|c|c|c|}
\hline & \multicolumn{2}{|c|}{ Total $(N=12,095)$} & \multicolumn{2}{|c|}{ Men $(N=8 B=40)$} & \multicolumn{2}{|c|}{ Women $(N=3255]$} \\
\hline & $\mathrm{Pa}$ & $\%$ & n & 粰 & $n$ & $\%_{0}$ \\
\hline \multicolumn{7}{|l|}{ Age grouph (years) } \\
\hline $16-25$ & 489 & 4.0 & 253 & 2.9 & 235 & 7.2 \\
\hline 26.35 & 3049 & 25.2 & 1924 & 21.8 & 1125 & 34.6 \\
\hline $36-45$ & 4530 & 37.5 & 3318 & 37.5 & 1242 & 37.2 \\
\hline $46-55$ & 3510 & 29.0 & 2005 & 32.9 & 605 & 18.6 \\
\hline $56-65$ & 518 & 4.3 & 440 & 5.0 & 78 & 2.4 \\
\hline \multicolumn{7}{|l|}{ Educational level } \\
\hline Primary schooll & 522 & 4.4 & 4.46 & 5.1 & 76 & 25 \\
\hline Lower wocational education & 1833 & 15.6 & 1524 & 17.6 & 309 & 10.1 \\
\hline Lower secondary school & 1526 & 13.0 & 932 & 10,8 & 594 & $\| 9.4$ \\
\hline Intermediatte vocational edtucalion & 2805 & 23.9 & 204.4 & 23.6 & 761 & 24.8 \\
\hline Upper secondary school & 1009 & 8.6 & 641 & 7.4 & 368 & 120 \\
\hline Upper vocational educaltion & 2705 & 23.1 & 2047 & 23.6 & 658 & 21.5 \\
\hline Universily & 1335 & 11,4 & 1035 & 14.9 & 300 & 98 \\
\hline \multicolumn{7}{|l|}{ Lwing alone } \\
\hline Yes & 1227 & 10.2 & 840 & 9.5 & 387 & 119 \\
\hline No & 10852 & 89.8 & 7989 & 90.5 & 2003 & 80,1 \\
\hline \multicolumn{7}{|l|}{ Dependent children } \\
\hline Yes & 6459 & 53.8 & 4922 & 56.2 & 1537 & 47.7 \\
\hline No & 5522 & 46,1 & 3835 & 43.8 & 1087 & 52.3 \\
\hline \multicolumn{7}{|l|}{ Presence of ofisedase } \\
\hline Yers & 2839 & 24.2 & 1987 & 23.1 & 852 & 26.9 \\
\hline No & 8914 & 75.8 & 6604 & 760.9 & 2310 & 73.1 \\
\hline \multicolumn{7}{|l|}{ Heath slatus } \\
\hline Excellent & 1144 & 9.5 & 44 & 96 & 300 & 9.3 \\
\hline Very good & 2653 & 22.4 & 2002 & 228 & 651 & 20.1 \\
\hline Good & 6437 & 53.6 & 4661 & 53.1 & 1770 & 550 \\
\hline Moderate & 1648 & 137 & 1987 & 13.5 & 461 & 143 \\
\hline Bad & 124 & 10 & 81 & 0.9 & 43 & 13 \\
\hline
\end{tabular}




\section{Statistical analysis}

In CIS questionnaires with missing data on the subscales "fatigue severity" (two items). "motivation" (one ttem) and "concentration" (one item), the missing items were replaced with the items means. CIS questionnaires with more than four missing items were excluded from analysis. In GHQ's with missing data on three items or fewer, the missing data were replaced with itern means. GHQ's with more than three missing data were excluded from analysis.

Principal component analysis (PCA) was used to investigate the factor structure of the CIS and GHQ-12. The correlation matrix eigenvalues (eigenvalue $>1$ criterion) and the factor loadings of individual items across factors were used to indicate the acceptability of a factor solution. Varimax rotation was appled to obtain factors approximating simple structure. Further statistical procedures comprised Pearson correlations, Cronbach's alpha for internal consistency, chi-square statistics, two-sided Studient's $t$ tests, univariate analysis of variance, and ANCOVA. Multiple comparisons were performed using the Tukey correction. First, we used the Likert scoring of the $\mathrm{CIS}$ and the GHQ-12 to a) determine the distribution of fatigue and psychological distress, b) conduct a PCA in order to investigate whether the CIS and the GHQ-12 formed separate factors, and c) explore the associations of the two constructs with demographic and health factors. We then used the simple dichotomy of "noncase" and probable "case" for the CIS and the GHQ-12 to determine the prevalence of fatigue and minor psychiatric disorder and to examine the relation between "fatigue only" and "psychological distress only" cases. The significance level for all statistical tests was fixed at .05. Data were analysed using SPSS $8.0^{20}$

\section{RESULTS}

\section{Distribution of fatigue and psychological distress in the working population}

A total of 236 CIS questionnaires were excluded because of more than four items missing. The mean CIS total score in the 11.859 complete questionnaires was 57.2 (S.D. 23.7). As shown in Figure 1, CIS total scores had a continuous distribution, ranging from 20 to 140 . Overall, 113 GHQ's were excluded because of more than three items missing. The mean GHQ score in the 11,982 complete questionnaires was 14.6 (S.D. 5.4), with scores from 0 to 36. Similar to faligue, a continuous distribution was found for psychological distress in the working population.

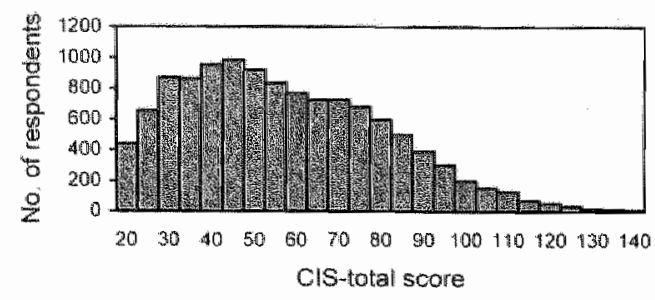




\section{Psychometrics of CIS and GHQ-12}

The scores on the CIS total and the GHQ-12 were fairly well correlated ( $\mathrm{r}=0.62$ ). The correlations between the four original factors of the CIS and the GHQ-12 were .56 for fatigue severity, 0.54 for concentration, 0.49 for motivation, and 0.34 for physical activity level respectively. To determine whether the CIS and the GHQ-12 assess different underlying conditions, a PCA with varimax rotation was conducted. For this analysis the continuous scoring of the items was used. In a first step, the $12 \mathrm{GHQ}$ items and the $20 \mathrm{CIS}$ items, covering the four aspects of fatigue, were analysed. The eigenvalue $>1$ criterion indicated a five-factor solution. The first factor explained $38 \%$ of the variance and consisted of the eight fatigue severity items and two motivation items. The second factor, which explained $8 \%$ of the variance, comprised all GHQ items. The third, fourth and fith factors consisted of five concentration items, three physical activity items, and two remaining motivation items, respectively, and captured $6 \%, 4 \%$, and $3 \%$ of the variance. The individual items loaded on either one of the four "CIS" factors or the "GHQ" factor, i.e., no substantial cross-loading was observed between the "CIS" factors and the "GHQ" factor.

Because of the concept of fatigue (composite CIS), the CIS and GHQ-12 items were analysed in a two-factor solution in a second step. Table 2 shows the varimax rotated factor structure for the two-factor solution. The first factor consisted of the $20 \mathrm{Cls}$ items (Cronbach's $\alpha=0.93$ ); the second factor comprised the 12 GHQ items (Cronbach's $\alpha=$ 0.89). Two items of the CIS factor "concentration" showed a tendency to load on both factors, though with higher loadings on the CIS (see Table 2). Generally, there was no substantial cross-loading between these two principal factors, which supports the notion of measuring different underlying concepts.

\section{Associations of fatigue with demographic and health factors}

The mean CIS total scores for men (57.2; S.D. 23.4) and women (57.1; S.D. 24.4) were highly similar. Age correlated very weakly positively with fatigue in men $(r=0.03)$ and very weakly negatively with fatigue in women $(r=-0.03)$. As shown in Table 3, among men, employees aged 46-55 years reported significantly higher levels of fatigue than the employees aged $26-35$ and the oldest ( $p<0.05$ ). whereas among women, no statistically significant differences in mean CIS scores between the age groups were found. The educational level, when adjusted for age, was only associated with differences in fatigue scores in men. There was a linear trend for declining scores on the CIS with higher educational levels ( $p<0.001$ ). In women, a curvilinear association was observed, with higher fatigue scores on the lower and higher educational levels. In both genders, employees who reported living alone had significant higher fatigue scores than those employees who did not live alone, when controlled for age and educational level (Table 3). 
Tatbe 2 Componem matrix for the fwo factor solution atter yarmax rotation (N=11, 807$)$

\begin{tabular}{|c|c|c|}
\hline cuestonnalre / item & Fantor 1 & Factor 2 \\
\hline \multicolumn{3}{|l|}{ 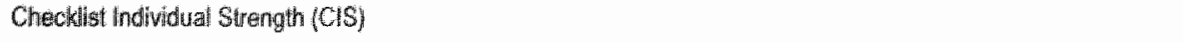 } \\
\hline 1. Unetried & Q.75 & 0.17 \\
\hline 2. Ifeel wery active & 0.75 & 0.22 \\
\hline 3. Thinking requires effort & 0.51 & 0.27 \\
\hline 4. Physically I feel exhausted & 0.71 & 0.17 \\
\hline 5. Ifeet like toing all kind of nice things & 0.54 & 0.18 \\
\hline 6. Ifeglit & 0.79 & 0.27 \\
\hline 7.1 do quite a lot within a day & 0.31 & 0.11 \\
\hline 8. Wher litit doing something, can concentrate quite well & 0.53 & 0.35 \\
\hline 9. I feel wealk & 0.76 & 0.22 \\
\hline 10. I dont do much during the day & 0.45 & 0.18 \\
\hline 11. I can concentrate well & 0.58 & 0.35 \\
\hline 12. I leel rested & 0.77 & 0.22 \\
\hline 13. I have trouble concentrating & 0.57 & 0.30 \\
\hline 14. Phys hally I feell am in a bad condition & 0.73 & 0.16 \\
\hline 15. I am full of plans & 0.45 & 0.16 \\
\hline 16. I am tired wery quickly & 0.78 & 0.19 \\
\hline 17. Ihave a low output & 0.57 & 0.24 \\
\hline 18. I feel no desire to do anyithing & 0.67 & 0.27 \\
\hline 19. My thoughts easily wander & 0.53 & 0.31 \\
\hline 20. Physically ! feel in a good shape & 0.74 & 0.16 \\
\hline \multicolumn{3}{|l|}{ GHQ $12^{*}$} \\
\hline 1. Lost sleep ower worry & 0.27 & 0.54 \\
\hline 2. Constantly under strain & 029 & 0.53 \\
\hline 3. Able lo concentrate & 0.27 & 0.67 \\
\hline 4. Playing usefuf part in things & 0.19 & 0.57 \\
\hline 5. Able to tace problems & 0.01 & 0.52 \\
\hline 6. Capable of making decisions & 0.13 & 0.62 \\
\hline 7. Couldn't overcome difficulties & 0.27 & 0.69 \\
\hline 8. Fogling teasonably happy & 0.18 & 0.75 \\
\hline 9. Enjoy norman activities & 0.23 & 0.71 \\
\hline 10. Unhappy and depressed & 0.33 & 0.73 \\
\hline 11. Losing confidence in seif & 0.28 & 0.71 \\
\hline 12. Thinking of sell as worthless person & 0.24 & 0.64 \\
\hline
\end{tabular}

"GHQ-12, the Dutch transtation of the 12-item General Health Questionnalire

Bold numbers $=$ factor loadings 
Table 3 Cndide and adjusted mean CIS total scores for men and women in relation to demographic and health factors: prevalence (\%)

\begin{tabular}{|c|c|c|c|c|c|c|}
\hline \multirow[b]{2}{*}{ Characteristic } & \multirow{2}{*}{\multicolumn{2}{|c|}{$\begin{array}{l}\text { Men }(n=8692) \\
\text { Crude }\end{array}$}} & \multirow{2}{*}{\multicolumn{2}{|c|}{$\begin{array}{l}\text { Women }(n=3167) \\
\text { Crude }\end{array}$}} & \multicolumn{2}{|c|}{ Prevalence $(\%)$} \\
\hline & & & & & Men & Wotnen \\
\hline Age group (in years) & $* *$ & & & & **: & \\
\hline $18-25$ & 55. & & 57.4 & & 189 & 20.3 \\
\hline $26-35$ & 56.9 & & 57.7 & & 18.4 & 23.3 \\
\hline $36-45$ & 57,3 & & 56.7 & & 22.1 & 223 \\
\hline $46-55$ & 58.4 & & 56.6 & & 23.4 & 22.5 \\
\hline \multirow[t]{2}{*}{$56-65$} & 55.0 & & 55.8 & & 23.0 & 20.8 \\
\hline & Crude & Adjustedt & Crude & Adjusted & & \\
\hline Educationallevel (age adjusted) & & **t & & & $*$ & $*$ \\
\hline Primary school & 63.0 & 62.7 & 59.6 & 60.2 & 31.7 & 34.3 \\
\hline Lower vocational education & 59.9 & 60.0 & 57.8 & 58.0 & 26.3 & 25.9 \\
\hline Lower secondary school & 58.8 & 58.7 & 57.2 & 57.4 & 23.3 & 25.6 \\
\hline Intermediate vocational education & 55.8 & 55.9 & 55.5 & 55.3 & 19.9 & 20.8 \\
\hline Upper secondary school & 57.5 & 57.5 & 55.9 & 55.8 & 22.2 & 17.3 \\
\hline Upper vocational education & 55.5 & 55.5 & 58.6 & 58.6 & 19.7 & 23.2 \\
\hline University & 55.2 & 55.2 & 58.3 & 58.3 & 16.2 & 21.4 \\
\hline Living alone & & $* *$ & & * & * & $*$ \\
\hline Yes & 60.4 & 60.9 & 59.9 & 60.2 & 24.6 & 26.5 \\
\hline Mo & 56.9 & 56.8 & 56.6 & 56.7 & 21.4 & 21.8 \\
\hline \multicolumn{7}{|l|}{ Dependent children } \\
\hline Yes & 57.1 & 57.1 & 56.5 & 56.8 & 21.6 & 22.0 \\
\hline $\mathrm{No}$ & 57.3 & 57.3 & 57.6 & 57.5 & 21,6 & 22.8 \\
\hline Presence of disease & & ** & & $* \star *$ & ** & $* *$ \\
\hline Yes & 68.2 & 68.1 & 67.4 & 67.8 & 38.0 & 35.1 \\
\hline No & 53.6 & 53.6 & 53.1 & 53.1 & 16.3 & 17.6 \\
\hline Hoafth status & & $w *$ & & min & 象 & $* *$ \\
\hline Excellent & 38.3 & 38.2 & 37.8 & 37.4 & 2.8 & 3.5 \\
\hline Very good & 45.0 & 45.0 & 46.2 & 46.0 & 5.2 & 9.5 \\
\hline Good & 58.8 & 58.8 & 57.2 & 57.4 & 20.3 & 20.0 \\
\hline Moderate & 82.4 & 828 & 80.0 & 80.9 & 63.4 & 56.4 \\
\hline Bad & 101.8 & 104.7 & 1026 & 1027 & 92.3 & 900 \\
\hline
\end{tabular}

CIS total mean score adjusted for age and educational level

"p<. 05 for differences in means between groups I differences in proportions by chi-square slatistics

i* $p<.001$ for differences in means between groups / differences in proportions by chi-square statistics 
A totall of 2839 (24\%) employees reported the presence of a disease (Table 1). Most commonly reported were: chronic back pain $(n=872,7 \%$ ), myocardial infarct and hypertension ( $n=611,5 \%)$, psychological disorder $(n=575,5 \%)$, and rheumatoid arthritis ( $n$ $=513,4 \%$ ). As shown in Table 3 , a substantial association was found between fatigue and the presence of a disease, with stalistically higher scores on the CIS in employees reporting the presence of a disease ( $p<0.001$ ). Among the most commonly reported diseases, the cls total scores varied from 67.0 for myocardial infarct and hypertension, 68.7 for chronic back pain, and 69.9 for meumatoid arthritis to 88.7 for psychological disorder. In both genders, employees with a "moderate" or "bad" self-rated health status scored higher on the CIS when adjusted for age and educational level than those with an "excellent", "very good" or "good" self-rated health status. In all, 2595 (22\%) employees had a score above the predefined cut-off for fatigue. The differences found in the proportions of fatigue cases with respect to demographic and health factors are comparable to those found for the continuous scoring (Table 3 ).

\section{Associations of psychological distress with demographic and health factors}

The mean GHQ score was 11.5 (S.D. 5.2) in men and 11.9 (S.D. 5.7) in women. The small difference in means between men and women was found to be statistically significant given the sample size. Age was positively but very weakly correlated with psychological distress in both genders (men: $r=0.05$; women: $r=0.03$ ). Table 4 shows that almong men employees aged 26-35 reported significantly lower levels of psychological distress than those aged 3645 and $46-55$ years $(p<0.001)$. As in fatigue, the GHQ scores did not differ significantly between the age groups among women. Overall, the patterns of associations for educational level, living alone, dependent children, the presence of a disease as well as for the self-rated health status were similar with those observed in fatigue. A total of 2746 (23\%) employees scored above the threshola for psychollogical distress, with a sitatistically significant difference in probable cases between women (26\%) and men (22\%). As Table 4 shows, the differences found in the proportions of psychological distress cases with respect to demographic and health factors were similar to those found for the continuous scoring.

\section{Assoclation of fatigue and psychological distress}

Of those amployees with prolonged fatigue, $43 \%$ reported fatigue only, while $57 \%$ reported both fatigue and psychological distress (Table 5). Because of the observed overlap of fatigue and psychological distress expressed by the correlation of 0.62 between the $\mathrm{C} / \mathrm{s}$ and the $\mathrm{GHQ}-12$, and the absence of distinct patterns of associations for fatigue versus psychological distress, the relation between these conditions was also examined in terms of "caseness". Therefore, we allocated the employees to four groups of caseness, based on the simple dichotomy for the CIS and GHQ-12: "fatigue (F) only case", "psychological distress (PD) only case", "fatigue and psychological distress (F+PD) case" and "no case". The prevalence in the total cohort was $9 \%, 10 \%, 13 \%$, and $68 \%$, respectively (Table 5 ).

With respect to the demographic factors, a comparison of "F only cases" and "PD only cases" in men showed that employees reporting fatigue were slightly older ( 42.8 versus 41.8 years) than those reporting psychological distress. In women, a difference between " $F$ only cases" and "PD only cases" was observed with respect to the educational level: women with lower 
Table 4 Crude and adjusted mean GHQ scores for men and women in relation to demographic and heewtentactors; prevalence $(\%)$

\begin{tabular}{|c|c|c|c|c|c|c|}
\hline \multirow[b]{2}{*}{ Characteristic } & \multirow{2}{*}{\multicolumn{2}{|c|}{$\begin{array}{l}\text { Men }(n=8764) \\
\text { Crude }\end{array}$}} & \multirow{2}{*}{\multicolumn{2}{|c|}{$\begin{array}{l}\text { Women }(n=3128) \\
\text { Crude }\end{array}$}} & \multicolumn{2}{|c|}{ Prevalince (\%) } \\
\hline & & & & & Men & Wornen \\
\hline Age group (in years) & $* *$ & & & & & \\
\hline $18-25$ & 11.2 & & 11.6 & & 23.8 & 253 \\
\hline $26-35$ & 11.0 & & 11.6 & & 19.6 & 25.5 \\
\hline $36-45$ & 11.6 & & 12.0 & & 22.4 & 25.6 \\
\hline $46-55$ & 11.8 & & 122 & & 22.6 & 27.7 \\
\hline \multirow[t]{2}{*}{56.65} & 11.3 & & 11.4 & & 21.5 & 230 \\
\hline & Crude & Adjustedi & Conde & Adjusted t & & \\
\hline Educational level (age adjusted) & & $: * *$ & & & $* *$ & \\
\hline Primary school & 12.2 & 12.0 & 130 & 128 & 28.3 & 35.2 \\
\hline Lower vocational education & 12.2 & 12.2 & 11.7 & 11.6 & 26,5 & 24.2 \\
\hline Lower secondary school & 11.8 & 11.8 & 11.7 & 11.6 & 224 & 24.2 \\
\hline Intermediate wocational education & 11.4 & 11.4 & 11.5 & 11.6 & 21.1 & 23.8 \\
\hline Upper secondary school & 11.6 & 11.6 & 120 & 120 & 228 & 27.6 \\
\hline Upper vocational education & 11.2 & 112 & 12.3 & 123 & 18.6 & 29.8 \\
\hline Unitwersity & 10.8 & 10.8 & 11.6 & 11.6 & 17.5 & 22.5 \\
\hline Living alone & & $*$ & & * & $*$ & $* *$ \\
\hline Yes & 12.5 & 12.7 & 12.8 & 12.8 & 29.4 & 34.4 \\
\hline No & 11.4 & 11.4 & 11.7 & 11.7 & 211 & 24.7 \\
\hline \multicolumn{7}{|l|}{ Dependent children } \\
\hline Yes & 11.5 & 11.5 & 11.8 & 11.8 & 21.4 & 24.5 \\
\hline No & 11.5 & 11.5 & 11.9 & 11.9 & 224 & 27.3 \\
\hline Presence of disease & & *t* & & ** & $* *$ & $* *$ \\
\hline Yes & 13.4 & 13.4 & 13.9 & 14.0 & 33.1 & 38.6 \\
\hline No & 10.9 & 10.9 & 11.1 & 11.0 & 17.9 & 21.0 \\
\hline Heath status & & $* *$ & & $*$ & $* *$ & $*$ \\
\hline Excellent & 8.8 & 8.8 & 8.6 & 8.5 & 8.0 & 10.0 \\
\hline Very good & 9.6 & 9.7 & 10.1 & 10.1 & 10.6 & 13.5 \\
\hline Good & 11.5 & 11.5 & 11.8 & 11.8 & 20.9 & 24.5 \\
\hline Moderate & 16.0 & 16.0 & 158 & 158 & 50.4 & 53.5 \\
\hline Bad & 21.0 & 207 & 21.5 & 20.9 & 77.8 & 800 \\
\hline
\end{tabular}

* GHQ lotal mean score adjusted for age and educational level

: $p<.001$ for differences in means between groups / differences in proportions by chi-square statistice 
educational levels were more likely to report fatigue, whereas women with thigher educational levels were more likely to report psychological distress (for each educational level, $p<0.05$ ). In both genders, the proportion of employees who reported living allone was higher among the "PD only cases" (men: 13\%, women: 14\%) than among the "F only cases" (men: $8 \%$, women: 10\%), whereas "fF only cases" (men and women: $37 \%$ ) were more likely to report the presence of a disease than "PD only cases" (men: $25 \%$, women: $35 \%$ ); both comparisons were statistically significant in men only (living alone: $p<0.05$; presence of disease $p<$ 0.001). Overall, a total of 673 employees $(6 \%)$ were reporting fatigue, without reporting psychological distress and the presence of a disease.

Table 5 Pychological distress among emplowees reponting fatigue and "caseness" groups ( $\mathrm{n}$, \%)

\begin{tabular}{|c|c|c|c|c|c|c|}
\hline & \multicolumn{2}{|c|}{ Men } & \multicolumn{2}{|c|}{ Women } & \multicolumn{2}{|c|}{ Total } \\
\hline & $n$ & $\%$ & $n$ & $9 \%$ & $\mathrm{n}$ & $\%$ \\
\hline \multicolumn{7}{|l|}{ Fatigue cases } \\
\hline Pyychological distress & 1030 & 56 & 434 & 62 & 1473 & 57 \\
\hline No psychological distress & 829 & 44 & 271 & 38 & 1100 & 43 \\
\hline \multicolumn{7}{|c|}{ Caseness atstribution of cohort } \\
\hline Fonly rase & 829 & 10 & 271 & 9 & 1100 & 9 \\
\hline PD only case & 843 & 10 & 375 & 12 & $12: 8$ & 10 \\
\hline$\vec{F}+\mathbb{P D}$ case & 1039 & 12 & 434 & 14 & 1473 & 13 \\
\hline No odse & 5910 & 68 & 2057 & 65 & 7967 & 68 \\
\hline
\end{tabular}

$F=$ Fafligue calses bersed on Cis

$\mathrm{PO}=$ Psychological distress cases based on GHQ-12

\section{DISCusSION}

The present study showed that fatigue is continuously distributed in the working population and fairly well associated with psychological distress $(r=0.62)$. As other authors of community and primary care studies, ${ }^{23,8}$ we found some degree of fatigue in nearly all of the working population. It has to be noted, however, that while reasonably distributed, there was an excess of the lowest possible fatigue scores, with a small percentage (2\%) completelly free of symptoms of fatigue (or completely unwilling to acknowledge them). The overall response rate of $45 \%$ raised the question of selective participation of employees, which may have biased the results. A nonresponse analysis, however, demonstrated that nonrespondents were less likely to report fatigue and sickness absence. This may have resulted in a slight overestimation of the prevalence of fatigue.

This study. which showed that fatigue and psychological distress were fairly well associated in the general working population, is consistent with the findings of previous studies on the relationship of fatigue and psychological distress conducted in the community, the primary care setting and among UK National Health Service employees. ${ }^{3.5 .10}$ Some degree of overlap between prolonged fatigue and psychological distress may be simply explained by the similar items included in the CIS and the GHQ. 
The two-factor principal component analysis of the proposed measure of prolonged fatigue (CIS) and the existing measure of psychological distress (GHQ-12) revealed a separation between $\mathrm{CIS}$ and $\mathrm{GHQ}$ items, suggesting the measurement of different underlying constructs. It should be noted that the five-factor solution produced similar results with respect to the distinction between four "fatigue" factors and one "GHQ" factor. Recently. studies of the relationship between prolonged fatigue states and psychological distress conducted among a community-based sample of twins aged over $50^{21}$ and in the primary care setting ${ }^{22}$ showed a separation between fatigue-related items and those describing anxiety and depression. In both studies, a two-factor solution, with one factor representing fatigue and a second factor representing psychological distress, was found to be most appropriate. It should be kept in mind, however, that a direcl comparison of these results with our findings is hindered because of a different conceptualisation and operationalisation of fatigue and psychological distress, and the different settings in which the studies were carried out.

No clear, distinct pafterns of associations were found for fatigue versus psychological distress with respect to demographic and health factors. While most studies ${ }^{13,5,10}$ found more fatigue in women than in men, others ${ }^{2}$ as well as the present study found no difference between men and women with respect to fatigue. In previous research, inconsistent findings have been reported regarding age. ${ }^{1.3}$ In this study, an extremely low association between age and fatigue was found, identical to the finding in a study of fatigue among the general Norwegian population. ${ }^{6}$ The observed relation between the educational level and fatigue in men, with a linear trend towards lower fatigue scores with increasing educational levels; found in the present study agreed with data from Loge et all. ${ }^{6}$ Although previous research showed no or minor effects of marital status on fatigue ${ }^{2.65}$ the results of this study indicated more fatigue among employees who reported living alone. This association is consistent with the finding of more fatigue among single individuals in a study among employees of the UK National Health Service. ${ }^{10}$ With respect to the relation between psychological distress and demographic factors a similar pattern of associations was found. For future research on fatigue and psychological distress, these demographic factors should be considered as confounders calling for statistical control in analyses.

A substantial association was found between the self-rated health stalus and fatigue and psychological distress, respectively. Employees reporting a moderate or bad health status had more fatigue (and psychological distress) compared with those reporting a good, very good or excellent health status. Most likely, this association means that both high fratigue and high psychological distress contribute to an overall sense of poorer health. It is also possible. however, that those with a poor self-rated health are prone to overreport symptoms of fatigue or psychological distress. The strong association with the presence of a disease found in our study is consistent with findings of previous studies " ${ }^{16}$ and needs to be further examined in the working population. When interpreting these demographic and health associations, another source of bias related to the assessment of exposure and outcome variables has to be kept in mind. In this cross-sectional study, both the independent and the dependent variables are measured by a self-administered questionnaine, which may cause an overestimation of the associations.

Like many medical conditions, fatigue is best viewed as a continuum, as opposed to a dichotomy. When using a cut-off point, one may lose important information. For that reason, fatigue (and psychological distress) should be treated as a continuous variable whenever 
possible. A dichotomy, however, is useful when the prevalence of fatigue has to be compared in different subgroups or when employees have to be selected for treatment. The prevalence found in the working population was $22 \%$ for fatigue and $23 \%$ for psychological distress. Although different definitions of fatigue, different settings, different response rates, the use of different fatigue questionnaires, and different duration criteria for caseness hinder a direct comparison of prevalence rates, it should be noted that previous studies reported prevalence rates of substantial fatigue varying from $22 \%$ (11\% for 6 month or longer) in the general Norwegian population ${ }^{6}$ and $25 \%$ (at least 2 weeks duration) in an Australian primary care study $y^{5}$ to $38 \%$ (18\% for 6 month or longer) in a UK community survey. ${ }^{3}$

We found a strong association between fatigue and psychological distress in the working population. Among the employees reporting fatigue, $57 \%$ reported also psychological distress using caseness definition. Still, when allocated to the caseness groups, "fatigue only" was reported by $9 \%$ of the employees. The comparison of "F only cases" versus "PD only cases ${ }^{38}$ with respect to demographic factors demonstrated some modest differences bewween these caseness groups.

These findings showed a) that fatigue and psychological distress are important public health problems, which are closely associated in the working population; b) that there is some evidence suggesting that fatigue and psychological distress are different conditions, which can be measured separately; and c) that there is no clear distinct pattern of associations for fatigue and psychological distress with demographic and health factors. Hence, an important issue, which has to be addressed in future research, is to determine whether work-related factors, work-family factors, or individual factors play a distinct role in the etiology of fatigue versus psychological distress in the working population.

\section{ACKNOWLEDGEMENTS}

The Maastricht Cohort Study is part of the Netherlands concerted research action on "Fatigue at work" granted by The Netherlands Organisation for Scientific Research (NWO). The work presented in this paper was and is currently supported by The Netherlands Organisation for Scientific Research (NWO grant no. 580-02.251). We would like to thank Dr. Helga wan den Elzen for initiating and establishing this project and Jos Slangen for his work in data management.

\section{REFERENCES}

1. Chen MK. The epidemiology of selfoperceived fatigue anong adults. Prev Med 1986;15:74-81.

2. David A, Pelosi A, McDonald E, Stephens D, Ledger D, Rathbone R, Mann A. Tired weak, or in meed of rest: fatigue among general practice attenders. BMJ 1990;301:1199-1202.

3. Pawlikowska T, Chalder T. Hirsch SR. Wallace P. Wright DJ, Wessely SC. Population based study of fatigue and psychological distress. BMJ 1994;308:763-6.

4. Fuhrer $R$, Wessely $S$. The epidemiology of fatigue and depression: a French primary-care study. Psychol Med 1995:25:895-905.

5. Hickie IB, Hooker AW. Hadzi Pavlovic D, Bennekt BK, Wilson A. Lloyd AR. Fatigue in selected primary care settings: sociodemographic and psychiatric correlates. Med $\backslash$ Aust 1996;164:585-8.

6. Loge $\sqrt{H}$. Ekeberg $\mathrm{O}$, Kaasa $\mathrm{S}$. Fatigue in the general Nowegian population: normative data and associations. J Psychosom Res 1998; $45: 53-65$. 


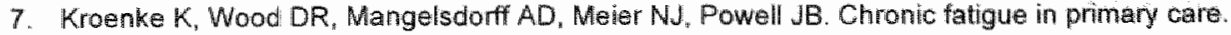
Prevalence, patient characteristics, and outcome. JAMA 1988;260:929-34.

8. Lewris $G$. Wesselly $S$. The epidemiology of fatigue: more questions than answers. J Epidemiol Community Heath 1992:46:92-7.

9. Chalder T, Berelowitz G, Pawlikowska T, Watts L, Wessely S, Wright D, Wallace EP. Development of a fatigue scale. J Psychosom Res 1993;37:147-53.

10. Hardy GE, Shapiro DA, Borrill CS. Fatigue in the workforce of National Heath Service Trusts: levels of symptomatology and links with minor psychiatric disorder, demographic, occupational and work role factors. J Psychosom Res 1997:43:83-92.

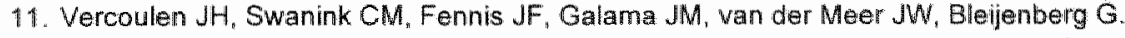
Dimensional assessment of chronic fatigue syndrome. J Psychosom Res 1994,38:383-92.

12. Vercoulen $J H_{\text {a }}$ Alberts M, Bleijenberg G. De Checklist Individuele Spankracht (CIS) (The Checklist Individual Strength (CIS)]. Gedragstherapie 1999;32:131-36.

13. Beurskens AJ, Bültmann U, Kant IJ, Vercoulen JH, Bleijenberg $G$, Swaen GM. Fatigue among working people: validity of a questionnaire measure. Occup Environ Med 2000,57:353-57.

14. Goldberg DP, Willians P. A User's Guide to the General Health Questionnaire. Windsor: NFERNelson; 1988 .

15. Koeter MW, Ormel J. General Health Questionnaire, Handleiding Nederiandse bewerking [General Health Questionnaire, Manual Dutch version]. Lisse: Swets \& Zeitlinger; 1901.

16. Vercoulen $J H$, Hommes $O R$, Swanink $C M$, Jongen PJ, Fennis JF, Galama JM, van der Maer WW, Bleijenberg $G$. The measurement of fatigue in patients with multiple sclerosis. A multidimensional comparison with patients with chronic fatigue syndrome and healthy subjects. Arch Neurol $1996 ; 53: 642-49$.

17. Vercoulen JH, Swanink CM, Fennis JF, Galama JM, van der Meer JW, Bleijenberg G. Prognosis in chronic fatigue syndrome: a prospective study on the natural course. $J$ Neurol Neurosurg Psychiatry 1996;60:489-94.

18. Bültmann U, De Vries $M_{1}$ Beurskens $A J$, Bleijenberg $G_{r}$ Vercoulen JH, Kant IJ. Measurement of prolonged fatigue in the working population: Determination of a cutoff point for the Checklist Individual Strength. J Occup Health Psychol 2000:5:41\%-16.

19. Aaronson NK, Muller M, Cohen PD, Essink Bat ML, Fekkes M, Sanderman R, Sprangers MA, te Velde $\mathrm{A}_{w}$ Verrips. $E$. Translation, validation, and norming of the Dutch language version of the SF. 36 Health Survey in community and chronic disease populations. J Clin Epidemiol 1998;51:105568.

20. SPSS. Base 8.0 for Windows User's Guide. Chicago: SPSS Inc; 1998.

21. Kirk KM Hickie IB, Martin NG. Fatigue as relatted to anxiety and depression in a community-based sample of twins aged over 50. Soc Psychiatry Psychiati Epidemiol 1999:34:85 90 .

22. Koschera A, Hickie I, Hadzi-Pavlowic D. Wilson A, Lloyd A. Prolonged fatigue, anxiety and depression: exploring relationships in a primary care sample. Aust N Z J Psychiatry 1999;33:54552. 
The relationship between psychosocial work characteristics and fatigue and psychological distress

Ute Bultmann" , Jmert Kant', Kees A.P. Schröer", Stanislav V. Kasic ${ }^{\circ}$

i Department of Epidemiology, Maastricht University, Maastricht the Netherlands

- Department of Medical Sociology, Maastricht University, Maastricht, the Netherlands

c Department of Epidemiology and Public Health, Yale University School of Medicine. New Haven, Connecticut, USA

International Archives of Occupational and Environmental Health 2002; in press 


\section{ABSTRACT}

Objectives: To examine the associations between psychosocial work characteristics and fatigue in emplayees in the Maastricht Cohor Study. A second objective was to compare the relationships for fatigue versus psychological distress with these psychosocial work characteristics. Methods: The design was cross-sectional and included 11,020 employees who responded to the self-administered baseline questionnaire of the Maastricht Cohort Study. Fatigue was measured with the Checklist Individual Strength, a 20-item self- report instrument. Psychological distress was measured with the 12-item version of the General Health Questionnaire. Psychosocial work characteristics comprised: psychological demands, decision latitude, and sociall support at work as measured by the Job Content Questionnaire. as well as emotional demands at work, physical demands at work, job insecurity, and conflict with supervisor/coworker, which were assessed with items from existing Dutch questionnaires. Results: Low decision latitude and low social support at work were associated with fatigue in both men and women. Associations were also found between emotional demands at work "job insecurity, physical demands and conflict with supervisor and fatigue in men; and high psychological demands and fatigue in women. As regards psychological distress "there was no association with low decision latitude, but strong associations with emotional demands and conflict with supervisor in both genders. Conclusions: The study provides strong support for associations between psychosocial work characteristics and fatigue in men and women, even after adjustment for psychological distress. Moreover, it suggests some differential effects of psychosocial work characteristics on fatigue and psychological distress. 


\section{INTRODUCTION}

Fatigue is a common complaint. Community and primary care studies have shown that some degree of fatigue is found in nearly all the population. ${ }^{1-3 / 3}$ In recent years, prolonged fatigue has atracted attention in occupational (mental) health research, ${ }^{4.5}$ since it may affect the individual's performance and functioning in the occupational as well as in the home setting. and may lead to sickness absenteeism and work disability. ${ }^{6}$ As reported by Houtman. ${ }^{7}$ about one in every three work disability benefit recipients in the Netherlands is classified as disabled for work on mental grounds. Some $90 \%$ of recipients of this kind of work disability benefit suffer from an "exogenous reaction" "the official diagnostic label that includes overstrain, chronic job stress, and burnout - mental states which include prolonged fatigue as a major symptom. Prolonged fatigue is, in contrast to acute fatigue, not easilly reversible and mot task specific; the compensating mechanisms that are useful in reducing acute fatigue are no longer effective. "Given the unfavorable prognosis of prolonged fatigue and the high cost implications for employees, employers, and society, ${ }^{6}$ it is of paramount importance to develop preventive measures.

The increasing awareness of the impact of prolonged fatigue on absenteeism and work disability has led to the recognition that there is very little information about work characteristics, which predict fatigue. This absence of data as well as the urgent need for preventive measures has prompted the establishment of the large-scale epidemiological Maastricht Cohort Study of "Fatigue at Work". "10,11 Cross-sectional anialyses at baseline revealed that $22 \%$ of the 12,000 employees reported fatigue. ${ }^{12}$ The same study explored whether the construct of fatigue is conceptually and operationally distinct from psychological distress and found that fatigue was fairly well associated with psychological distress, expressed by a correlation of 0.62. Moreover, there was no clear distinction in patterns of associations with demographic and health factors. A principal component analysis, however, showed a separation between fatigue items and psychological distress items, suggesting the measurement of different underlying constructs. ${ }^{12}$

For the development of effective preventive measures for fatigue, it is important to identify the psychosocial factors at work involved in the onset of fatigue. While the likely multifactorial etiology of fatigue is emphasized in the literature, ${ }^{13}$ with 'psychosocial' (e.g., work, family. and lifestyle) being the commonest reason for the feeling of fatigue, ${ }^{2}$ only very few studies have examined the relationship between psychosocial factors at work and fatigue. Using specific accupational groups in the workforce of the UK National Health Service Trusts, Hardy et al. ${ }^{14}$ reported that high work demands and role conflict are related to high levels of fatigue and that these factors were sufficient to explain occupational and gender differences. Moreover, fatigue was associated with high levels of psychological distress. A generalization of these findings, however, is difficult because the study was conducted on a limited range of occupations.

In the Maastricht Cohort Study, a large, heterogeneous working population was used to explore the relationship between a broad range of psychosocial factors at work and fatigue. Moreover, to further determine whether fatigue is conceptually distinct from psychological distress, associations between psychosocial work characteristics and psychological distress were also examined. We included work characteristics, such as psychological demands and decision latitude, which have been extensively examined as determinants of (mental) health, and for which many studies have accumulated evidence for a relationship with psychological 
outcomes, e.g. psychological distress, depressive symptoms. ${ }^{\text {t5.-2 }}$ Since fatigue is a somewhat different construct, and therefore may be associated with different work characteristics, we also included measures of emotional demands, physical demands, job insecurity and conflict with supervisor/co-workers.

The objective of the present study was to determine whether psychosocial work characleristics are associated with fatigue in employees in the Maastricht Cohort Study. A second objective was to compare the associations for fatigue and psychological distress with these psychosocial work characteristics. Given the observed difference between men and women with respect to psychological distress, all analyses were conducted separately for men and women.

\section{MATERIAL AND METHODS}

\section{Study design and participants}

In May 1998, a total of 26,978 male and female employees, aged 18-65 years, from 45 companies and organizations, received both a letter at home inviting participation and the questionnaire "Fatigue at Work". The letter explained the purpose and the general outtine of the study, described how the data would be used, and guaranteed anonymity of responses. The voluntary nature of participation was emphasized. The self-administered questionnaire included items on fatigue, psychological distress, demographic variables, and work characteristics, as well as on family and individual characteristics. To minimize reporting bias, none of these items was indicated by subheadings. Altogether 12,161 employees completed and returned the baseline questionnaire and gave written consent. The overall response rate was $45 \%$. Sixty-six questionnaires were excluded from the analysis because of technical reasons or because the age criterion was not met. Full details of the procedure, the baseline characteristics, and the non-response analyses have been reported elsewhere. ${ }^{10,12}$ In the present study we also excluded 1,075 employees who reported themselves to be absent from work due to illness or reported working under modified conditions related to former sickness absence (e.g. fewer hours, modified tasks of other functions). The final study sample was therefore 11,020 employees; $8,159(74 \%)$ men and 2,861 women $(26 \%)$. The mean age of the total cohort was 41.0 years (SD 8.9); 42.0 years (SD 8.7) in men and 38.0 years (SD 8.8) in women. Further characteristics of the study population are given in Table 1.

\section{Psychosocial work characteristics}

A validated Dutch version of the self-administered Job Content Questionnaire (JCQ) was used to measure psychological demands, decision latitude and support at work. ${ }^{22.23}$ Psychological demands (Cronbach's alpha coefficient 0.69 for both genders) were measured by the sum of five items (excessive work, conflicting demands, insufficient time to do work, working fast, and working hard). Decision latitude (Cronbach's alpha coefficient 0.82 for men and 0.78 for women) was measured by the sum of two subscales: sikill discretion (keep learning new things, can develop skills, job requires skill, task variety "work not repetitious, job requires creativity) and decision authority (have freedom to make decisions, can choose 
Table 1. Charactertstics of the sildy population

Characteristics

Educational level

Pintivary school

Lower vocationat education

Lower secondary school

Intermediate wocational education

Upper secondary school

Upper wocational education

University

Living alone

No

Yes

Presence of disease

No

Yes

Employment status

Permanent contract

Temporary contract

Tola
$(n=11,020)$

$\begin{array}{rr}446 & 42 \\ 1,617 & 15.1 \\ 1,356 & 12.7 \\ 2,563 & 24.0 \\ 913 & 8.5 \\ 2,541 & 23.7 \\ 1,264 & 11.8\end{array}$

\section{9,906}

1,100

90.0

10.0

8,49

2,323

78.4

21.6

6,306

1.649

Meri

$(n=8,159)$

Women

$(n=2,861)$

n 8

$\begin{array}{rrrr}386 & 4.8 & 60 & 22 \\ 1.360 & 17.0 & 257 & 9.5 \\ 830 & 10.4 & 526 & 19.5 \\ 1.894 & 23.7 & 669 & 24.8 \\ 596 & 7.4 & 317 & 11.8 \\ 1.948 & 24.3 & 593 & 22.0 \\ 990 & 12.4 & 274 & 10.2\end{array}$

22

9.5

9.5

24.8

11.8

220

10.2

88.3

11.7

$9.4 \quad 335 \quad 11.7$

.


men and 0.53 for women. For the present study, emotional demands at work was indicated: as "no emotional demands" (score $=0$ ), "low emotional demands" (score $=1$ ), and "high emotional demands" (score $=2-5$ ). To assess whether employees perceived their work as being physically demanding, a single ftem (yes/no) from the Dutch questionnaire on work and health ${ }^{24}$ was used. Another three items from the Dutch questionnaire on perception and judgment of work ${ }^{25}$ were used to measure job insecurity (yes/no). conflict with supervisor (yes/no), and conflict with co-worker (yes/no).

\section{Fatigue}

The self-report Checklist Individual Strength (CIS). which was originally developed for hospital studies of chronic fatigue syndrome, was used to measure fatigue. ${ }^{26,27}$ The 20 statements cover four aspects of fatigue, such as severity, concentration, motivation, and physical activity level. These factors were confirmed in a principal component analysis. ${ }^{12}$ The CIS was extensively tested in the clinical setting, ${ }^{28.29}$ and was validated in the working population during pilot work. ${ }^{30}$ Using a seven-point Likert scale, participants are instructed to indicate how they had felt during the previous 2 weeks. Higher scores indicate a higher degree of fatigue, more concentration problems, reduced motivation or low levels of activity. In the Maastricht Cohort Study, the responses to the individual statements were summed to generate a ClS totall score, ranging from 20 to 140 . The Cronbach's alpha coefficient was 0.93 for both genders. The cutoff point for case classification used in the present study was ClS total $>76$, with a specificity of $90 \%$ and a sensitivity of $73 \%$. This cutoff was established in a separate pilot study on the basis of receiver operating characteristic (ROC) analysis in defined samples with differences in fatigue levels. ${ }^{11}$ All those employees scoring $>76$ on the cis were designated as probable fatigue cases.

\section{Psychological distress}

Psychological distress was assessed with a Dutch translation of the 12-item version of the General Health Questionnaire $(\mathrm{GHQ}-12),{ }^{31_{1}^{32}}$ The GHQ-12 was developed as a screening instrument for detecting minor psychiatric disorder in the general population. For the fourpoint response scale two scoring systems were used. The Likert sconing method $(0,1,2,3)$ summed the responses of the 12 items to give a continuous distribution of the scores ranging from 0.36. The Cronbach's alpha coefficient was 0.87 for men and 0.88 for women. The traditional $\mathrm{GHQ}$ scoring method $(0,0,1,1)$ is designed to identify individuals reporting sufficient psychological distress to be classified as probable cases of minor psychiatric disorder. Given a possible range of scores from 0 to 12, the threshold for case classification in the present study was 4 or higher. That means that all those employees scoring on four or more of the $12 \mathrm{GHQ}$-items were considered to be probable cases of psychological distress. The threshold for case classification is high, but comparable to the threshold used in previous studies in the working population. ${ }^{14,33}$ 


\section{Demographic and health variables}

The respondents provided information on gender, age, educational level, living alone (yes/no), employment status (permanent contract or temporary contract), and the presence of a disease (yes/no). Details of these measures, which are considered in the analyses as confounding factors, have been reported elsewhere. ${ }^{12}$

\section{Statistical Analysis}

All analyses were conducted separately for men and women because of the observed gender difference with respect to psychological distress. ${ }^{12}$ The prevallence of fatigue and psychological distress was calculated, and Pearson intercorrelations were computed for the study variables. To examine the associations between psychosociall work characteristics separately as well as between the four demand/control categories and fatigue and psychological distress, we used logistic regression. Adjustments for potential confounding variables were made in 3 steps. In step 1, we adjusted for age and educational level; in step 2 we controlled for age, educational level, employment status, living alone, and the presence of a disease. Additionally, since fatigue and psychological distress are fairly well associated. and to study effects independent of the other outcome measure, we adjusted in step 3 for the continuous scores of either the GHQ or the CIS when fatigue or psychological distress was considered as the dependent variable. All analyses were conducted on the individual level since analyses on the job title/occupational levell showed that "occupation" adds little explanatory information above the perceived measures of the work environment. Odds ratios (ORs) and $95 \%$ confidence intervals (95\% Cls) were calculated for psychosocial work characteristics and for the four demand/control categories. Statistical analyses were performed with SPSS $9.0^{34}$

Table 2. Comelation matrix of the study wariables for men (bold) and women:

\begin{tabular}{|c|c|c|c|c|c|c|c|c|c|c|c|}
\hline & 1 & 2 & 3 & 4 & 5 & 6 & 7 & 8 & 9 & 10 & 11 \\
\hline 1. Psychological demands & & .01 & $.20^{1 / *}$ & $.06^{60}$ & $.26^{\text {*1/4 }}$ & nflow & $.17^{* * a}$ & $.08^{m i n}$ & $.05^{\mathrm{sin}}$ & $.16^{4+4}$ & $22^{2 *}$ \\
\hline 2. Decision llafinde & 03 & & $.36^{\text {aik }}$ & $.22^{4-3}$ &. $.14^{k \|}$ & $-{ }_{n} 32^{2 *}$ & a. $16^{\text {inte }}$ & ${ }^{4} 05^{5}$ & $-.144^{* *}$ & $-27^{6 \%}$ &,$- 21^{* 4}$ \\
\hline 3. Superyisor stupport & $-.20^{* * 4}$ & $.31^{* *}$ & & $.25^{* *}$ & $-24^{* * *}$ & $-16^{6-k}$ & $.33^{\text {the }}$ & 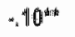 & $.16^{\text {thit }}$ & $\cdot 2^{3-4}$ & $-23^{4 \mathrm{~A}}$ \\
\hline 4. Co-worker suppont & $.09^{* a}$ & $.188^{* *}$ & $.30^{* *}$ & & $-.17^{* * t}$ & $-.07 * *$ & $* .077^{\text {sit }}$ & $-.22^{* 14}$ &,-\|\|$^{\text {tit }}$ &., $15 * *$ &. $.14^{* *}$ \\
\hline 5. Emotional defnands & $25^{\text {*4* }}$ & .03 & $-17^{* *}$ & $-09^{\mathrm{Di*}}$ & & $26^{*}$ & $29^{m *}$ & $.26^{m+4}$ & $18^{* *}$ & $.25^{* *}$ & $.32^{25}$ \\
\hline 6. Physidal demarts & $.22^{* 1}$ & $-13^{\mathrm{x} *}$ & $-.0 .5 \%$ & -02 & $33^{* *}$ & & $.43^{\text {inth }}$ & $.06^{* 2 *}$ & $.07^{\text {ind }}$ & $.17^{* *}$ & $.94^{* * *}$ \\
\hline 7. Conflict supenvisor & $.96^{* *}$ & $-13^{* 2}$ & $-33^{n i}$ & $-.06^{* i:}$ & $20^{* *}$ & $.04 *$ & & $23^{m+4}$ & $.10^{* *}$ & $.16^{* *}$ & $20^{* *}$ \\
\hline 8. Conflict coworker & $.12^{\mathrm{nix}}$ & $-.07^{12:}$ & $-.14^{* t}$ & $.20^{\mathrm{nis}}$ & $22^{*}$ & .04 & $26^{\mathrm{wi}}$ & & $.08^{* * 3}$ & $.10^{* *}$ & $.94^{k}$ \\
\hline 9. Job insecurity & 02 & $-.11^{* 0}$ & $-19 y^{4 x}$ & $-.07^{* *: *}$ & $.00^{*}$ & .04 & $07^{74}$ & .03 & & $14^{\text {ini }}$ & $.18^{* *}$ \\
\hline 10. Fatigue & $.18^{\text {kit }}$ & $-17^{* 0}$ & $-23^{2 t}$ & $-.13^{18}$ & $.18^{* 6}$ & $.0 g^{*}$ & $.12^{\mathrm{dii}}$ & $.13^{3 y}$ & $.10^{* *}$ & & $.59^{2 *}$ \\
\hline 11.Pswchological distress & $20^{* *}$ &. $.15^{*}$ & $.21^{* *}$ & $-15^{\text {nith }}$ & $.22^{* *}$ & $00^{2 *}$ & $.17^{4+x}$ & $.14^{: 1 *}$ & $.11^{* *}$ & $60^{84}$ & \\
\hline
\end{tabular}

* $p<0.05:$ : *hip $p<0.01$ 


\section{RESULTS}

Among the 8,159 men and 2,861 women the prevalence of fatigue was $20 \%$ and $19 \%$, respectively, and the prevalence of psychological distress was $20 \%$ and $23 \%$ respectively. As shown in Table 2, fatigue was fairly well associated with psychological distress, expressed by the correlations of 0.59 for men and 0.60 for women. In both genders, the highest correlation between psychosocial work characteristics was observed for supervisor social support and conflicts with supervisor. Overall, work characteristics were rather weakly correlated with each other. Since the ORs after the adjustmervt in step 2 (see data analysis above) did not vary meaningfully from those after step 1. we omitted step 1. The additional adjustment for either psychological distress or fatigue at step 3 had a stronger effect on the size of the associations, and these are presented.

Table 3. Adjusted odds ratios (OR) and $95 \%$ confidence intervals ( $95 \%$ Cl) for fatigue among men by psychosocial work characteristics

\begin{tabular}{|c|c|c|c|c|c|}
\hline Characteristic & Level & $\mathrm{OR}^{\mathrm{a}}$ & $95 \% \mathrm{Cl}$ & $\mathrm{OR}^{\mathrm{b}}$ & $95 \% \mathrm{Cl}$ \\
\hline \multirow[t]{3}{*}{ Psychological demands } & High & 1.81 & $1.58-2.09$ & 1.13 & $0.96-1.32$ \\
\hline & Medium & 126 & $1.08-1.47$ & 0.98 & $0.82-1.17$ \\
\hline & Low & 1 & & 1 & \\
\hline \multirow[t]{3}{*}{ Decision latitude } & Low & 262 & $2.24-3.06$ & 1.94 & $1.62-2.31$ \\
\hline & Medium & 1.36 & $1.16-1.59$ & 1.25 & $1.05-1.49$ \\
\hline & High & 1 & & 1 & \\
\hline \multirow[t]{2}{*}{ Supervisor support } & Low & 1.84 & 1.63 .2 .06 & 1.26 & $1.10-1.45$ \\
\hline & High & 1 & & 1 & \\
\hline \multirow[t]{2}{*}{ Co-worker suppoit } & Low & 1.64 & $1.46-1.86$ & 1.34 & $1.17-1.54$ \\
\hline & High & 1 & & 1 & \\
\hline \multirow[t]{3}{*}{ Emotional demands } & High & 2.70 & $2.34-3.12$ & 1.32 & $1.11-1.56$ \\
\hline & Low & 1.79 & $1.55-2.08$ & 1.38 & 1.17 .1 .62 \\
\hline & No & 1 & & 1 & \\
\hline \multirow[t]{2}{*}{ Physical demands } & Yos & 1.77 & 1.532 .04 & 1.29 & 1.091 .53 \\
\hline & No & 1 & & 1 & \\
\hline \multirow[t]{2}{*}{ Job insecurity } & Yes & 233 & $1.92-283$ & 1.30 & $1.03 \mathrm{~m} .63$ \\
\hline & No & 1 & & 1 & \\
\hline \multirow[t]{2}{*}{ Conffict with supervisor } & Yes & 2.18 & $1.85-2.57$ & 1.22 & $1.00 \cdot 1.49$ \\
\hline & No & 1 & & 1 & \\
\hline \multirow[t]{2}{*}{ Conflicl willh co-workers } & Yos & 1.91 & $1.57-2.32$ & 1.22 & $0.97-1.54$ \\
\hline & No & 1 & & 1 & \\
\hline High-strain work & & 3.48 & $2.89-4.20$ & 1.88 & $1.52 \cdot 2.32$ \\
\hline Passive work & & 1.96 & 1.61 .2 .38 & 1.56 & $1.26-1.95$ \\
\hline Active work & & 1.63 & $1.34 \times 1.98$ & 1.10 & $0.88-1.36$ \\
\hline Low-straim work & & 1 & & 1 & \\
\hline
\end{tabular}

Adjusted for age, educational level, living alone, employment status, and presence of disease;

b Adjusted for age, aducational lewel, uning alone, employment status, presence of disease, and continuous GHQ-12 score 


\section{Psychosocial work characteristics in men}

As shown in Table 3, all psychosocial work characteristics were associated with fatigue after adjustments in step 2, with ORs ranging from 1.64 for low co-worker support to 2.70 for high emotional demands. Although the ORs were reduced in size after the additional adjustment for psychological distress, the associations remained significant for most of the psychosocial work characteristics, with the strongest association for low decision latitude $(\mathrm{OR}=1.94 ; 95 \%$ Cl 1.62-2.31). For high psychological demands and conflict with co-worker, however, the association with fatigue became non-significant. Compared with men in low-strain work, men in high-strain work and passive work were at a higher risk of fatigue, even after additional adjustment for psychological distress. As in fatigue, there was a consistent picture of psychosocial work characteristics associated with psychological distress (Table 4). In contrast, all work characteristics remained significant when we also controlled for fatigue, with the strongest associations for high emotional demands ( $O R=2.95,95 \% \mathrm{Cl} 2.51-3.47)$, experiencing job insecurity, high psychological demands, and conflict with supervisor. Next to high-strain work and passive work, a strong association was found between active work and psychological distress.

Table 4. Adjusted odds ratios (OR) and $95 \%$ confidence intervals (95\% Cl) for psychological distress among men by psychosocial work characteristics

\begin{tabular}{|c|c|c|c|c|c|}
\hline Characteristic & Lewe! & $\mathrm{OR}^{\mathrm{a}}$ & $95 \% \mathrm{Cl}$ & ORb & $95 \% \mathrm{Cl}$ \\
\hline \multirow[t]{3}{*}{ Psychological demands } & High & 2.56 & $2.22-2.95$ & 2.05 & 1.75 .2 .41 \\
\hline & Medium & 1.52 & $1.29 \times 1.78$ & 1.38 & 1.151 .65 \\
\hline & Low & 1 & & 1 & \\
\hline \multirow[t]{3}{*}{ Decision latitude } & Low & 2.17 & $1.86-2.52$ & 1.25 & $4.05-1.48$ \\
\hline & Medium & 1.22 & $1.05-1.43$ & 1.00 & $0.85-1.119$ \\
\hline & High & 1 & & 1 & \\
\hline \multirow[t]{2}{*}{ Supervisor support } & Low & 2.23 & $1.98-2.51$ & 1.65 & $1.44-1.88$ \\
\hline & High & 1 & & 1 & \\
\hline \multirow[t]{2}{*}{ Ca-worker support } & Low & 1.72 & $1.53-1.94$ & 1.31 & $1.15 \cdot 1.50$ \\
\hline & High & 1 & & 1 & \\
\hline \multirow[t]{3}{*}{ Ernotional demands } & High & 4.19 & $3.62-4.85$ & 2.95 & $251-3.47$ \\
\hline & Low & 1.99 & $1.70-2.32$ & 1.53 & $1.29 \cdot 1.82$ \\
\hline & No & 1 & & 1 & \\
\hline \multirow[t]{2}{*}{ Physicial demands } & Yas & 1.74 & $1.51-2.01$ & 1.27 & $1.07-1.49$ \\
\hline & No & 1 & & 1 & \\
\hline \multirow[t]{2}{*}{ Job insecurity } & Yes & 3.23 & $2.69-3.89$ & 2.43 & $1.96-3.02$ \\
\hline & No & 1 & & 1 & \\
\hline \multirow[t]{2}{*}{ Conflict with supervisor } & Yes & 2.85 & 243335 & 2.04 & $1.70 \cdot 2.45$ \\
\hline & No & 1 & & 1 & \\
\hline \multirow[t]{2}{*}{ Conflict with co-workers } & Yes & 2.37 & $1.97-286$ & 1.94 & $1.56-2.40$ \\
\hline & No & 1 & & 1 & \\
\hline High-strain work & & 4.05 & $3.34-4.91$ & 2.17 & $1.75-2.69$ \\
\hline Passive work & & 1.85 & $1.511-2.27$ & 1.26 & $1.00-1.58$ \\
\hline Active work & & 2.33 & $1.92-2.84$ & 1.94 & $1.57-2.40$ \\
\hline Low-sitrain work & & 1 & & 1 & \\
\hline
\end{tabular}

adjusted for age, educalional level, living alone, employment status, and presence of disease:

- Adjusted for age, educational level, living alone, employment status, presence of disease, and continuous faligue scone 


\section{Psychosocial work characteristics in women}

Table 5 shows that, except for physical demands, significant associations were found between psychosocial work characteristics and fatigue. Of these, low decision latitude (OR = $1.82 ; 95 \% \mathrm{Cl} 1.36-2.44$ ) and low supervisor support (OR $=1.71 ; 95 \% \mathrm{Cl} 1.35-2.16$ ) as well as high psychological demands, low co-worker support, and conflict with co-worker were still significant after adjustment for psychological distress. Compared to women reporting lowstrain work, those in high-strain work and passive work were at a higher risk for fatigue, even after adjustment for psychological distress.

Table 5. Adjusted odds ratios (OR) and $95 \%$ confidence intervals $(95 \% \mathrm{Cl}$ ) for fatigue amomg women by psychosocial work charanchisticu

\begin{tabular}{|c|c|c|c|c|c|}
\hline Characteristic & Level & OR: & $95 \% \mathrm{Cl}$ & OR' & $95 \% \mathrm{Cl}$ \\
\hline \multirow[t]{3}{*}{ Psycholcicical demands } & High & 1.79 & $1.39 \cdot 2.28$ & 1.36 & $1.02-1.81$ \\
\hline & Medium & 1.23 & $0.94-1.61$ & 1.20 & $0.89-1.62$ \\
\hline & Low & 1 & & 1 & \\
\hline \multirow[t]{3}{*}{ Decision latifude } & Low & 222 & $1.72-2.87$ & 1.82 & $136-2.44$ \\
\hline & Medium & 1.25 & $0.96-1.62$ & 1.03 & $0.77-1.39$ \\
\hline & High & 1 & & 1 & \\
\hline \multirow[t]{2}{*}{ Supervisor support } & Low & 2.25 & $1.83-2.77$ & 1.71 & $1.35-2.16$ \\
\hline & High & 1 & & 1 & \\
\hline \multirow[t]{2}{*}{ Co-worker support } & Low & 1.68 & 1.34 .2 .09 & 1.30 & $1.04-1.69$ \\
\hline & High & 1 & & 1 & \\
\hline \multirow[t]{3}{*}{ Emotional demands } & High & 1.94 & 1.51 .2 .49 & 1.29 & $0.97 \cdot 1.71$ \\
\hline & Low & 1.42 & $1.07 \times 1.87$ & 1.09 & $0.80-1.49$ \\
\hline & No & $\|$ & & 1 & \\
\hline \multirow[t]{2}{*}{ Physical demands } & Yes & 1.13 & $0.89 \cdot 1.43$ & 0.99 & $0.76-1.30$ \\
\hline & No & $\uparrow$ & & 1 & \\
\hline \multirow[t]{2}{*}{ Job insecurity } & Yes & 1.99 & $1.41-2.80$ & 1.39 & $0.93-2.08$ \\
\hline & No & 1 & & 1 & \\
\hline \multirow[t]{2}{*}{ Conflict with supervisoir } & Yos & 1.96 & $1.39-2.78$ & 1.14 & $0.76-1.71$ \\
\hline & No & 1 & & 1 & \\
\hline \multirow[t]{2}{*}{ Conflict with co-workers } & Yes & 2.16 & $1.51-3.09$ & 1.52 & $1.00-230$ \\
\hline & No & 1 & & 1 & \\
\hline High-strain work & & 2.85 & $2.07-3.92$ & 2.01 & $1.41-2.88$ \\
\hline Passive work & & 1.92 & $1.39-2.65$ & 1.51 & $1.05-2.17$ \\
\hline Activa work & & 1.72 & $126-2.34$ & 1.25 & $0.89-1.76$ \\
\hline Low-strain work & & 1 & & 1 & \\
\hline
\end{tabular}

Adjusted for age, oduciational level, living alone, employment status, and presence of disease:

"Adjusted for age, educrational lovel, living alone, employment status, presence of disease, and conkinuous GHQ-12 score

In contrast, low decision latitude and conflict with co-worker were no longer significantly associated with psychological distress when we adjusted for fatigue (Table 6). Strong associations, however, were found for conflict with supervisor ( $O R=2.44 ; 95 \%$ Cl 1.69-3.53) and high emotional demands ( $O R=1.73 ; 95 \% \mathrm{Cl} 1.32-2.25)$. As shown in Table 6 , a higher risk for psychological distress was found im women reporting active work. 


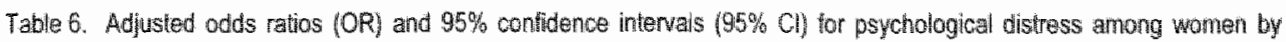
psychosocial wortic characteristics

\begin{tabular}{|c|c|c|c|c|c|}
\hline Characteristic & Level & $O R^{3}$ & $95 \% \mathrm{Cl}$ & $O R^{b}$ & $95 \% \mathrm{cl}$ \\
\hline \multirow[t]{3}{*}{ Psychological demands } & High & 190 & 1.51 .2 .39 & 1.36 & $1.04-1.76$ \\
\hline & Medium & 1.08 & $0.84-1.30$ & 0.91 & $0.68-1.20$ \\
\hline & Low & 1 & & 1 & \\
\hline \multirow[t]{3}{*}{ Decision latutude } & Low & 1.55 & $1.22-1.97$ & 0,95 & $0.71-1.25$ \\
\hline & Medium & 1.28 & $1.02-1.02$ & 1,09 & $0.84-1.42$ \\
\hline & High & 1 & & 1 & \\
\hline \multirow[t]{2}{*}{ Supervisor support } & Low & 1.90 & $1.57-2.30$ & 1.30 & $1,05-1,62$ \\
\hline & High & 1 & & 1 & \\
\hline \multirow[t]{2}{*}{ Co-worker support } & Low & 1.73 & 1.41 .2 .13 & 1.35 & $1.06-1.72$ \\
\hline & High & 1 & & 1 & \\
\hline \multirow[t]{3}{*}{ Emotional demands } & High & 221 & $1.75-279$ & 1.73 & $1.32-2.25$ \\
\hline & Low & 1.72 & $1.33-2.22$ & 1.52 & $1.44 .2,03$ \\
\hline & No & 1 & & 1 & \\
\hline \multirow[t]{2}{*}{ Physical demands } & Yes & 1.21 & $0.97-1.50$ & 1.01 & $0.78 \times 1.30$ \\
\hline & No & 1 & & $\uparrow$ & \\
\hline \multirow[t]{2}{*}{ Job insecurity } & Yes & 1.92 & 1.39 .2 .64 & 1.42 & $0.97-208$ \\
\hline & No & 1 & & 1 & \\
\hline \multirow[t]{2}{*}{ Conflich with supervisor } & Yes & 3.11 & 2.26 .4 .29 & 2.44 & $1.69-3.53$ \\
\hline & No & 1 & & 1 & \\
\hline \multirow[t]{2}{*}{ Contlict with conworkers } & Yes: & 2.37 & $1.69 \times 3.34$ & 1.47 & 0.992 .19 \\
\hline & No & 1 & & 1 & \\
\hline High-strain work & & 2.44 & $1.82-3.29$ & 1.34 & $0.95-1.88$ \\
\hline Passive work & & 1.71 & $1.27-2.30$ & 1.25 & $0.991 \times 1.75$ \\
\hline Active work & & 1.96 & 1.49 .2 .58 & 1.50 & $1.11-2.04$ \\
\hline Low-strain work & & 1 & & 1 & \\
\hline
\end{tabular}

adjusted for age, aducational level, living alone, employment status, and presence of disease:

s. Adjusted for age, educational level living alone, employment status, presence of disease, and continuous fatigue score

\section{Discussion}

Our findings showed that psychosocial work characteristics were associated with fatigue in both men and women, even after adjustment for psychological distress. As regards the comparison of associations, the results provide some support for differential effects of psychosocial work characteristics on fatigue and psychological distress, which lends weight to the argument that they are different constructs.

To our knowledge, this is the first comprehensive study of the relationship between psychosocial factors at work and fatigue. The findings provide support for the existence of an association between psychosocial work characteristics and fatigue in men and women. As regards high psychological demands, there was only an association with falligue in women, but not in men. It is notable that we found the strongest association between low decision latitude and fatigue in both men and women. In men, we also found associations between high emotional demands job insecurity, and conflict with supervisor and fatigue. These associations, however, were stronger when psychollogical distress was the dependent variable. In women, conflict with co-workers was also associated with fatigue, but emotional 
demands and conflict with supervisor were related only to psychological distress. Moreover, our findings showed that in both genders high-strain work and passive work were found to be associated with fatigue. Both high-strain and passive work include low levels of decision latitude, indicating the possible negative impact of low levels of decision latitude on fatigue. In both genders, no association was found between low decision latitude and psychological distress.

Given the cross-sectional design of the study, it is important to note that the observed associations between psychosocial work characteristics and either fatigue or psychological distress are not readily interpretable as cause-effect associations. Whether, for example, reverse causation ${ }^{35}$ may partly account for the observed associations cannot be determined.

Another important issue concerns the assessment of both the independent and dependent variables, i.e., the potential limits related to self-reported measures in terms of shared method variance or shared response biases. ${ }^{36}$ In our study, information on psychosocial work characteristics, as well as on fatigue and psychological distress, is obtained by a selfadministered questionnaire, which may result in an overestimation of the associations. Moreover, we have to keep in mind the potential underlying effects of negative affectivity ${ }^{37}$ on the relationship between self-reported measures: individuals high on negative affectivity may perceive their work enviromment more negatively, thereby creating spurious associations between work characteristics and the reports of adverse health outcomes, which are also influenced by negative affectivity. In the present study negative affectivity was not measured. However, we controlled for either psychological distress or fatigue when appropriate, which as a proxy for negative affectivity may overestimate its effect and lead to overcorrection.

An overall response rate of $45 \%$ was reasonable for a survey in the working population, though potential biasing of the results related to selective participation of the employees cannot be ruled out. A non-response analysis, however, revealed that non-respondents were less likely to report fatigue and sickness absence, which may have led to a slight overestimation of the level of fatigue.

The validated CIS was used to measure fatigue in the working population. ${ }^{30}$ Fatigue is, like many medical conditions, best viewed as a continuum as opposed to a dichotomy. ${ }^{3,13}$ This is in line with our previous findings, indicating a continuous rather than a discrete distribution of fatigue. ${ }^{12}$ Although one may lose important information when using a cutoff point, it is useful when employees have to be monitored or when employees have to be selected for treatment. With respect to the $\mathrm{ClS}$ and $\mathrm{GHQ}-12$ it is important to note that both instruments were used with their origimal time periods in order to leave their validity intacl. Given the time course of cause and effect of latigue and psychological distress, major methodological implications due to a time discrepancy of 2 weeks are unlikely.

Whereas this study primarily focused on the relationship between psychosocial wark characteristics and fatigue (and psychological distress), other work-related aspects (e.g., working hours), work-family aspects (e.g. domestic load), and non-work-related aspects (e.g. lifestyle habits, individual characteristics) may also be considered as related to fatigue in men and women.

In conclusion, aithough the present study has limitations related to the cross-sectional nature of its design, it provides strong support for associations between psychosocial work characteristics and fatigue in men and women. It also suggests some differential effects of psychosocial work characteristics on fatigue and psychological distress, even after adjustment for each ather. Since these psychosocial work characteristics represent 
potentially modifiable conditions, which can be addressed by interventions at the workplace to improve health, further research is needed to clarify their role in the onset of fatigue.

\section{ACKNOWLEDGMENTS}

The Maastricht Cohort Study is part of The Netherlands concerted research action on 'Fatigue at work" granted by The Netherlands Organization for Scientific Research (NWO). The work presented in this paper was, and is currently, supported by The Netherlands Organization for Scientific Research (NWO grant no. 580-02.251).

\section{REFERENCES}

1. Loge $\mathrm{JH}$, Ekeberg $\mathrm{O}$, Kaasa $\mathrm{S}$. Fatigue in the general Norwegian population: nomative data and associations. J Psychosom Res 1998;45:53-65.

2. Pawlikowska $T_{1}$ Chalder T, Hirsch SR, Wallace $P_{n}$ Wright DJ Wessely SC. Population based study of fatigue and psychological distress. BMJ 1994; 308:763-6.

3. David A, Pelosi $A_{1}$ McDonald $E_{1}$, Stephens D, Ledger D, Rathbone R, et al. Tired, weak, or in need of rest: Fatigue among general practice attenders. BMJ 1990; 301: 1199.1202.

4. Mounstephen A. Sharpe M. Chronic fatigue syndrome and occupational health. Occup Med Oxf $1997: 47: 217-27$.

5. Meijman T, Schaufeli W. Psychische vermoeidheid en arbeid. Ontwikkelingen in de A\&Opsychologie [Fatigue at work. Developments in Industrial \& Organizational Psychology]. De Psycholoog 1996;6:236-41.

6. Schröer $C$. De toename van arbeidsongeschiktheid wegens psychische aandoeningen [The increase of work disability due to mental disorders]. TBV 1997;5:16-23.

7. Houtman I. Feiten en fabels op een rij. Werkdruk in cijfers [Work pace in numbers]. Arbeidsomstandigheden $1999 ; 75: 2-5$.

8. Van Eck M. De Diagnosestelling 'Categorie V' [The diagnase 'eategory V"]. In: Bijl R, Bauduin D, editors. Categarie $\mathrm{V}$ : Arbeidsongeschiktheid wegens psychische stoornissen [Category $\mathrm{V}$ : Work disability due to mental disorders]. Utrecht: NcGW, 1991:79-94.

9. Meijman TF. Over vermoeidheid: arbeidspsychologische studies naar beleving van belastingseffecten. [Fatigue: studies on the perception of workload effects]. Amsterdari: University of Amsterdam, 1991.

10. Kamt IJ, Beurskens $A$, Schröer $C$, Nijhuis F, Schayck van C, Van den Elzen $H$, et al. De Maastrichtse Cohort Studie naar langdurige psychische vermoeidheid in de arbeidssituatie [The Maastricht Cohort Study of prolonged Fatigue at Work]. TBV 2000;8:226-232.

11. Bültmann U, De Vries $M$, Beurskens A. Bleijenberg $G$, Vercoulen J, Kant lu. Measurement of prolonged fatigue in the working population: Determination of a cutoff point for the Checklisit Individual Strength. $d$ Occup Health Psychol 2000;5; 411-416.

12. Büllmann U, Kant $\mathrm{J}_{\mathrm{x}}$ KasI $\mathrm{S}$, Beurskens $\mathrm{A}$, Van den Brandt $P$. (in press) Fatigue and psychological distress in the working population: Psychometrics, prevalence, and correllates

13. Lewis $G$, Wessely $S$. The epidemiology of fatigue: more questions than answers. J Epideminiol Community Health $1992 ; 46: 92-7$.

14. Hardy GE, Shapiro DA, Borrill CS. Fatigue in the workforce of National Health Service Trusts: levels of symptomatology and links wilh minor psychiatric disorder, demographic, occupational and work role factors. J Psychosom Res 1997:43:83-92.

15. Karasek. RA. Job demands, job decision latitude, and mental strain: implications for job redesign. Adm Sci Q 1979;24:285-309. 
16. Karasek $R$, Theorell T. Healthy Work: stress, productiwly, and the reconstruction of working life. New York (NY): Basic Books, 1990.

17. Landsbergis PA, Schnall PL. Deitz D, Friedman R. Pickering T. The patterning of poychological atributes and distress by "job strain" and social support in a sample of working men. J Behav Med $1992,15: 379-405$

18. Stansfeld SA, North FM, White 1, Marmot MG. Work characteristics and psychiatric disorder in civil servanis in London. J Epidemiol Community Health 1995:49:48-53

19. Bourbonnais $R$, Brisson $C$, Moisan $J$, Vezina $M$. Job smain and psychological distress in whitecollar workers. Scand J Work Environ Health 1996;22:139-45.

20. Stansfeld SA, Fuhrer R, Head J, Ferrie J, Shipley M. Work and psychiatric disorder int the Whitenall il Study. I Psychosom Res 1997;43:73-81

21. Niedhammer I, Goldberg M, Leclerc A, Bugel I, David S. Psychosocial factors at work and subsequent depressive symptoms in the Gazel cohort. Scand J Work Environ Health $1998 ; 24: 197-205$

22. Karasek RA. Job Content Questionnaire and Users's Guide. Los Angeles (CA): University of Southern Calfornia: Department of Industrial and Systems Engineering. 1985.

23. Houtrian 1. Reliability and validity of the Dutch version of the Karasek Job Content Questionnaire. APA/NIOSH conference on Work, Stress \& Health; Washington (DC): APA, 1995.

24. Gründemann R, Smulders P. Winter de C. Handleiding Viagenlist Arbeid en Gezondheid [Questionnaire on Work and Health. Manual]. Lisse: Swets \& Zeitlinger, 1993.

25. Van Veidhoven M, Meijman T. Het meten van psychosociale arbeidsbelasting met een vragenlijst: De Vragenilist Beleving en Beoordeling van de Arbeid (VBBA) [Questionnaire on Perception and Judgement of Work.]. Amsterdam: N⿴囗十 1994.

26. Vercoulen JH, Swanink CM, Fennis JF, Galama UM, vam der Meer JW, Blejenberg 0. Dimensional assessment of chronic fatigue syndrome. „Psychosom Res 1994;38:383-92.

27. Vercoulen $\mathrm{H} H$, Alberts M, Bleijenberg G. De Checklist Individuele Spankracht (CIS) [The Checklist Individual Strength [CIS》]. Gedragstherapie $1999 ; 32: 131-136$.

28. Vercoullen.$H$, Hommes OR, Swanink CM, Jongen PJ, Fennis JF, Galama JM, et al. The measurement of fatigue in patients with multiple sclerosis. A imultidimensionall comparison with patients with chronic fatigue syndrome and healthy subjects. Arch Neurol 1996;53:642-9.

29. Vercoulen JH, Swanink CM, Fennis JF, Galama JM, van der Meer WW, Bleijenberg G. Prognosis in chronic fatigue syndrome: a prospective study on the natural course. J Neurol Neurosurg Psychiatry 1996;60:489-94.

30. Beurskens A. Bülmann U, Kant IJ, Vercoulen JH, Bleijenberg G, Swaen GM. Fatigue among working people: validity of a questionnaire measure. Occup Environ Med $2000,57: 353,7$.

31. Goldborg DP. Willans P. A User's Guide to the General Health Questionnarre. Windsor: NFERNeison, 1988 .

32. Koeter M, Orme L. General Health Questionnaire. Handleiding Nederlandse bewerking lGeneral Health Questionnaire, Manual Dutch version/. Lisse: Swets \& Zeitlinger, 1991.

33. Wall TD, Bolden RI. Borrill CS, Carter A. Golya DA, Hardy GE, et al. Minor psychiatric disorder in NHS trust staff: occupational and gender differences. Br J Psychiatry $1997 ; 171: 519-23$.

34. SPSS. Base 9.0 for Window's Usar"s Guide. Chicago (L): SPSS Inc. 1998.

35. Zapf D. Dormann $G$. Frese M. Longitudinal Studies in Organizational Stress Research: A Review of the literature with Reference to Methodollogical Issues. J Occup Health Psychol 1996:1:145-69.

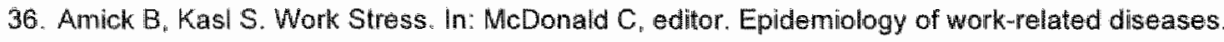
London: BMJ Publishing Group; 2000:283-308:

37. Watson D, Clark LA. Negative affectivily: the disposition to experience aversive emotional states Psycholog Bull 1984:96:465-90. 
Psychosocial work characteristics as risk factors for the onset of fatigue and psychological distress:

\section{Prospective results from the Maastricht Cohort Study}

Ute Bültmann ${ }^{a}$, IJmert Kant ${ }^{a}$, Piet A. van den Brandt ${ }^{\mathrm{a}}$, Stanislav V. Kast ${ }^{\mathrm{p}}$

${ }^{a}$ Department of Epidemiology, Maastricht University, Maastricht, the Netherlands

- Department of Epidemiology and Public Health, Yale University School of Medicine, New Haven, Connecticut, USA 


\section{ABSTRACT}

Background. Prolonged has recently attracted attention in occupational (mental) health research since it may lead to sickness absenteeism and work disability. To date, little is known about the role of psychosocial work characteristics in the aetiology of fatigue. In this study we examined prospectively a wide range of psychosocial work characteristics as possible risk factors for the onset of fatigue and psychological distress in the working population. Methods. This study is based on 8833 employees "participating in the Maastricht Cohori Study of "Fatigue at Work". A wide range of psychosocial work characteristics, measured at baseline, was used to predict the onset of fatigue and psychological distress 1 year later. Fatigue was measured with the Checklist Individual Strength; the General Health Questionnaire was used to measure psychological distress. Results. The cumulative incidence of fatigue during one year follow-up was $9.7 \%(n=492)$ in men, and $13.5 \%$ ( $n=$ 241) in women. Psychological demands at work as well as physical and emotional demands increased the risk for fatigue in men, whereas decision latitude in men and co-worker social support in women were protective against fatigue. These prospective associations remained significant after adjustments for potential confounders and baseline fatigue. As regards psychoingical distress, no association was found with decision latitude, while conflicts at work increased the risk of psychological distress. Conclusions. Psychosocial wark characteristics were significant predictors for the onset of fatigue in the working population. The prospective associations suggest some differential effects in the aetiology of fatigue and psychological distress. Good interpersonal relationships at work and high decision authority were demonstrated to be relevant aspects that should be targeted for prevention. 


\section{INTRODUCTION}

Fatigue is a common symptom of ill-health. ${ }^{-4}$ Fatigue that becomes prolonged is reported to be associated with impairments comparable to chronic medical conditions ${ }^{5}$ and may interfere with an individual's performance and functioning in the occupational as well as in the home setting. In recent years, prolonged fatigue has attracted attention in occupational (mental) health research, since it may lead to sickness absenteeism and work disability. ${ }^{6}$ As pointed out by Houtman, ${ }^{7}$ about one in every three work disability benefit recipients in the Netherlands is classified as disabled for work on mental grounds. Given the unfavourable prognosis of prolonged fatigue and the high cost implications for employers, employees and the society, ${ }^{*}$ there is an urgent need for preventive measures.

Recently, the large-scale epidemiological Maastricht Cohort Study of 'Fatigue at Work' has shown that fatigue is a common complaint in the working population: $22 \%$ of the 12000 employees reported fatigue. For the development of preventive measures for sickness absenteeism and work disability due to fatigue, it is important to identify the risk factors for the onset of fatigue. While the likely multi-factorial aetiology of fatigue is stressed in the literature ${ }^{9}$ and "psychosocial" (e.g. work, family and lifestyle) is the commonest mentioned reason for feeling fatigued, ${ }^{2}$ there is very little information about psychosocial work characteristics which predict fatigue. At present, we do know from a cross-sectional study among specific occupational groups in the workforce of the UK National Health Service Trusts $^{10}$ that high work demands and role conflicl are related to high levels of fatigue. Moreover, cross-sectional analyses of the baseline data of the Maastricht Cohort Study revealed relationships between psychosocial work characteristics (e.g. low decision latitude, low social support at work, high emotional demands) on the one hand, and fatigue on the other. ${ }^{11}$ The same study found that fatigue and psychological distress are fairly well associated in the working population ( $r=0.62$ ), and that about $23 \%$ of the 12000 employees were considered to be probable cases of psychological distress. ${ }^{8}$

To disentangle which psychosocial work characteristics play a role in the onset of fatigue and psychological distress, prospective longitudinal analyses are invaluable. Previous longitudinal studies such as the Whitehall $\|$ cohort of British civil servants ${ }^{12,13}$ and the Gazel cohort in France ${ }^{14}$ accumulated evidence for a relationship between psychosocial work characteristics and psychiatric disorder or depressive symptoms, respectively. Although their operationalization of psychosocial work characteristics and the occupational seltings differ, these studies showed that low social support at work, high psychological demands, and low decision latitude (decision authority) were predictors of psychiatric disorder and depressive symptoms. As regards to fatigue, however, such prospective associations are not yet established. Moreover, the role of emotional and physical demands, job insecurity, and conflicts with supervisor/co-worker as possible determinants of faligue and psychological distress in the working population has rarely been examined.

In the present study we explored prospectively a wide range of psychosocial work characteristics as possible risk factors for fatigue and psychological distress in the working population, thereby comparing associations for fatigue and psychological distress. We examined this through the Maastricht Cohort Study, a large-scale prospective study of 'Fatigue at Work'. The longitudinal relations between psychosocial work characteristics, measured at baseline, and (the incidence of) fatigue and psychological distress at follow-up 1 year later, were examined using linear regression analysis and logistic regression analysis. 
Both analyses controlled for potential sociodemographic confounding variables and for either fatigue or psychological distress, depending on the outcome assessed. Given the observed difference between men and women as regards to psychological distress, all analyses were conducted separately for men and women.

\section{METHODS}

\section{Sampling and procedures}

The present report is based on the Maastricht Cohort Study of 'Fatigue at work', a largescale prospective study of the onset and natural history of fatigue and psychological distress in the working population. ${ }^{15}$.16 In May 1998, 26978 employees aged 18-65 years from 45 companies and organizations received a letter at home, inviting participation, and the self. administered baseline questionnaire, which included items on psychosocial work characteristics, demographic, work-family and health factors as well as on fatigue and psychological distress. A total of 12161 employees completed and retumed the baseline questionnaire (response rate of $45 \%$ ). Written consent was obtained from all participants. Sixty-six questionnaires were excluded from the analysis because the age criterion was not met and due to technical reasons. The baseline cohort consists of 8840 men (73\%) and 3255 women $(27 \%)$.

A non-response analysis revealled no significant differences between respondents and nonrespondents with respect to demographic characteristics. Non-respondents were less likely to report fatigue complaints $\left(42 \% \mathrm{v}, 55 \%, \chi^{2}=11.1, p<0.05\right)$, sickness absence $(21 \% \mathrm{v}$. $\left.39 \%, \chi^{2}=21.5, p<0.05\right)$, and difficulties in work execution due to health complaints ( $17 \% \mathrm{v}$. $26 \%, x^{2}=7.75, p<0.05$ ). The main reason for non-response was no time to complete the questionnaire" (30\%), followed by "nothing would be done with the results' ( $18 \%$ ), and "no interest in the study subject' (15\%). Full details of the sampling and the baseline characteristics of the study population have been reported elsewhere. ${ }^{8}$

In May 1999, those employees $(n=11272)$ who had completed the baseline questionnaire and at least one of the two short questionnaires, which were sent in September 1998 and January 1999, were approached again to complete the follow-up questionnaire. Overall, 9625 employees, 7025 men $(73 \%)$ and 2600 women $(27 \%)$, completed and returned the follow-up questionnaire (response rate of $80 \%$ ). In the present analysis, we excluded those employees who reported themselves at baseline absent from work or reported working under modified conditions related to former sickness absence (e.g. fewer hours, modified tasks or other functions). Therefore, the final study population on whom follow-up data were available was 8833 employees, 6522 men $(74 \%)$ and 2311 women $(26 \%)$.

\section{Psychosocial work characteristics}

All information on psychosocial work characteristics used in this study was obtained from the baseline questionnaire. A validated Dutch version of the Job Content Questionnaire (JCQ) was used to measure psychological demands, decision latitude and social support at work. ${ }^{17,10}$ Psychological demands are assessed by the sum of five items (excessive work, conlilicting demands, insufficient time to do work, work fast and work hard). Decision latitude is measured by the sum of two subscales: skill discretion (keep learning new things, can 
develop skills, job requires skills, task variety, work not repetitious, job requires creativity) and decision authority (have freedom to make decisions, can choose how to perform work, and have a lot to say on the job). Social support is assessed by wo scales, each consisting of four items: supervisor support (concerned about the welfare of those under himiher, pays attention, helpful in getting the job done, successful in getting people to work together) and co-worker support (they take a personal interest in me, are friendly, heipful in getting the job done, and competent in doing work). For each item the response options varied on a fourpoint scale from "strongly disagree" to 'strongly agree'. In the logistic regression analysis, the total scores for psychological demands and decision latitude were grouped into tertiles, for both support measures the total score was dichotomized at the median.

Emotional demands at work are measured by the sum of five items (confronted with personally upsetting things, personal attacked or threaten, getting annoyed about others, moving work situations, and one or more shocking events at work during last year e.g. accident, violent crime, sexual harassment, aggression at work). The questions were derived from a Dutch questionnaire on Work and Health, ${ }^{19}$ a Dutch questionnaire on Perception and Judgement of Work. ${ }^{20}$ and self-formulated (item on shocking events at work). The response option for each item was yes/no. In the present study, emotional demands at work was indicated as no emotional demands (score $=0$ ). low emotional demands (score $=1$ ), and high emotional demands (score $=2-5$ ). To assess whether employees perceive their work as physically demanding (yes/no), one item from the Dutch questionnaire on Work and Health ${ }^{19}$ was used. Three items from the Dutch questionnaire on Perception and Judgement of Work ${ }^{20}$ were used to measure job insecurity (yes/no), conflicts with supervisor (yes/no) and conflicts with co-workers (yes/no).

\section{Demographic and health factors}

At baseline employees provided information on age, educational level, living alone (yes/ no), status of employment (permanent contract or temporary contract) and the presence of disease (yes/no), comprising for example chronic low back pain, theumatoid arthritis and hypertension. Details of these measures, which are considered in the analyses as confounding factors, have been reported elsewhere.

\section{Fatigue}

The 20-item self-report Checklist Individual Strength (CIS), which was originally developed for hospital studies of chronic fatigue syndrome, was used to measure fatigue. 21.22 The CIS covers several aspects of fatigue, such as severity, concentration, motivation and physical activily level, which fit in with the concept of fatigue. The instrument was extensively lested in the clinical setting ${ }^{23.24}$ and was validated in the working population. ${ }^{25}$ Subjects are inistructed to indicate how they felt during the last 2 weeks. The response to each statement is scored on a 7 -point Likert scale ( $1=$ Yes, that is true; to $7=$ No, that is not true). Higher scores indicate a higher degree of fatigue, more concentration problems, reduced motivation or low levels of activity. In the Maastricht Cohort Studly, the responses to the individual items were summed to generate a CIS-total score, ranging from 20-140. The cut-off point for case classification used in the present study was CIS-total $>76$. This cut-off was established in a separate pilot study by means of defined samples with differences in fatigue levels. ${ }^{15}$ All 
those employees scoring $>76$ on the CIS were considered to report a level of fatigue indicative of being "at risk" for sickness absence or work disability, and were designated as probable fatigue cases.

\section{Psychological distress}

The 12-item version of the General Health Questionnaire (GHQ-12) was used to assess psychological distress. ${ }^{20,27}$ The GHQ-12 was developed as a sereening instrument for detecting minor psychiatric disorders in the general population. Two scoring systems were used for the four-point response scale. The Likert scoring method $(0,1,2,3)$ summed the responses of the 12 items to generate a continuous distribution, ranging from $0-36$. The traditional $\mathrm{GHQ}$ scoring method $(0,0,1,1)$ is designed to identify individuals reporting sufficient psychological distress to be classiffed as probable cases of minor psychiatric disorder. In the present study, the threshold for case classification was $\geq 4$, given a possible range of scores from $0-12$. That means, employees scoring on 4 ar more of the 12 items were consiciered to be probable cases of psychological distress. The threshold for case classification is high, but identical to the threshold used in previous workplace studies, ${ }^{10.28}$ permitting direct comparison of the results, and likely to indicate very symptomatic employees as probable cases of minor psychiatric disorder.

\section{Data analysis}

All analyses were performed separately for men and women because of the observed gender difference regarding psychalogical distress. Pearson intercorrelations were calculated for the psychosocial work characteristics and the cumulative incidence of fatigue and psychological distress during 1 year follow-up period was determined. To examine the role of psychosocial work characteristics, measured at baseline, in the onset of fatigue and psychological distress after 1-year follow-up, the data were analysed using two methods. The primary analysis was linear regression analysis, which makes no assumptions about a diagnostic cut-off point and therefore fully reflects the continuous nature of the dependent measures. In addition, logistic regression analysis with dichotomized dependent measures was used. Data were analysed using SPSS $9.0^{29}$

Multiple linear regression analysis was used to examine the effect of each psychosocial work characteristic separately on changes in fatigue and psychological distress 1 year later. Additionally, given there are intercorrelations among the psychosocial work characteristics, the predictive effects of psychosocial work characteristics for future fatigue and psychological distress were examined by entering them all together, rather than one at a time. Adjustments for potential confounding variables were made in three steps: covariates age; educational level" living alone; employment status; and, presence of disease were entered at the first step. At the second step, we also controlled for the continuous baseline values of the dependent measure. Finally, since fatigue and psychological distress are fairly well associated, we adjusted for the continuous baseline value of $\mathrm{GHQ}-12$ or CIS score, when fatigue or psychological distress was considered as dependent variable, respectively. Unstandardized regression coefficients (B) and their standard errors (SE B) were determined for each model. 
Multiple logistic regression was conducted in two steps for each psychosocial work characteristic separately. Either fatigue or psychological distress cases at baseline were excluded. Because a simple incidence analysis ignores the issue that those close to the CIS cut-off and making only small changes will be counted as incident cases, we introduced the refinement that they also have to have an increase of a certain size. The size was determined by calculating the mean within person variance for baseline and follow-up CIS measurement ( 8 points). Then the delta CIS score, which is the follow-up CIS score minus the baseline CIS score, was calculated for all employees. Hence, those who crossed the predefined CIS cut-off of $>76$ at follow-up and had a delta CIS $\leq 8$ were excludied from the analysis. In a first step, we adjusted for age, educational level, living alone, emplayment status, and presence of disease. Since fatigue and psychological distress are fairly well associated, we adjusted in a second step for the continuous baseline GHQ-12 of CIS score. when subsequent fatigue or psychological distress was considered as dependent variable. respectively. Odds ratios (ORs) and their $95 \%$ confidence intervals $(95 \% \mathrm{Cls}$ ) were calculated for each psychosocial work characteristic.

\section{RESULTS}

\section{Intercorrelations of psychosocial work characteristics}

Table 1 shows the Pearson intercorrelations of all psychosocial work characteristics for men and women separately. In both genders, the highest correlation was observed between supervisor social support and conflicts with supervisor $(r=-0.37, n=6394, p<0.01$ in men; $r$ $=-0.31, n=2259, p<0.01$ in women). Overall, psychosocial work characteristics were rather weakly correlated with each other.

Table 1. Correlation matrix of psychosocial work characteristics for men (bold lype face $n=6522$ ) and women ( $n=2341$ )

\begin{tabular}{|c|c|c|c|c|c|c|c|c|c|}
\hline & 1 & 2 & 3 & 4 & 5 & 6 & 7 & 8 & 9 \\
\hline 1. Psychological job demands & & $0.03^{*}$ & 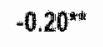 & $-0.05^{* i}$ & $0.26^{* * 4}$ & $0.18^{* *}$ & $0.15^{\mathrm{kn}}$ & $0.07^{\text {th* }}$ & $0.05^{* *}$ \\
\hline 2. Decision latitude & $0.06^{* *}$ & & $0.35^{* *}$ & $0.23^{k *}$ & $-0.14^{* *}$ & $-0.32^{* * *}$ & $-0.15^{\mathrm{kh}}$ & $.0 .05^{\text {int }}$ & $-0.15^{3 x}$ \\
\hline 3. Supervisor social support & $-0.18^{4 *}$ & $0.29^{* * 4}$ & & $0.24^{* *}$ & $.0 .24^{* *}$ & $-0.16^{* * *}$ & $-0.37^{* *}$ & $0.10^{\text {स* }}$ & $-0.17^{* x}$ \\
\hline 4. Co-worker social support & $-0.09^{* *}$ & $0.16^{* \star}$ & $0.30^{\text {t*t }}$ & & $.0 .17^{\star *}$ & $-0.07 *$ & $-0.07^{\text {thi }}$ & $.0 .24^{* * *}$ & $-0.12^{* *}$ \\
\hline 5. Emotional demands & $0.24^{* *}$ & 0.02 & $=0.15^{* * *}$ & $-0.09^{* *}$ & & $0.26^{\mathrm{kN}}$ & $0.29^{\circ *}$ & $0.26^{\text {w** }}$ & $0.49^{* *}$ \\
\hline 6. Physical demands & $0.19^{+* *}$ & $-0.12^{* *}$ & -0.02 & 0.01 & $0.31^{* * t}$ & & $0.11^{\text {k* }}$ & $0.08^{* *}$ & $0.08^{*}$ \\
\hline 7. Conflicts supervisar & $0.14^{* *}$ & $-0.11^{k * x}$ & $-0.31^{* h}$ & $-0.06^{* *}$ & $0.20^{\text {tif }}$ & 0.04 & & $0.24 * *$ & $0.09^{8 *}$ \\
\hline 8. Conflicts co-worker & $0.1 \|^{*}$ & $-0.07^{ \pm \star x}$ & $-0.14^{\text {t.t }}$ & $.0 .19^{* *}$ & $0.18^{\text {*ix }}$ & 0.03 & $0.26^{4 x}$ & & $0.09^{* x}$ \\
\hline 9. Jab insecurity & 0.03 & $-0.13^{2 k}$ & $-0.14^{* *}$ & $-0.07^{6 * k}$ & $0.07^{\text {制 }}$ & -0.02 & $0.07^{* *}$ & 0.03 & \\
\hline
\end{tabular}

Correlation significant: * $p<0.05 ; * * 0<0.01$ 
Table 2. Wo characteristos at basaline predic fatige afier 1-year follow ap in men and women, adjusted for potental confounders and basenting measures

\begin{tabular}{|c|c|c|c|c|c|c|}
\hline \multirow[b]{3}{*}{ Work characteristic } & \multicolumn{6}{|c|}{ Meri $(n=6522)$} \\
\hline & \multicolumn{2}{|c|}{ Moded It } & \multicolumn{2}{|c|}{ Model 2} & \multicolumn{2}{|c|}{ Model 33} \\
\hline & B & S.E. & $B$ & S.E. & $\mathrm{B}$ & S.E. \\
\hline Psychological demands & $0.632^{\text {nitat }}$ & 0.052 & $0.184^{\text {tim }}$ & 0037 & $9.140^{m * 2}$ & 0.038 \\
\hline Decision latitude & $-0.493^{\text {ink. }}$ & 0,027 & $-0.103^{\text {ink }}$ & 0.020 & $0.094^{\text {timizh }}$ & 0.020 \\
\hline Supervisor support & $-1.529^{\text {thix }}$ & 0.128 & -0.093 & 0.093 & 0,0008 & 0.093 \\
\hline Cownorker suppont & $-1.589^{* * 4}$ & 0.188 & -0.135 & 0.135 & -0.088 & 0.135 \\
\hline Physical demands & $8.959^{\mathrm{kst}}$ & 0.784 & $2.213^{* k *}$ & 0.563 & $1.958^{* *}$ & 0.564 \\
\hline Emotional demands & $4.016^{\text {kztit }}$ & 0.236 & $0.882^{* * *}$ & 0.175 & $0.624^{\text {taix }}$ & 0.179 \\
\hline Job insecurity & $7.488^{* * *}$ & 1.129 & -0.939 & 0.807 & $.1 .658^{\circ}$ & 0.809 \\
\hline Conflicis supervisor & $8.712^{\text {ints }}$ & 0.975 & 1.012 & 0.698 & 0.40 .4 & 0.701 \\
\hline \multirow[t]{2}{*}{ Conflicts co-worker } & $6.737^{* * *}$ & 1.117 & $1.548^{*}$ & 0.791 & 0.941 & 0.793 \\
\hline & \multicolumn{6}{|c|}{ Women $(n=2311)$} \\
\hline Work characteristic & B & S.E. & $B$ & S.E. & 8 & S.E. \\
\hline Psychological demands & $0.427^{\text {iscet }}$ & 0.095 & -0.007 & 0.080 & -0.011 & 0.081 \\
\hline Decision latitude & $.0 .313^{\text {naw: }}$ & 0.051 & -0.073 & 0.043 & -0.071 & 0.044 \\
\hline Supervisor supporn & $-1.539^{\text {milix }}$ & 0.233 & 0.222 & 0.200 & -0.215 & 0.203 \\
\hline Co-worker support & $-2.226^{\text {*at*k}}$ & 0.330 & $-1.112^{\text {*t* }}$ & 0.279 & $-1.105^{\text {**xt }}$ & 0.281 \\
\hline Physical demands & $3.967^{* *}$ & 1.250 & 1.881 & 1.042 & 1.801 & 1.049 \\
\hline Emotional demands & $1.924^{* * *}$ & 0.422 & 0.274 & 0.358 & 0.243 & 0.364 \\
\hline Job insecurity & $6.326^{* *}$ & 1.967 & 1.202 & 1.642 & 1.113 & 1.652 \\
\hline Conflicts supervisor & $8.377^{* * *}$ & 2.123 & 2.062 & 1.787 & 1.973 & 1.823 \\
\hline Conllicts co-worker & $9.015^{k \times 16}$ & 2.243 & 2.759 & 1.888 & 2795 & 1.904 \\
\hline
\end{tabular}

idjusted for age, educational level, living alone, employment status and presence of disease

i Adiusted for age, educational level, liwing alone. employment status, presence of disease and baseline CIS score (continuous)

Adjusled for age, educational level, liwing alone, employmemt status, presence of disease, baseline CIS score (continuous) and baseline GHQ score (contimuous)

$* * 0<0.001 ; * 0<0.01 \% " p<0.05$

\section{Work characteristics at baseline predicting fatigue at follow-up}

In men and women, the linear regression analyses of each psychosocial work characteristics separately showed that after adjustment for potential confounding variables, all psychosocial work characteristics were significantly associated with fatigue (Table 2, Model 1). In men. when controlled for baseline CIS score psychological, physical and emotional demands as well as conflicts with co-worker were related to higher CIS scores, whereas decision latitude was significantly associated with lower CIS scores (Model 2). Lower CIS scores were also related to the two original subscales of decision latitude, skill discretion and decision authority, though stronger with decision authority (specific data not shown). While most 
associations remained significant after additional adjustment for baseline $\mathrm{GHQ}$ score, the association between conflicts with co-worker and fatigue was explained away (Model 3 ).

For job insecurity a negative association with fatigue was found after control for both baseline measures. Given the weak to modest intercorrelations among the predictors, the analyses of all psychosocial work characteristics together, adjusted for potential confounding wariables and the baseline measures, showed similar effects for the various work characteristics as the effects seen in the separate analyses (specific data not shown).

As shown in Table 2, arnong women only co-worker social support was significantly related to lower CIS scores after adjustment for baseline CIS score and also after additional adjustment for baseline GHQ score. The findingl was confirmed when all psychosocial work characteristics were entered together (specific data not shown).

\section{Work characteristics at baseline predicting psychological distress at follow-up}

As presented in Table 3 , in men and women each psychosocial work characteristic separately was significantly associated with psychological distress (Model 1). In men, only job insecurity was no longer significant after adjustment for baseline GHQ score (Model 2). When we also controlled for baseline CIS score, psychological, physical and emotional demands as well as conflicts with co-worker and supervisor were still significantly related to higher GHQ scores, while decision authority (specific data not shown) was significantly associated with lower GHQ scores. When all psychosocial work characteristics were analysed together and adjusted for potential confounders as well as baseline measures, the predictive effects of psychosocial work characteristics were found to be similar to those obtained in the separate analyses (specific data not shown).

In women, all associations between the separate psychosocial work characteristics and psychological distress were weakened and no longer significant after control for baseline GHQ score (Model 2). The analyses of all psychosocial work characteristics together confirmed the finding of the separate analyses (specific data not shown). 
Table 3. Work characteristics all baseline predict psychological disfress after 1-year follow-up in men and women, adjusted for potential confounders and baseline measures

\begin{tabular}{|c|c|c|c|c|c|c|}
\hline \multirow[b]{3}{*}{ Work characheristic } & \multicolumn{6}{|c|}{$\operatorname{Men}(n=6522)$} \\
\hline & \multicolumn{2}{|c|}{ Model 1} & \multicolumn{2}{|c|}{ Mode의 2} & \multicolumn{2}{|c|}{ Model $3 \frac{1}{3}$} \\
\hline & B & S.E. & B & $S . E$ & 8 & S.E. \\
\hline Psychological demands & $0.158^{\text {. }}$ & 0.011 & $0.068^{i+4.7}$ & 0.010 & $0.064^{\text {tht }}$ & 0.010 \\
\hline Decision latitude & $-0.063^{* * 2 \times t}$ & 0.006 & $-0.021^{* * * *}$ & 0.005 & -0.010 & 0.005 \\
\hline Supervisor support & $-0.293^{+* 4}$ & 0.027 & $-0.072^{\text {bik }}$ & 0.024 & -0.046 & 0.024 \\
\hline Co-worker support & $0.276^{\text {wimint }}$ & 0.040 & $-0.077^{* *}$ & 0.035 & 0.038 & 0.035 \\
\hline Physical demands & $1.291^{\text {shem }}$ & 0.167 & $0.484^{* k i}$ & 0.148 & $0.345^{k}$ & 0.148 \\
\hline Emotional demandls & $0,906^{* \text { thot }}$ & 0.050 & $0.345^{* * \times x}$ & 0.047 & $0.302^{* * *}$ & 0.047 \\
\hline Job insecurity & $1.804^{t+2 * x}$ & 0.237 & $0.30 \%$ & 0.211 & 0.202 & 0.211 \\
\hline Conflicts supervisor & $2.079^{* * * x}$ & 0.205 & $0.697^{4 * *}$ & 0.184 & $0.600^{* / 8}$ & 0.183 \\
\hline \multirow[t]{2}{*}{ Confficts co-worker } & $1.976^{\text {tat }}$ & 0.236 & $0.634^{* *}$ & 0.209 & $0.579^{* * *}$ & 0.208 \\
\hline & \multicolumn{6}{|c|}{ Women $(n=2311)$} \\
\hline Work characteristic & B & S.E. & B. & S.E. & B & S.E. \\
\hline Psychological demands & $0.095^{* * *}$ & 0.021 & 0.020 & 0.020 & 0.011 & 0.020 \\
\hline Decision latitude & $-0.032^{\text {ix }}$ & 0.011 & 0.0004 & 0.011 & 0.007 & 0.011 \\
\hline Supervisor support & $-0.217^{* \# / 4}$ & 0.052 & -0.021 & 0.050 & 0.021 & 0,050 \\
\hline Co-worker support & $0.317^{* \min }$ & 0.075 & -0.111 & 0.070 & .0 .097 & 0.070 \\
\hline Physical demands & $0.666^{*}$ & 0.282 & 0.331 & 0.26 .1 & 0.281 & 0.262 \\
\hline Emotional demands & $0.502^{\mathrm{akm}}$ & 0.095 & 0.157 & 0.090 & 0.113 & 0.090 \\
\hline Nob insecurily & $1.100^{*}$ & 0.443 & 0.254 & 0.411 & 0.202 & 0.410 \\
\hline Contlicts supervisor & $1.620^{\text {kik }}$ & 0.476 & 0.196 & 0.449 & 0.189 & 0.453 \\
\hline Conflicts co-worker & $1.261^{*}$ & 0.508 & 0.063 & 0.473 & -0.078 & 0.480 \\
\hline
\end{tabular}

Adjusted for age, educational level, living alone, employment status and presence of disease

1 Adjusted for age, educational lewel, living alone, employment status, presence of disease and baseline GHQ score (continuous)

\$ Adjusted for age, educational level, living alone, employment status, presence of disease, baseline GHQ score (continuous) and baseline CIS score (continuous)

s*** $p<0.001 \% * * 0<0.01 ; p<0.05$

\section{Work characteristics at baseline predicting fatigue caseness}

In the supplementary logistic regression analysis 66 cases ( 53 men and 13 women) were excluded because of a delta CIS $\leq 8$, even though their follow-up score was above the cutoff. The cumulative incidence of fatigue during 1 year follow-up was $9.7 \%(n=492)$ in men, and $13.5 \%(n=241)$ in women. In both genders significant associations between psychosocial work characteristics and fatigue were found. As shown in Table 4, in men all psychosocia! work characteristics, except job insecurity, were significantly associated with fatigue. Although the odds ratios were reduced in size after adjustment for baseline $\mathrm{GHQ}$ score, the onset of fatigue was predicted by low decision latitude $(O R=1.5995 \%$ confidence interval $(1.23-2.06)$ ), high emotional demands $(\mathrm{OR}=1.47(1.14-1.88))$ and low social support at work. As regards the original subsciales of decision latitude, low decision authority (OR = 
Table 4. Prospective associations between work characleristics and the onset of fatigue in men ( $=5030$ ), adjustod for potential contounders and baseline GHQ score

\begin{tabular}{|c|c|c|c|c|}
\hline Mork characteristic & OR: & $95 \% \mathrm{Cl}$ & OR! & $95 \% \mathrm{Cl}$ \\
\hline \multicolumn{5}{|c|}{ Psychological demands } \\
\hline High & 1.61 & $1.27 \cdot 2.04$ & 1.28 & 1.004 .64 \\
\hline Medium & 1.42 & $\$ .10-1.82$ & 1.23 & $0.95-1.59$ \\
\hline Low & 1 & & 1 & \\
\hline \multicolumn{5}{|l|}{ Decision latitude } \\
\hline Low & 1.87 & $1.46 \cdot 2.40$ & 1.59 & $1.23 \cdot 2.06$ \\
\hline Medium & 0.91 & $0.70 \cdot 1.17$ & 0.88 & $0.68-1.14$ \\
\hline High & 1 & & 1 & \\
\hline \multicolumn{5}{|c|}{ Supervisor social support } \\
\hline Low & 1.62 & $1.33-1.98$ & 1.38 & $1.42-1.69$ \\
\hline High & 1 & & 1 & \\
\hline \multicolumn{5}{|c|}{ Co-worker social support } \\
\hline Low & 1.57 & $1.29-1.93$ & 1.45 & $1.18-1.78$ \\
\hline High & 1 & & 1 & \\
\hline \multicolumn{5}{|l|}{ Physical demands } \\
\hline Yes & 1.54 & $1.20-1.98$ & 1.32 & $1.02-1.72$ \\
\hline No & 1 & & 1 & \\
\hline \multicolumn{5}{|l|}{ Emotional demands } \\
\hline High & 2.01 & $1.59-2.54$ & 1.47 & 1.14 .1 .88 \\
\hline Low & 1.23 & $0.96-1.57$ & 1.12 & $0.87-1.44$ \\
\hline No & 1 & & 1 & \\
\hline \multicolumn{5}{|l|}{ Conflicts supervisor } \\
\hline Yes & 1.60 & $1.18-2.17$ & 1.20 & $0.87-1.65$ \\
\hline No & 1 & & 1 & \\
\hline \multicolumn{5}{|l|}{ Conflicts co-worker } \\
\hline Yes & 1.49 & $1.05-2.11$ & 1.17 & $0.81 \cdot 1.68$ \\
\hline No & 1 & & 1 & \\
\hline \multicolumn{5}{|l|}{ Sob insecurity } \\
\hline Yes & 1.28 & 0.87 .1 .89 & 0.93 & $0.62-1.39$ \\
\hline No & 1 & & 1 & \\
\hline
\end{tabular}

Acljusted for age, educational level, living alone, employment stalus and presence of disease

I. Adjusted for age, educational level, Ilving alone, employment stafus, presence of disease and baseline GHQ score (continuous)

1.73 (1.34-2.23)) was strongly predictive for the onset of fatiguie, whereas low skill discretion was no longer related to fatigue (not shown). For conflicts with co-worker and superwisor the associations were explained away.

In women, the ORs for physical demands and conflicts with supervisor were reduced in size after control for baseline GHQ score and these characteristics were no longer related to the onset of fatigue (Table 5). Strong predictors for the onset of fatigue were conflicts with coworker $(O R=2.12(1.23-3.67))$ and low co-worker social support $(O R=1.78(1.29-2.47))$. High psychological demands and low decision latitude, in particular low decision authority $(\mathrm{OR}=1.71(1.18-2.49)$ " not shown), were also predictive for the onset of fatigue. 
Table 5. Prospective associations between work characteristics and the onsel of fatigue in women ( $n=1787$ ), adjusted for potential contounders and baseline GHO score

\begin{tabular}{|c|c|c|c|c|}
\hline Worth charagteristic & OR: & $95 \% \mathrm{Cl}$ & OR: & $95 \% \mathrm{Cl}$ \\
\hline \multicolumn{5}{|c|}{ Pisychological demands } \\
\hline High & 1.65 & $1.16-2.37$ & 157 & $1.09-2.26$ \\
\hline Medium & 1.26 & $0.87-1.82$ & 1.19 & $0.82-1.73$ \\
\hline Low & 1 & & 1 & \\
\hline \multicolumn{5}{|l|}{ Decision letitude } \\
\hline Low & $\$ .56$ & $1.07-2.25$ & 1.51 & $1.04 \cdot 2.19$ \\
\hline Medium & 1.28 & $0.90-1.81$ & 1.22 & $0.86-1.74$ \\
\hline High & 1 & & 1 & \\
\hline \multicolumn{5}{|c|}{ Supervisor social support } \\
\hline Low & 1.26 & $0.94-1.69$ & 1.17 & $0.85-1.58$ \\
\hline High & 1 & & 1 & \\
\hline \multicolumn{5}{|c|}{ Co-worker social support } \\
\hline Low & 1.83 & 1.332 .52 & 1.78 & $1.29-2.47$ \\
\hline High & 1 & & 1 & \\
\hline \multicolumn{5}{|l|}{ Physical demands } \\
\hline Yes & 1.41 & $1.01-1.97$ & 1.34 & $0.95-1.87$ \\
\hline No & 1 & & 1 & \\
\hline \multicolumn{5}{|l|}{ Emotional demands } \\
\hline High & 1.15 & $0.82-1.62$ & 1.04 & $0.73-1.48$ \\
\hline Low & 1.17 & $0.81-1.69$ & 1.10 & $0.76-1.60$ \\
\hline No & 1 & & 1 & \\
\hline \multicolumn{5}{|l|}{ Conflicts supervisor } \\
\hline Yes & 1.80 & $1.06-3.06$ & 1.6 & $0.94-2.76$ \\
\hline No & 1 & & 1 & \\
\hline \multicolumn{5}{|l|}{ Conflicts co-worker } \\
\hline Yes & 2.25 & $1.31 \cdot 3.87$ & 2.12 & $1.23-3.67$ \\
\hline No & 1 & & 1 & \\
\hline \multicolumn{5}{|l|}{ Job insecurity } \\
\hline Yes & 1.42 & $0.934-2.42$ & 1.33 & $0.77-2.28$ \\
\hline No & 1 & & 1 & \\
\hline
\end{tabular}

I Adjusted for age, educational level, living alone, employment status and presence of disease

t Adjusted for age, educalional level, living alone, employment status, presence of disease and baseline GHQ score (continuous)

\section{Work characteristics at baseline predicting psychological distress caseness}

The cumulative incidence of psychological distress during 1 year follow-up was $12.6 \%(\mathrm{~N}=$ $657)$ in men, and $18.2 \%(\mathrm{~N}=321)$ in women. Table 6 shows that in men, except for physical demands, significant associations were found between psychosocial work characteristics and the onset of psychological distress. Of these, conflicts with supervisor (OR $=1.75$ (1.342.30), high emotional demands $(O R=1.73(1.40-2.14)$ ), job insecurity and high psychological demands were still predictive for the onset of psychological distress after adjustment for baseline CIS score, whereas the associations for low decision latitude and conflicts with co-worker were explained away. 
Table 6 . Prospective associations between work characteristics and the onset of psychological distriss in men $(n-5243)$, adjusted for potential confounders and baseline cis score

\begin{tabular}{|c|c|c|c|c|}
\hline Work characteristic & ORt & $95 \% \mathrm{Cl}$ & OR: & $95 \% \mathrm{Cl}$ \\
\hline \multicolumn{5}{|c|}{ Psychological demands } \\
\hline Hight & 1.63 & $4.33-2.00$ & 1.51 & $1.23-4.85$ \\
\hline Medium & 1.20 & $0.96 \cdot 1.50$ & 1.16 & $0.93-1.45$ \\
\hline Low & 1 & & 1 & \\
\hline \multicolumn{5}{|l|}{ Decision latitude } \\
\hline Low & 1.43 & $1.15-1.78$ & 1.14 & $0.90-1.43$ \\
\hline Medium & 0.89 & $0.72-1.10$ & 0.82 & $0.66-1.02$ \\
\hline High & 1 & & 1 & \\
\hline \multicolumn{5}{|c|}{ Supervisor social support } \\
\hline Low & 1.39 & $1.17 \times 1.65$ & 1.25 & $1.05-1.49$ \\
\hline High & 1 & & 1 & \\
\hline \multicolumn{5}{|c|}{ Co-worker social support } \\
\hline Low & 4.38 & $1.15-1.65$ & 1.25 & $1.04 \cdot 1.49$ \\
\hline High & 4 & & 1 & \\
\hline \multicolumn{5}{|l|}{ Physical demands } \\
\hline Yes & 1.21 & $0.96 \times 1.53$ & 1.05 & $0.83-1.34$ \\
\hline Na & 1 & & 1 & \\
\hline \multicolumn{5}{|l|}{ Emational domands } \\
\hline High & 1.94 & $1.57-2.39$ & 1.73 & $1.40-2.14$ \\
\hline Low & 1.33 & $1.08-1.63$ & 4.23 & $1.00-1.52$ \\
\hline No & 1 & & 1 & \\
\hline \multicolumn{5}{|l|}{ Conticts supenisor } \\
\hline Yes & 1.93 & $1.48-2.52$ & 1.75 & $1.34-2.30$ \\
\hline No & 1 & & 1 & \\
\hline \multicolumn{5}{|l|}{ Conflicls comworker } \\
\hline Yes & 1.49 & $1.08-2.06$ & 1.36 & $0.98 \times 1.89$ \\
\hline No & 1 & & 1 & \\
\hline \multicolumn{5}{|l|}{ Nob insecurity } \\
\hline Wes & 1.83 & $1.33-2.54$ & 1,63 & $1,18-2.27$ \\
\hline No & 1 & & 1 & \\
\hline
\end{tabular}

\# Adjusted for age, educational level, living alone, employment stalus and presence of disease

"Adjusted for age, educational level, living alone, eniployment stalus, presence of disease and baseiline CIS scorê (continuous)

As presented in Table $7_{\text {" }}$ in women low supervisor and co-worker social support were no longer associated with psychological distress when controlled for baseline CIS score. High psychological demands $(O R=1.44(1.03-2.01)$ ) and high emotional demands, however, were predictive for the onset of psychological distress. 
Tablo 7. Prospoctive asisaciations botween work characteristics and the onset of psychological distress in women $[$ in $=1785$ ), adfusted for potential conlounders and baseline CIS score

\begin{tabular}{|c|c|c|c|c|}
\hline Work characteristic & OR & $95 \% \mathrm{Cl}$ & OR & $95 \% \mathrm{Cl}$ \\
\hline \multicolumn{5}{|c|}{ Psychological demands } \\
\hline High & 1.59 & $1.15-2.19$ & 1.44 & $1.03-2.01$ \\
\hline Nedum & 1.24 & $0.90-1.70$ & 1.20 & $0.86-1.66$ \\
\hline Low & 1 & & 1 & \\
\hline \multicolumn{5}{|l|}{ Decision taffude } \\
\hline Low & 1.01 & $0.73-1.41$ & 0.88 & $0.62-1.24$ \\
\hline Medium & 0.90 & $0.66-1.23$ & 0.85 & $0.62-1.17$ \\
\hline High & 1 & & 1 & \\
\hline \multicolumn{5}{|c|}{ Supervisor social support } \\
\hline Low & 1.30 & $1.00-1.70$ & 1.12 & $0.85-1.47$ \\
\hline High & 1 & & 1 & \\
\hline \multicolumn{5}{|c|}{ Co-worker social support } \\
\hline Low & 1.40 & $1.05-1.89$ & 1.31 & $0.97-1.78$ \\
\hline High & 1 & & 1 & \\
\hline \multicolumn{5}{|l|}{ Physical demands } \\
\hline Yess & 1.26 & $0.93-1.72$ & 1.18 & $0.86-1.62$ \\
\hline No & 1 & & 1 & \\
\hline \multicolumn{5}{|l|}{ Emotional demands } \\
\hline High & 1.53 & $1.19-2.09$ & 1.39 & $1.01-1.91$ \\
\hline Low & 1.49 & $1.07-2.07$ & 1.45 & $1.04-2.04$ \\
\hline No & 1 & & 1 & \\
\hline \multicolumn{5}{|l|}{ Conflicts suppervisor } \\
\hline Yes & 1.10 & $0.60-2.02$ & 0.99 & $0.53-1.83$ \\
\hline No & 1 & & 1 & \\
\hline \multicolumn{5}{|l|}{ Confficts co-morker } \\
\hline Yes & 1.37 & $0.76-2.46$ & 1.20 & $0.56-2.18$ \\
\hline No & 1 & & 1 & \\
\hline \multicolumn{5}{|l|}{ Job insecurity } \\
\hline Yes & 1.03 & $0.62-1.71$ & 0.94 & $0.56-1.59$ \\
\hline $\mathrm{No}$ & 1 & & 1 & \\
\hline
\end{tabular}

t Adjusted for age, educational level, living allone, employment status and presence of disease

- Adjusted for age, educatianal level, living allone, employment status, presence of disease and baseline cis score (continuous)

\section{Discussion}

This prospective, longitudinal study showed that psychosocial work characteristics were sigmificant predictors for the onset of fatigue during 1 year follow-up in the working population. Psychological demands at work as well as physical and emotional demands increased the risk for future fatigue in men, whereas decision latitude in men and co-worker social support in women were protective against future fatigue. As regards psychological distress, no association was found with decision latitude, while conflicts at work increased the risk of psychological distress in both genders, suggesting that work characteristics which 
predict fatigue may differ from those which predict psychological distress. The prospective associations between psychosocial work characteristics and either fatigue or psychological distress remained significant after adjustment for potential confounding factors and baseline measures of fatigue or psychological distress, strengthening our results which are based on self-reported data.

To our knowledge, this is the first time that psychosocial work characteristics have been analysed as determinants of future fatigue in the working population. Our results suggest predictive effects of a wide range of psychosocial work characteristics on fatigue in men and women. Overall, given the weak to modest intercorrelations of the psychosocial work characteristics, the predictive effects of the separate psychosocial work characteristics were quite similar to those obtained from analyses when all psychosocial work characteristics were entered together.

We found clear differences between men and women regarding the effects of work characteristics on fatigue after the adjustment for baseline fatigue. Notably, co-worker social support had a strong protective effect on future fatigue in women. In men, psychological, emotional and physical demands were predictive of fatigue, compared to decision latitude which remained significantly associated with llower fatigue scores. Somewhat unexpectedly, also job insecurity was found to be protective against future fatigue, when controlled for baseline measures in men. We have to keep in mind, however, that job insecurity was measured at baseline, while the follow-up of fatigue was 1 year later. Therefore, it is possible that when the threat of losing the job was removed - after all, the employees were still working one year later - the employees high on job insecurity at baseline likely experienced a decline in insecurity, which was then associated with less fatigue at follow-up. Whether the observed gender differences with respect to the effects of psychosocial work characteristics on fatigue may be partly explained by differences in the structure of occupations and work characteristics for men and women ${ }^{30}$ or by differences in the perception of work conditions requires further exploration.

Consistent evidence for predictive effects of psychosocial work characteristics on fatigue was found in the logistic regression analysis. The cut-off point for fatigue was empirically derived in a separate pilot study. ${ }^{15}$ Upon crossing the cut-off, an additional refinement of a minimum amount of increase was required, thereby excluding those who are close to the cutorf and make only a small change. Hence, we note that in our conservative strategy, the findings underline the strong protective effects of high social support at work in both genders, and suggest a strong impact of conflicts with co-workers in particular among women. Low decision latitude and high emotional demands were found to be strong predictive factors of fatigue in men, even after the adjustment for baseline psychological distress, which did not drastically weaken the associations and therefore shows the robustness of our findings. Thus, good interpersonal relationships at work and high decision latitude, especially decision authority, are of particular importance, and may be relevant aspects that should be addressed in workplace interventions.

The pattern of associations between psychosocial work characteristics and psychological distress showed partly similar and partly distinct effects compared to fatigue. In men, similar effects were found for psychologicall, emotional and physical demands, whereas conflicts at work was an important predictor of future psychological distress, but not of fatigue. Moreover; there was no effect of decision latitude on psychological distress. We found no prospective associations between psychosocial work characteristics and psychological distress in women 
after adjustment for baseline distress. The results of the logistic regression analysis, however, suggest differential effects of high emotional demands on psychological distress, while low decision latitude and bad relationships at work increased the risk of faligue. One reason that psychosocial work characteristics might have a common effect on fatigue and psychological distress is because the two measures are correlated. Our prospective results, however, suggest some differential effects in the aetiology of fatigue versus psychological distress, which lends weight to the notion of the existence of two different concepts.

With respect to the present study, several issues have to be acknowledged. First, an overall response rate of $45 \%$ at baseline was reasonable for a survey in the working population, though a potential biasing of the results related to a selective participation of employees cannot be ruled out. A non-response analysis, however, demonstrated that non-respondents were less likely to report fatigue and sickness absence, which may have resulted in a slight overestimation of the level of fatigue. Regarding the response at follow-up, we have to recognize that non-respondents reported higher fatigue levels at baseline than respondents, which may have resulted in a slight underestimation of the cumulative 1-year incidence of fatigue. Nevertheless, we would like to emphasize that the response rate at follow-up was $80 \%$, and that the response was not affected by selective non-response from different sectors, trades and companies participating in the Maastricht Cohort Study.

A second issue concerns the time span between the assessment of psychosocial work characteristics, which reflect the condition at baseline, and the follow-up of fatigue and psychological distress of 1 year. Where most work characteristics were assumed to be relatively stable, others, like social support, job insecurity and conflicts at work could have changed during follow-up, so that the associations between these work characteristics and either fatigue or psychologicall distress would be attenuated. Frese \& Zapf $f^{31}$ extensively discussed of how work characteristics may affect ill-health in the course of time and presented different conceptual models. Moreover, they suggested that different outcomes of ill-health may follow different models. In order to clarify whether work characteristics have immediate, delayed or cumulative effects, to specify the impact of exposure changes on future fatigue and psychological distress, as well as to elucidate the time course of ill-health, repeated exposure and outcome assessments in a broader time-frame are required.

Following on this issue, the potential underlying effects of negative affectivity (NA) on the self report nature of our measures ${ }^{32}$ have to be recognized. It is argued that individuals high on NA may perceive their work environment more negatively, thereby creating spurious associations between work characteristics and the reports of adverse health outcomes, which are also influenced by NA. Other authors ${ }^{8,33}$ have reported that work characteristics, although reduced in magnitude, remained associated with health functioning and psychiatric disorder after controlling for NA. However, in longitudinal analyses which adjust for baseline values of the outcome variable, the possible influence of NA is reduced. In our study, while negative affectivity is not measured, we adjusted for either baseline fatigue or psychological distress, thereby controlling for the influence of NA on baseline values. Moreover, to demonstrate the distinctness of the concepts of fatigue and psychollogical distress we aiso controlled for the other baseline measure which may lead to an overcorrection.

Finally, the present study focuses primarily on psychosocial work characteristics as risk factors for the onset of fatigue and psychological distress, while a broader, multi-factorial aetiology of fatigue is emphasized in the literature. "Thus, it is possible thal other factors, such as work-family aspects (e.g. domestic load, leisure time activities) and individual 
characteristics (e.g. health behaviour, coping style), may play a role in the onset of fatigue and psychological distress. Although we have not yet examined these relationships, it seems unlikely that these factors would affect strongly the associations found here. Nevertheless, in our analyses the presence of disease at baseline was taken into account as a confounding variable, because it might influence the reporting of either psychosocial work characteristicsi or fatigue and psychological distress. The findings showed, however, that the associations between psychosocial work characteristics and either fatigue or psychological distress were independent of the presence of a disease.

In conclusion, the findings of this prospective study provide support for the predictive effects of psychosocial work characteristics on fatigue in the working population. These associations are independent of baseline fatiguie. Moreover, the study supports differential effects of psychosocial work characteristics in the aetiology of fatigue versus psychological distress and suggests that they may operate in different ways for men and women. Given the considerable impact of fatigue and psychological distress on the individual worker; the employers and the society, these findings underline the need for interventions addressing the psychosociall work environment in order to prevent, or at least reduce, the risk of fatigue and psychological distress in the working population. However, future research should further elucidate the multi-factorial aetiology of fatigue and psychological distress, thereby focusing an the role of work-family factors and individual characteristics as well as their interplay with psychosocial work characteristics.

\section{ACKNOWLEDGMENTS}

The Maastricht Cohort Study is part of The Netherlands concerted research action on 'Fatigue at work' granted by The Netherlands Organization for Scientific Research (NWO). The work presented in this paper was and is currently supported by The Netherlands Organization for Scientific Research (NWO grant no. 580-02.251).

\section{REFERENCES}

1. Chen, M.K. (1986). The epidemiclogy of self-perceived fatigue among adults. Preventive Medicine 15, 74-81.

2. Pawlikowska, T., Chalder, T., Hirsch, S.R., Wallace, P., Wright, D.J. \& Wesselly S.C. (1994). Population based study of fatigue and psychological distress. British Medical Journal $308,763-$ 766.

3. Hickie, I.B., Hooker, A.W., Hadzi Pavlowic, D. Bennett, B.K., Wilson, A.J. \& Lloyd, A.R. (1996). Fatigue in selected primary care settings: sociodemographic and psychiatric correlates. Medical Journal of Australia 164, 585-588.

4. Loge, J.H. Ekeberg, O. \& Kaasa, S. (1998). Fatigue in the general Nonwegian population: normative data and associations. Journal of Psychosomatic Research 45, 53-65.

5. Kroenke, K. Wood, D.R., Mangelsdorfi, A.D. Meier, N.J. \& Powell, J.B. (1988). Chronic fatigue in primary care. Prevalence, patient characteristics, and outcome. Journal of the American Medical Association 260, 929-934.

6. Schröer, C.A.P. (1997). De toename van arbeidsongesichiktheid wegens psychische aandoeningen [The increase of work disability due to mental disorders]. Tijdschrift voor Bedrijfsen Verzekeringsgeneeskunde 5, 16-23. 
7. Houtman, I. (1989). Feiten en fabels op een rij. Werkdruk in ciffers [Work pace in numbers]. Aibeidsomstandigheden $75,2-5$.

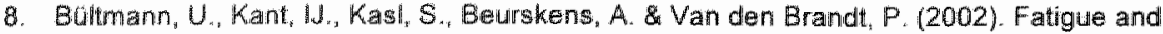
psychological distress in the working population: Psychometrics, prevalence, and correlates. Journal of Psychosomatic Research (in the press).

9. Lewis, G. \& Wessely, S. (1992). The epidemiology of fatigue: more questions than answers. Jounal Epidemiology Community Health $46,92-97$.

10. Hardy, G.E., Shapiro, D.A. B Borrill, C.S. (1997). Fatigue in the workforce of National Health Service Trusts: levets of symptomatology and links with minor psychiatric disorder, demographic, occupational and work role factors. Journal of Psychosomatic Research 43,83-92.

11. Bultmann, U., Kant, IJ., Schroer, K. \& Kasi, S.V. (2002). The relationship between psychosocial work characteristics and fatigue and psychological distress. International Archives of Occupational and Environmental Health (in the press).

12. Stansfeld, S.A. Fuhrer, R., Head, J., Ferrie, J. \& Shipley, M. (1997). Work and psychiatric disorder in the Whitehall II Study. Journal of Psychosomatic Research 43, 73-81.

13. Stansfeld, S.A. Fuhrer, R., Shipley, M.J. \& Marmot, M.G. (1999). Work characteristics predict psychiatric disorder: prospective results from the Whitehall II Study. Occupational \& Environmental Medicine 56, 302-307

14. Niecthammer. I., Goldberg, M., Leclerc, A., Bugel, I. \& David, S. (1998). Psychosccial factors at work and subsequent depressive symptoms in the Gazell cohort. Scandinavian Journal of Work, Environment and Health 24, 197-205.

15. Bütmann, U., De Vries, M. , Beurskens, A.J.H.M., Bleijenberg, G., Vercoulen, J.H.M.M. \& Kant, IJ (2000). Measurement of prolonged fatigue in the working population: Determination of a cutoff point for the Checklist Individual Strength. Journal of Occupationall Health Psychology 5, 411-416.

16. Kant, IJ., Beurskens, A., Schröer, C., Nijhuis, F. \& Sehayck van, C. (2000). De Maastrichtse Cohort Studie naar langdurige psychische vermoeidheid in de arbeidssituatie [The Maastricht Cohort Study of prolonged Fatigue at Work]. Tijdschrift voor Bedrijfs- en Verzekeringsgeneeskunde $8,226-232$.

17. Karasek, R.A. (1985), Job Content Questionnaire and Users's Guide. University of Southern California, Department of Industrial and Systems Engineering: Los Angeles.

18. Houtman, 1. (1995). Reliability and validity of the Dutch version of the Karasek Job Content Questionnaire. NIOSH/APA conference on Stress, Work, and Health. APA: Washington, DC.

19. Gründemann, R., Smulders, P. \& Winter de, C. (1993). Handleiding Vragenlijst Arbeid en Gezondheid [Questionnaire on Work and Health. Manual]. Swets \& Zeitlinger: Lisse.

20. Van Veldhoven, M. \& Meijman, T. (1994). Het meten van psychosociale arbeidsbelasting met een vragenlijst: De Vragenlijst Beleving en Beoordeling van de Arbeid (VBBA) [Questionnaire on Perception and Judgement of Work] NIA: Amsterdam.

21. Vercoulen, J.H., Swanink, C.M., Fennis, J.F., Galama, J.M., van der Meer, J.W. \& Bleijenberg, G. (1994). Dimensional assessment of chronic fatigue syndrome. Journal of Psychosomatic Research $38,383-392$.

22. Vercoulen, J.H.H.M., Alberts, M. \& Bleijenberg, G. (1999). De Checklist Individuele Spankracht (CIS) [The Checklist Individual Strength (CIS)]. Gedragstherapie 32, 131-136

23. Vercoulen, J.H., Hommes, O.R., Swanink, C.M., Jongen, P.J.. Fannis, J.F. Galama, J.M. van der Meer, J.W. \& Bleijenberg. G. (1996). The measurement of fatigue in patients with multiple sclerosis. A multidimensional comparison with patients with chronic fatigue syndrome and healthy subjects. Archives of Neurology 53, 642 649.

24. Vercoulen, J.H., Swanink, C.M. Fennis, J.F., Galama, J.M., van der Meer, J.W. \& Bleijenberg, G. (11996). Prognosis in chronic fatigue syndrome: a prospective study on the natural course. Journal of Neurology, Neurosurgery and Psychiatry $60,489-494$

25. Beurskens, A.J., Bültmann, U., Kant, IJ., Vercoulen, J.H., Bleijenberg, G. \& Swaen, G.M. (2000) Fatigue among working people: validity of a questionnaire measure. Occupalional \& Environmental Medicine 57, 353-357. 
25. Goldberg, D.P. \& Wilams, P. (1988). A User's Guide to the General Heath Questionnaira. NFERNelson: Windsor.

27. Kaeter, M.W.J. Ormel, J. (1981). General Health Questionnaire, Handleiding Nedenandse bewerking [General Health Questionnaire, Manual Dutch version]. Swets \& Zeitlinger: Lisse.

28. Wall, T.D., Bolden, R.I., Borrill, C.S., Carter. A.J., Golya, D.A., Hardy, GE., Maunes, C.E., Rick, J.E. Shapiro, D.A. \& West, M.A. (1997). Minor psychiatric disorder in NHS trust staff: occupational and gender differences. British Journal of Psychiatry 171,519-523.

29. SPSS (1998). Base 9.0 for Windows User's Guide. SPSS Inc. Chicago.30. Lennon. M. (1995). Work conditions as explanations for the relation between socioeconomic status, gender, and psychological disorders. Epidemiological Reviews 17, 120-127.

31. Frese, M. \& Zapf, D. (1988). Methodological issues in the study of work stress: Objective vs subjective measurement of work stress and the question of longitudinal studies. In Causes, Coping and Consequences of Stress at Work (ed. C.L. Cooper \& R. Payne), pp. 375 411. Wiley: Chïchester.

32. Watson, D. \& Clark, L.A. (1984). Negative affectivity: the disposition to experience aversive emotional states. Psychological Bulletin 96, $465-490$.

33. Stansfeld, S.A. Bosma, H. Hemingway, H. \& Marmat. M.G. (1998). Psychosocial work characteristics and social support as predictors of SF-36 health functioning: the Whitehall II study. Psychosomatic Medicine 60, 247-255. 
Differences in fatigue and psychological distress across occupations: Results from The Maastricht Cohort Study of Fatigue at Work

Ute Bültmann ${ }^{a}$, IJmert Kant ${ }^{\mathrm{a}}$, Ludovic G.P.M. van Amelsvoort ${ }^{\mathrm{a}}$, Piet A. van den Brandt ${ }^{\mathrm{a}}$ Stanislav V. Kasl ${ }^{\circ}$

Department of Epidemiology, Maastricht University, Maastricht, the Netherlands

- Department of Epidemiology and Public Health, Yale University School of Medicine, New Haven, Connecticut, USA

Journal of Occupational and Environmental Medicine 2001:43:976-983 


\begin{abstract}
Differences in fatigue and psychological distress across occupations were examined among 8521 employees participating in the Maastricht Cohort Study of "Fatigue at Work". Additional information on the perceived psychosocial work environment was incorporated. A total of 131 occupations, classified according to the Netherlands Standard Classification of Occupations 1992, were studied. Results showed that occupation as a proxy index of the "objective" work environment adds little explanatory information beyond perceived measures of the work environment. Although "occupation" seems to be an easy entree for intervention, focusing on occupation exclusively to prevent, or at least reduce, fatigue and psychological distress may be inadequate. Supplementary information about the perceived work environment of the job occupant is needed to develop preventive measures on the individual level. Further research, including a longitudinal analysis, is required to elucidate the complex relation between occupation, psychosocial risk factors, and fatigue and psychological distress.
\end{abstract}




\section{INTRODUCTION}

It thas long been recognized that fatigue is a common complaint among the general population and the working population. ${ }^{4}$ In recent years, interest in prolonged fatigue has grown in occupational (mental) health research" performance and ability to function in the occupational and home settings and may lead to absenteeism and work disability. ${ }^{7}$ Given the unfavorable prognosis of prolonged fatigue and the high social and economic costs, ${ }^{7}$ the development of preventive measures is of paramount importance. To gain insight into the prevalence and incidence of prolonged fatigue in the working population, and to examine the psychosocial risk factors in the etiology and matural course of prolonged fatigue, the large-scale epidemiological Maastricht Cohort Study of "Fatigue at Work" was established.

Cross-sectional analyses with baseline data collected in this study showed that some degree of fatigue was present in nearly all of the working population, and that $22 \%$ of the 12,000 employees crossed the predefined cutoff point for fatigue and were designated as probable fatigue cases. The same study revealed that fatigue and psychological distress are fairly well associated in the working population ( $r=0.62)$, and about $23 \%$ of study employees were considered to be probable cases of psychalogical distress. ${ }^{10}$ Moreover, in cross-sectional analyses, associations have been found between a wide range of psychosocial work characteristics and fatigue (manuscript submitted). Recently, longitudinal analyses of the Maastricht Cohort Study showed that psychosocial work characteristics are significant predictors for the onset of fatigue and psychological distress, after 1 year of follow-up in the working population and controling for baselline values of the two outcome variables. For example, emotional. psychological and physical demands at work are risk factors for future fatigue in men, whereas decision latitude and good interpersonal relationships at work protect against fatigue in both genders. These observed longitudinal associations suggest some differential effects of psychosocial work characteristics in the etiology of latigue versus psychological distress. These work characteristics represent potentially modifiable factors that could be addressed to prevent, or at least reduce, the risk of fatigue and psychological distress in the working population (manuscript submitted).

So far, the analyses have ignored potential occupational differences in fatigue and psychological distress and have linked psychosocial work characteristics to fatigue and psychological distress across all occupations. This means that we do not know if some occupations are notably high or low on fatigue and psychological distress, and whether the perceptions of work characteristics in these occupations help to explain the differences in reported fatigue and psychological distress across occupations. In this article, we propose to use occupation as an additional measure of the work environment that is not dependent on the perceptions of the job occupants.

Strategies of exposure measurement in the field of work stress research have been subject of controversy for many years. ${ }^{11-16}$ Arguments have been made for both objective and subjective measures of the work environment, for new approaches in the measurements, ${ }^{15}$ and for assessing the validity of such measurements. " The issues remain largely unresolved, and the research community has not reached consensus, as can be seen in the recent exchange in the September 1999 issue of the Journal of Organizational Behavior. ${ }^{19-20}$ Earlier, we argued" (p 398) that "paying attention to job titles is a minimal strategy of utilizing objective data and is often quite informative." Jab titles or occupations can be viewed as a proxy index 
of the objective work enwronment, albeit a rather crude one; by using this additional information, we have a somewhat more complete picture of how the work environment influences fatigue and distress. Moreover, from the standpoint of developing preventive measures, occupations might help identify specific groups at risk and, in particular, might be the easiest entree for interventions.

The purpose of the present study is to address the following questions: (1) How much of the wariance in fatigue and psychological distress is explained by occupation? (2) How much of the variance in psychosocial work characteristics is explained by occupation? (3) Will the explariatory power of occupation alone for fatigue and psychological distress be diminished if one psychosocial work characteristic, or all of them; are added to the model?

\section{METHODS}

\section{The Maastricht Cohort Study}

In May 1998, the Maastricht Cohort Study of "Fatigue at Work" was started in the Netherlands. A total of 26,978 male and female employees, aged 18 to 65 , from 45 companies and organizations, received a letter at home inviting participation and the baseline questionnaire. This self-administered questionnaire comprised items on psychosocial work characteristics, demographic, work-family, health factors, fatigue, and psychological distress. Altogether 12,160 employees completed and returned the baseline questionnaire (response rate of $45 \%$ ). Sixty-six questionnaires were excluded from the analysis because the age criterion was not met or because of technical reasons. The study population at baseline consisted of 8840 men $(73 \%)$ and 3255 women $(27 \%)$. For the analyses reported below, the study population was restricted to those employees $(n=11,020)$ who did not report themselves as absent from work or working under modified conditions because of former sickness absence (eg, fewer hours, modified tasks, or other functions). Full details of the sampling, (non-) response, and baseline characteristics of the study population are reported elsewhere. ${ }^{10}$

\section{Assignment of occupations}

Occupation was assessed by two open questions concerning the current job: "What is your job in the companylorganization?" and "What is your most important task?" Trained coders used the responses to the open-ended questions to assign an occupation, expressed by a five-digit code, based on The Netherlands Standard Classification of Occupations 1992. ${ }^{21}$ Examples include "assembler" (26511), "waiteriserver" (37203", "head nurse" (69210), "designeridesign engineer" (86602), and "manager public institution" (99101). Eighty-eight employees did not report their function or work activities, thus preventing the assignment of an occupation, and were excluded from the analysils. A total of 687 different occupations were assigned to the study population at baseline. The present analyses (1) are based on employees reporting to be at work at beseline $(n=11,020)$, and $(2)$ use only occupations with at least 20 employees. This minimum number of employees within one occupation was chosen to provide an adequate basis for analysis. An "occupation" variable was created that included 131 different occupations, comprising a total of 8521 employees, thereby covering about $77 \%$ of the baseline population. Of these 131 occupations, only three were related exclusively to one 
company/organization, whereas the rest were distributed throughout differant companies/ organizations.

\section{Measurement of fatigue}

Fatigue was measured with the self-report Checklist Individual Strength (CIS), which was originally developed for hospital studies of chronic fatigue syndrome. ${ }^{22,23}$ The 20 statements of the CIS cover several aspects of fatigue, such as severity, concentration, motivation, and physical activity level. The instrument was extensively tested in the clinical setting ${ }^{2425}$ and was validated in the working population. ${ }^{26}$ Employees were instructed to indicate how they had felt during the previous 2 weeks, and the response to each statement was scored on a sevenpoint Likert scale. Higher scores indicate a higher degree of fatigue, more concentration problems, reduced motivation, or low levels of activity. In the Maastricht Cohort Study, the CIS total score, ranging from 20 to 140 , was used to measure fatigue. A cutoff point for case classification of CIS total > 76 was established in a separate pilot study by means of defined samples with differences in fatigue levels. ${ }^{B}$ All employees scoring $>76$ were designated as probable fatigue cases.

\section{Measurement of psychological distress}

Psychological distress was measured with the 12-item version of the General Health Questionnaire (GHQ-12). ${ }^{27,28}$ The GHQ-12 was developed as a screening instrument for minor psychiatric disorders in the general population. For the four-point response scale, two scoring systems were used. The Likert scoring method $(0,1,2,3)$ summed the responses of the 12 items to generate a continuous distribution, ranging from 0 to 36 . The traditional GHQ scoring method $(0,0,1,1)$ is designed to identify individuals reporting sufficient psychological distress to be classified as probable cases of minor psychiatric disorder. Given a possible range of scores from 0 to 12, the threshold for case classification in the present study was 4 or higher, meaning that employees scoring on 4 or more of the 12 items were considered to be probable cases of psychological distress. The threshold for case classification is high but comparable with that used in previous studies in the working population. ${ }^{3.29}$

\section{Measurement of psychosocial work characteristics}

A validated Dutch version of the Job Content Questionnaire was used to assess psychological job demands, decision latitude, and social support at work. ${ }^{30,31}$ Pisychological job demands were measured by the sum of five items (excessive work, conflicting demands, insufficient: time to do work, work fast, and work hard). Decision latitude was assessed by the sum of two subscales: skill discretion (keep learning new things, can develop skills, job requires skills, task variety, work not repetitious, and job requires creativity) and decision authority (have freedom to make decisions, can choose how to perform work, and have a lot to say on the job). Social support was measured by two scales: (1) coworker support (they take a personal interest in me, are friendly, helpful in getting the job done, and competent in doing work), and (2) supervisor support (concerned about the welfare of those under him/her, pays attention. 
helpful in getting the job done, successful in getting people to work together). The response options for each item varied on a four-point scale, from "strongly agree" to "strongly disagree". Emotional demands at work were measured by the sum of five items: confronted with personally upsetting things, personally attacked or threatened, gets annoyed with others, moving working situations, and one or more shocking events at work during the past year (eg, accident, wiolent crime, sexual harassment, aggression at work). The items were derived from a Dutch questionnaire on Work and Health, ${ }^{32}$ a Dutch questionnaire on Perception and Judgment of Work, ${ }^{33}$ and self-formulated (shocking events at work). To assess whether employees perceive their work as physically demanding, one item of the Dutch questionnaire on Work and Health ${ }^{32}$ was used. Three items from the Dutch questionnaire on Perception and Judgment of Work ${ }^{33}$ were used to measure conflicts with coworker, conflicts with supervisor, and job insecurity. The response option for each item was yes/no.

Table 1 Prevalence of faltgue across selected occupatons $(n=8521)$

Occupation $\quad n$ Prevalence (\%)

\section{Lowest provalence}

Economist, business economist

$\begin{array}{rr}36 & 0.0 \\ 44 & 4.5 \\ 21 & 4.8 \\ 51 & 5.9 \\ 34 & 6.1 \\ 30 & 6.7 \\ 31 & 9.4 \\ & \\ 31 & 9.4 \\ 58 & 10.3 \\ 111 & 11.7\end{array}$

Plumber, heating engineer, gas fitter, pipefitter

Executive automation

Physicallspeectwaudio therapist

fistephone operator

Execulive secretary

Accountant assistant, administrative assistant

Manager: building industry, security service, industrial production, roadconstruction:

hydraviluc engineering

Occupatonal/acilvity/play/music therapist

Home help, geriatric help, social work aide, (nurse's) aid

Highest prevalence

Controller, tester eleclio-technical machinery

Hogd wallor

Tax officer, culstoms officar

Car, curriago aprayor

Assembler: cars, office machinas

Field worker. social services, santitakon, cleaning depantment

Statistical analyst, statistician

Loader, unloader, warehouse helper, mover 


\section{Data analytic procedure}

All data were analyzed using SAS statistical software ${ }^{34}$ To identify occupations high and low on fatigue and psychological distress, primarily descriptive analyses were performed. Prevalence was calculated for each occupation by applying the cutoff point of CIS total $>76$ for fatigue and the GHQ-12 threshold of 4 or more for psychological distress. Regarding psychosocial work characteristics, we calculated mean scores for each occupation. Analyses of variance (SAS General Linear Model procedure) were conducted to evaluate (1) how much of the variance in tatigue (continuous CIS score) and psychological distress (continuous $\mathrm{GHQ}$ score) among the 8521 employees was explained by occupation (between-occupation variance), and (2) how much of the variance in each psychosocial work characteristic was explained by occupation. Moreover, to investigate whether the explained variance due to occupation alone will be diminished if psychosocial work characteristics are added, analyses of variance (SAS General Linear Model procedure) were performed in two steps. First, each psychosocial work characteristic was added separately to occupation. Then, after computing the intercorrelations between the various psychosocial work characteristics to check for collinearity (no correlation exceeded 0.38 ), a multivariate analysis was conducted by entering all psychosocilal work characteristics together. All analyses of variance were adjusted for age and gender. The results are presented as $R^{2}$ partial and $R^{2}$ total.

Table 2 Prevalence of psychological distress across selected occupations $(n=8521)$

Docupation $n$ Prevallence (\%)

Lowest prevalence

Maternity care worker 2343

Concrete worker, parcuet (foor) layer, engineer

Accountant

District nurse, health care policy-making offleial

Production supervisor (automation)

Delivery man, truck driver

plumber, heating engineer, gas fitter, pipefitter

Design engineer: energy and telecommunication, electronics, electric molors

Foreman: glass, earthenware, paper, loxtie fabrics, food and lixuly food, petrochemical industry

Highest prevalence

Controller, tester electro-technical machimery

Archivisl, librarian

Wailer, server

Typist, data typist

Manager, wholesale, retail trade, mowie theater, salesipurchasing department 


\section{Results}

\section{Prevalence of fatigue and psychological distress}

The crude prevalence of fatigue and psychological distress varied considerably across the occupations. Table 1 presents a description of the 10 lowest and 10 highest prevalence of fatigue by occupation. A prevalence of zero was found in the occupation "economistbusiness aconomist" ( $n=36$ ), and the occupation with the highest prevalence of fatigue $(43.5 \%)$ was "controller, tester electro-technical machinery" $(n=23)$. As can be seen in Table 2, the occupation with the lowest prevalence of psychological distress $(4.3 \%$ ) was "maternity care worker" $(n=23)$. The highest prevalence of psychological distress $(45.5 \%)$ was found among the occupation "controller, tester electro-technical machinery" ( $n=22$ ).

Table 3 Explained varlance in fatigues, psychological disiress, and psychosocial work characteristics by occupation, adjusted for age and gender

\begin{tabular}{lrrr}
\hline & $\begin{array}{c}\text { Sum of squans } \\
\text { Regression } \\
(\text { Type III) }\end{array}$ & $\begin{array}{c}\text { Corrected iotal } \\
\text { Sum of squares }\end{array}$ & $R^{2}$ \\
\hline Fatigue & 151365.88 & 4298903.47 & 0.036 \\
Psychological distress. & 4934.57 & 200311.83 & 0.026 \\
Psychological demands & 15659.50 & 264538.42 & 0.061 \\
Decision latilude & 256321.73 & 1098929.68 & 0.248 \\
Coworker support & 820.09 & 21486.78 & 0.056 \\
Supervisor support & 2306.58 & 46064.83 & 0.058 \\
Emolional demands & 1746.29 & 13353.58 & 0.142 \\
Physical demands & 594.62 & 1646.39 & 0.375 \\
Conflict with coworker & 12.40 & 558.16 & 0.025 \\
Conflict with supervisor & 15.88 & 759.89 & 0.025 \\
Job insecurity & 24.95 & 595.44 & 0.046 \\
\hline
\end{tabular}

\section{Explained variance in fatigue, psychological distress and $^{\text {asychosocial work }}$ characteristics by occupation}

Table 3 shows the explained variance in fatigue and psychological distress by occupation and the between-occupation variance for a wide range of psychosocial work characteristics. All analyses were adjusted for age and gender. Among the 8521 employees, occupation explained onlly $3.6 \%$ of the observed differences in fatigue, and even less of the variance in psychological distress $(2.6 \%)$. Regarding work characteristics, occupation explained most of the variance in physical demands $(37.5 \%)$, followed by decision latitude $(24.8 \%)$, and emotional demands (14.2\%). For example, mean scores for decision latitude (range, 24 to 96 ) varied between $52.3(S D, 12.2)$ among "pollsters, code clerks and traffic tellers" $(n=20)$ and $82.8(\mathrm{SD}, 5.8)$ among "directors/managers governmentall institution" $(n=21)$. With respect to emotional demands (range, 0 to 5 ), mean scores varied between 0.32 (SD, 0.67) among "system analysts, system designers, programmers" $(n=78)$ and $2.98(\mathrm{SD}, 1.3)$ among 
"firemen" ( $n=32$ ). Occupation explained only a little of the variance in conflicts with and support of supervisortcoworker and in job insecurity. With respect to psychological job demands, $6.1 \%$ of the wariance was explained by occupation.

Table 4 Explained variance in faligue by occupation and psychosocial work characheristics; uniwariate and multivariate analysis adjusted for age and gender

\begin{tabular}{|c|c|c|}
\hline & \multicolumn{2}{|c|}{$R^{2}$} \\
\hline & Partial & Total \\
\hline Occupation & $0.035^{* *}$ & \\
\hline Psychological demands & $0.032^{\text {r* }}$ & 0.068 \\
\hline Occupation & $0.027^{* \pi}$ & \\
\hline Decision latilude & $0.053^{48}$ & 0.089 \\
\hline Occupation & $0.032^{* *}$ & \\
\hline Cowarker support & $0.019^{n+i}$ & 0.055 \\
\hline Occupation & $0.027^{\text {**t; }}$ & \\
\hline Supervisor support & $0.046^{* *}$ & 0.082 \\
\hline Occupation & $0.038^{\text {tit }}$ & \\
\hline Emotional demands & $0.060^{\text {nis }}$ & 0.096 \\
\hline Occupation & $0.037^{\text {thit }}$ & \\
\hline Physical demands & $0.027^{*+1+x}$ & 0.063 \\
\hline Occupation & $0.034^{\text {k* }}$ & \\
\hline Conflict with coworker & $0.010^{* *}$ & 0.046 \\
\hline Occupation & $0.031^{* *}$ & \\
\hline Conflict with superwisor & $0.023^{\text {** }}$ & 0.058 \\
\hline Occupation & $0.034^{\text {t* }}$ & \\
\hline Job insecurily & $0.016^{\mathrm{nw}}$ & 0.053 \\
\hline Occupation & $0.035^{* *}$ & \\
\hline Psychological demands & $0.008^{\mathrm{k*}}$ & \\
\hline Decision latitude & $0.024^{\text {nik }}$ & \\
\hline Coworker support & $0.001^{* *}$ & \\
\hline Supervisor support & $0.003^{\mathrm{kt}}$ & \\
\hline Emotional demands & $0.017^{* *}$ & \\
\hline Physical demands & $0.006^{* *}$ & \\
\hline Conflict with coworker & 0.0002 & \\
\hline Conflict with supervisor & $0.0006^{*}$ & \\
\hline Job insecurity & $0.003^{\mathrm{atx}}$ & 0.173 \\
\hline
\end{tabular}

${ }^{*} P<0.001: " P<0.05$ 


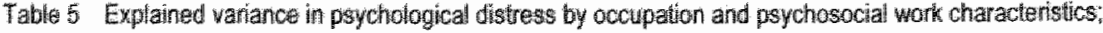

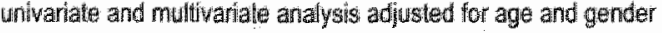

\begin{tabular}{|c|c|c|}
\hline & \multicolumn{2}{|c|}{$R^{2}$} \\
\hline & Partial & Total \\
\hline Occupation & $0.022^{m+4}$ & \\
\hline Psychological demands & $0.045^{* * i}$ & 0.070 \\
\hline Occupiation & $0.021^{\circ}$ & \\
\hline Decision latitude & $0.034^{4 i}$ & 0.060 \\
\hline Occupation & $0.023^{*}$ & \\
\hline Coworker support & $0.019^{* *}$ & 0.045 \\
\hline Occupation & $0.018 \mathrm{f}$ & \\
\hline Supervisor support & $0.048^{\text {int }}$ & 0.073 \\
\hline Occupation & $0.029^{* *}$ & \\
\hline Emotional demands & $0.094^{ \pm *}$ & 0.119 \\
\hline Occupation & $0.028^{* *}$ & \\
\hline Physical demands & $0.022^{* *}$ & 0.049 \\
\hline Occupation & $0.023^{* *}$ & \\
\hline Conflict with coworker & $0.018^{* *}$ & 0.043 \\
\hline Occupation & $0.022^{\text {k* }}$ & \\
\hline Contlict with supervisor & $0.036^{* *}$ & 0.062 \\
\hline Occupation & $0.023^{\text {ints }}$ & \\
\hline Job insecurity & $0.026^{\text {m* }}$ & 0.052 \\
\hline Occupation & $0.027^{* * *}$ & \\
\hline Psychological demands & $0.011^{* *}$ & \\
\hline Decision latitude & $0.012^{* *}$ & \\
\hline Coworker support & $0.001^{*}$ & \\
\hline Supervisor support & $0.003^{ \pm *}$ & \\
\hline Emotional demands & $0.030^{* 2}$ & \\
\hline Plnysical demands & $0.003^{\text {t* }}$ & \\
\hline Conflict with coworker & $0.0007 t$ & \\
\hline Conflic with supervisor & $0.003^{* * *}$ & \\
\hline Job insecurty & $0.008^{* * \pi}$ & 0.187 \\
\hline
\end{tabular}

w.t $P<0.001 ; * P<0.01 ;+P<0.05$

\section{Explained differences in fatigue and psychological distress by occupations supplemented with psychosocial work characteristics}

Table 4 presents the explained variance in fatigue by occupation, along with psychosocial work characteristics, entered separatelly and together. By adding decision latitude to occupation, the explained variance by occupation was reduced from $3.6 \%$ to $2.7 \%$, whereas decision latitude explained $5.3 \%$ of the observed differences in fatigue on the individual level. This implies that between-occupation differences in decision latitude explain part of the differences in fatigue on the individual level. Similarly, the addition of supervisor social support reduced the explained variance by occupation to $2.7 \%$ and explained $4.6 \%$ of the variance in fatigue. In contrast emotional demands explained $6 \%$ of the abserved variance in fatigue on 
the individual level but did not reduce the explained variance by occupation. Thus, betweenoccupation differences in emotional demands do not explain differences in fatigue on the individual level, although emotional demands explained more of the variance in fatigue compared with the other work characteristics. When all psychosocial work characteristics were entered together, $6.3 \%$ of the observed differences in fatigue on the individual level were explained by these psychosocial work characteristics in addition to occupation (3.5\%). Table 4 also shows that the sum of the partial $R^{2}$ values is $9.8 \%$, whereas the presented $R^{2}$ total is $17.3 \%$. This means that $9.8 \%$ is the sum of the independent variances and another $7.5 \%$ is variance explained by shared pairs (or more) of variables and by age and gender.

The explained variances in psychological distress by occupation, along with separate psychosocial work characteristics and all work characteristics together, are shown in Table 5. Of the observed differences in psychological distress on the individual level, $2.6 \%$ were explanned by occupation. This was slightly reduced to $2.2 \%$ when we controlled for psychological job demands, which explained $4.5 \%$ of the observed differences in psychological distress on the individual level. The explained variance by occupation was reduced to $1.8 \%$ when supervisor social support which explained $4.8 \%$ of the variance, was added. As in fatigue, emotional demands did not reduce the variance explained by occupation and accounted for $9.4 \%$ of the observed differences in psychological distress on the individual level In the multivariate analyses, $7.1 \%$ of the observed differences in psychological distress on the individual level were explained by all psychosocial work characteristics together, along with occupation (2.7\%).

\section{Discussion}

The present study found that occupation, as a proxy index of the objective work environment, explained only $3.6 \%$ and $2.6 \%$ of the observed differences in fatigue and pisychological distress, respectively. Thus, occupation, which is measured separately from the perceptions of job occupants, adds relatively little explanatory information beyond perceived measures of the psychosocial work environment. Nevertheless, the analysis did identify occupations high and low on fatigue and psychological distress, and it showed some linkagies of perceived psychosocial work conditions with objective occupations. In terms of developing measures to prevent, or at least reduce, fatigue and psychological distress, occupation allone seems to be an inappropriate entree for intervention. The study suggests that supplementary information about the perceived work environment is needed to provide a sound basis for the development of preventive measures on the individual level (ie, interventions tailored to the specific needs of emplayees).

To our knowledge. this is the first study to rank occupations according to fatigue and psychological distress. Fatigue, like many other conditions based on the presence of symptoms, is best viewed as a continuum ${ }^{35}$ rather than a dichotomy. The validated Checklist Individual Strength was used to measure fatigue in the working population. ${ }^{2}$ The Checklist cutoff point of $>76$ for fatigue was empirically derived in a separate pilot study. ${ }^{8}$ When using a cutoff point, however, one may lose important information. Therefore, fatigue (and psychological distress) should be treated as a continuous variable whenever possible.

We found considerable occupational differences regarding the prevalence of fatigue and psychological distress. Previous studies in occupational mental health research also described 
occupational differences with respect to such factors as prevalence of major depressive disorder ${ }^{36}$ or prevalence of depression and global health. ${ }^{37}$ Both were US studies." thus it is difficult to compare their results with the findings reported here, not only because of the occupational classification used (ie, Census code), but also because of the different outcome measures.

The high and low occupational groups for fatigue (Table 1) and psychological distress (Table 2) did not have the same occupations in them (with one exception), supporting the notion of different underlying concepts of fatigue and psychological distress. It is interesting to note that the occupation "controller/tester" scored high on both outcomes; that work enwironment might be conductive to both fatigue and psychological distress. Although the prevalence of fatigue and psychological distress may quite informative by helping to identifying high-level and lowlevel occupations, it should be remembered that the two factors may reflect other (sociodemagraphic) characteristics of the occupations besides the influence of the occupational environments on the workers.

Regarding the between-occupation variance explained by psychosocial work characteristics, as might be expected, the proportion was high for physical demands $(37.5 \%)$ and decision latitude $(24.8 \%)$. Both conditions are more anchored in the objective occupation, in contrast to such other work characteristics as conflict with coworker and superwisor, in which the proportion of explained variance by occupation is rather low. However, these conditions reflect interpersonal relations on the job and are not inherent to particular occupations. The results from this study are mainly consistent with the explained variances described in US random samples, ${ }^{38,39}$ though a direct comparison of between-occupation variances for these scales is hindered because of the different occupational classifications being used. For job insecurity, the between-occupation variances have been reported at around $10 \%,{ }^{38,39}$ whereas we found a between-occupation variance of $4.6 \%$. Whether nationall variations may partly account for the difference in explained variance or the distinct measurement of job insecurity cannot be determined. Concerning the poorly explained variance in psychological job demands, as we noted earlier ( $\mathrm{p} 398)^{13}$ it is unclear whether the classification of occupations was too crude to recognize variation in job demands or whether job demands are a subjective reaction that cannot be correlated to objective work conditions. In addition, our question remains as to whether job demands measure psychological reactions to objective work conditions, albeit with enormous individual differences, or whether they measure mostly preexisting personal characteristics that would manifest themselves in a similar way on different jobs ( $p 398)^{13}$ Overall, the results from this study indicate that occupation is variably linked to psychosacial work characteristics, some of which correspond very poorly to the objective work environment (als effected by the occupation).

Several other issues regarding the use of occupation as a proxy index for the objective work environment must be acknowledged. First, occupation seems to be a rather crude, inexact objective measure. For example, it is possible that two employees with the same occupation who were asked to complete the questionnaire may actually work under different psychosocial work conditions in different companies or even within the same company or organization. In short, using occupation in analysis cannot even approximately substitute for the use of objectively measured individual dimensions of work (however difficult and laborious that may be), and it cannot be sensitive to variations in these objective dimensions within an occupation foil subgroups of workers. However, when occupation is analyzed together with psychosocial work characteristics, as described in Table 4 and 5 , it still explains part of the differences in 
either fatigue or psychological distress. Perhaps other variables linked to fatigue and psychological distress, such as preexisting personal characteristics or socioeconomic status (eg, income), are reflected by occupation. In the present study. personal characteristics and income were not assessed. Another issue concerns possible self-selection into some occupations. It cannot be disregarded that an individual at high risk for fatigue or psychological distress might have characteristics that select him or her into a particular accupation.

Given the cross-sectional nature of the present study, it is important to note that a secure interpretation concerning cause and effect is not possible. Nevertheless, the strength of this study is its use of occupation as a proxy index of the objective work enwironment, supplemented with perceived measures of the work environment, to explain differences in fatigue and psychological distress in a large working sample.

The psychosocial work characteristics listed together with occtpation in Tables 4 and 5 explain $9.8 \%$ of the variance in both fatigue and psychological distress, and the total variance jointly explained is $17.3 \%$ and $18.7 \%$, respectively. These differences in explained total variance may be attributed to contributions of age and gender, along with occupation plus shared variance of pairs (or more) of variables. Whether more of the variance in fatigue and psychological distress can be explained when other work-related factors, domestic factors, or individual characteristics are added, and how the role of measurement error in fatigue and psychological distress affects the results, requires further examination, including research of a longitudinal nature.

In conclusion, although occupation seems to be an easy entree for intervention, attempts to prevent or at least reduce, fatigue and psychological distress by focusing on occupation exclusively may be inadequate. The present study showed that it is probably more appropriate to use additional measures of the work environment as perceived by the job occupant to develop effective workplace interventions that focus on the individual rather than on the occupation alone. Further research is needed to clarify the role of preexisting personal characteristics regarding occupational differences in fatigue and psychological distress. With insight into the complex interplay of the factors involved in fatigue and psychological distress. adequate preventive measures can be developed.

\section{ACKNOWLEDGEMENTS}

The Maastricht Cohort Study is part of the Netherlands concerted research action an "Fatigue at Work" granted by the Netherlands Organization for Scientific Research. The present study was and is currently supported by a grant from the Netherlands. Organization for Scientific Research (NWO grant no. 580-02.251). 


\section{REFERENCES}

1. Chen MK. The epidemiology of self-perceived fatigue among adults. Prev Med. 1986;15:74-81.

2. Pawikowska T, Chalder T, Hirsch SR. Wallace P, Wright DJ. Wessely SC. Population based study of fatigue and psychological distress. BMJ. 1994;308:763-6.

3. Hardy GE, Shapiro DA, Borrill CS. Fatigue in the workforce of National Health Service Trusts: levels of symptomatology and links with minor psychiatric disorder, demographic, accupational and work role factors. J Psychiosom Res. 1997:43:83-92.

4. Loge $\mathbb{J H}$, Ekeberg $\mathrm{O}$, Kaasa $\mathrm{S}$. Fatigue in the general Morwegian population: normative data and associations. J Psychosom Res. 1998;45:5365.

5. Meijman T, Schaufeli W. Psychische vermoeidheid en arbeid. Ontwikkelingen in de A\&Opsychologie [Fatigue at work. Developments in 110 psychology]. De Psycholoog. 1996; June:236-41.

6. Mounstephen A, Stiarpe M. Chronic fatigue syndrome and occupational health. Occup Med Oxf. $1997: 47: 217-27$.

7. Schröer CAP. De toename van arbeidsongeschiktheid wegens psychische aandoeningen [The increase of work disability due to mental disorders]. TBV (Tijdschriff Bedrijfs- en Verzekeringsgeneeskunde) 1997;5:16-23.

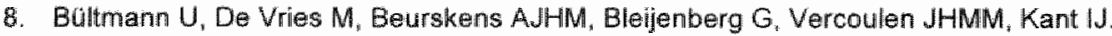
Measurement of prolonged fatigue in the working population: Determination of a cutoff point for the Checklist Individual Strength. J Occup Health Psychol. 2000;5:411-416.

9. Kant IJ, Beurskens A, Schröer C, Nijhuis F, van Schayck C, Swaen G. De Maastrichtse Cohort Studie naar langdurige psychische vermoeidheid in de arbeidssituatie [The Maastricht Cohort Study of prolonged Fatigue at Work]. TBV. 2000;8:226-232.

10. Bültmann U, Kant I, Kasl S, Beurskens A, Van den Brandt P. Fatigue and psychological distress in the working population: Psychometrics, prevalence, and correlates. JPsychosom Res. in press.

11. KasI SV. Epidemiological Contributions to the Study of Work Stress. In: Cooper CL, Payme R, eds. Stress at Work. Chichester: Wiley; 1978: 3-48.

12. Kas| SV. Methodlologies in Stress and Health: Past Difficulties, Present Dilemmas, Future Directions. In: Cooper CL, Kasi SV, eds. Stress and Health: Issues in Research Methodology. Chichester: Willey: 1987: 307-318

13. Kasi SV. Measuring job stressors and studying the health impact of the work environment: An epidemiolgic commentary. $₫$ Occup Health Psychol. 1998;3:390-401.

14. Frese $M_{n}$ Zapf D. Methodological issues in the study of work stress: Objective vs subjective measurement of work stress and the question of longitudinal studies. In: Cooper $\mathrm{CL}$, Payne $\mathrm{R}$, eds. Causes, Coping and Consequences of Stress at Work. Chichester: Wiley: 1988: 375-411.

15. Kristensen TS. The demand-control-support model: Methodological challenges for future research. Stress Med. 1995:11:17-26.

16. Kristensen TS. Job stress and cardiovascular disease: a theoretic crifical review. J Occup Health Psychol. 1996:1:246; 60

17. Semmer N, Zapf D, Greif S. 'Shared job strain': A new approach for assessing the validity of job stress measurements. I Occup Organ Psychol. 1996;69:293-310.

:8. Frese $\mathrm{M}$. Zapf $\mathrm{D}$. On the importance of the objective environment in stress and attribution theory. Counterpoint to Perrewe and Zellars. J Organ Behav. 1999; 20:761-765.

19. Perrewe $\mathrm{PL}$, Zellars KL. An examination of attributions and emotions in the transactional approach to the organizational stress process. J Organ Behav. 1999;20:739-752.

20. Schaubroeck J. Should the subjective be the objective? On studying mental processes, coping behavior, and actual exposures in organizational stress research. J Organ Behav. 1999;20:753760 .

21. Central Bureau of Statistics. Standaard Beroepenclassificatie 1992 [The Netherlands Standard Classification of Occupations 1992]. 's-Gravenhage: SDU/uitgeverij; 1993.

22. Vercoulen JH, Swanink CM, Fennis JF, Galama JM, van der Meer JW. Bleijenberg $G$. Dimensional assessment of chronic fatigue syndrame. J Psychosom Res. 1994;38:383-92. 
23. Vercoulen JHHM, Alberts $M$, Bleijenberg G. De Checklist Individuele Spankracht (CIS) IThe Checklist Individual Strength (CIS)]. Gedragstherapie. 1999;32:131-136.

24. Vercoulen $\mathrm{JH}$, Hommes $\mathrm{OR}$, Swanink $\mathrm{CM}$, et al. The measurement of flatigue in patients with multiple sclerosis. A multidimensional comparison with patients with chronic fatigue syndrome and healthy subjects. Arch Neurol. 1996;53:642-9.

25. Vercoulen JH, Swanink CM, Fennis JF, Galama JM, van der Meer JW, Blelienberg G. Prognosis in chronic fatigue syndrome: a prospective study on the natural course. J Neurol Neurosurg Psychiatry 1996;60:489-94.

26. Beurskens AJ, Bültmann U, Kant IJ, Vercoutlen JH, Bleijenberg G, Swaen GM. Fatigue among working people: validity of a questionnaire measure. Occup Environ Med. 2000;57:353-7.

27. Goldberg DP', Williams P. A User's Guide to the General Health Questionnaire. Windsor: NFERNelson: 1988.

28. Koeter MWJ, Ormell J. General Health Questionnaire, Handleiding Nederlindse bewerking [General Health Questionnaire, Manual Dutch version]. Lisse: Swets \& Zeitlinger; 1991.

29. Wati TD, Bolden RI, Borrill CS, et all. Minor psychiatric disorder in NHS trust staff: occupational and gender differences. Br J Psychiatry. 1997:171:519-23.

30. Karasek RA. Job Content Questionnaire and Users's Guide. Los Angeles: University of Southern California: Department of Industrial and Systems Engineering: 1985.

31. Houtman I. Rellability and validity of the Dutch version of the Karasek Job Content Questionnaire. In: NIOSH/APA conference on Stress, Work, and Health. Washington, DC: 1995.

32. Gründemann $R$, Smulders $P$, de Winter $C$. Handleiding Vragenlijst Arbeid en Gezondheid [Questionnaire on Work and Health. Manuali. Lisse: Swets \& Zeitlinger, 1993.

33. Van Veldhoven $M$, Meijman $T$. Het meten van psychosociale arbeidsbelasting met een vragenlijst: De Vragenlijst Beleving en Beoordeling van de Arbeid (VBBA) [Questionnaire on Perception and Judgment of Work]. Amsterdam: NIA; 1994.

34. SAS Institute. SAS version 6.12. Cary, North Carolina; 1989.

35. Lewis $G$, Wessely $S$. The epidemiology of fatigue: more questions than answers. J Epidemiol Community Health. 1992;46:92-7.

36. Eaton WW, Anthony JC, Mandel W, Garrison R. Occupations and the prevalence of major depressive disorder. J Occup Med. 1990;32:1079-87.

37. Grosch JW, Murphy LR. Occupational differences in depression and global health: results from a national sample of US workers. J Occup Environ Med. 1998;40:153-64.

38. Karasek R, Theorell T. Healthy Work: stress, productivity, and the reconstruction of working life. New York: Basic Books; 1990.

39. Karasek $R$, Brisson $C$. Kawakami $N$, Houtman I, Bongers P. Amick $B$. The Job Content Questionnaire $(J C Q)$ : an instrument for internationally comparative assessments of psychosocial job characteristics. J Occup Health Psychol. 1998;3:322-55. 


\section{Lifestyle factors as risk factors for fatigue and psychological}

distress in the working population:

\section{Prospective results from the Maastricht Cohort Study}

Ute Bültmann ${ }^{a}$, IJmert Kant ${ }^{a}$, Stanislav V. Kasl'; Kees A.P. Schröerc, Gerard M.H. Swaen ${ }^{a}$, Piet A. van den Brandt ${ }^{3}$

"Department of Epidemiology, Maastricht University, Maastricht, the Netherlands

- Department of Epidemiology and Public Health, Yale University School of Medicine, New Haven, Connecticut, USA

"Department of Medical Sociology, Maastricht University, Maastricht, the Netherlands 


\section{ABSTRACT}

We examined potentially modiflable lifestyle factors as possible risk factors for the onset of fatigue and psychological distress after 1-year follow-up among 8833 employees who participated in the prospective Maastricht Cohort Study of "Fatigue at Work". Results showed, even after adjustment for demographics, the presence of disease, other lifestyle factors, psychosocial work characteristics and psychological distress, that overweight (body mass index, 25 to 29.9\%, and being physically inactive during leisure time were strongly related to onset of fatigue in men, whereas underweight (body mass index $<18.5$ ) in women increased the risk for future fatigue. In addition, the study suggests some differential effects of lifestyle factors in the onset of psychological distress. Certainly, these modifiable factors can be targeted in interventions, either on an individual or group level, to prevent or at least reduce the risk of developing fatigue and psychological distress in the working population. 


\section{INTRODUCTION}

Fatigue in the working population, although recognized in previous studies ${ }_{\mathrm{x}}{ }^{\text {-4 }}$ has recently attracted attention in occupational (mental) health research, because it may interfere with an individual's performance and functioning in the occupational and in the home setting. Moreover, because fatigue may also lead to sickness absenteeisn and work disability, it is not only a pressing social problem but also an economic problem calling for preventive action.

In the literature, the likely multifactorial etiology of fatigue is emphasized," and "psychosocial" reasons (eg, work, family, and lifestyle) are most often mentioned as explanations for feeling fatigued. ${ }^{7}$ To date, research has mainly focused on the relationship between work characteristics and fatigue..$^{3.8}$ Longitudinal analyses conducted within the Maastricht Cohort Study, a large-scale epidemiological study of "Fatigue at Work", revealed that psychosocial work characteristics are predictive of fatigue after 1-year follow-up. Although previous. studies have shown that lifestyle factors, such as smoking, alcohol comsumption, and physical activity during leisure time, and related variables such as body mass index, may affect the (mental) health status ${ }^{1,10-11}$ and may be regarded as possible risk factors, information is sparse about lifestyle factors and the risk of fatigue in the working population. A cross-sectional study among 3785 Israeli industrial employees showed that "not being physically active during leisure time" was associated with severe fatigue (odds ratio [OR], $1.7 ; 95 \%$ confidence interval $[\mathrm{Cl}], 1.3$ to 2.3 ), that more complaints of severe fatigue were found among employees who smoked 10 or more cigarettes per day, and that no relation was found between body mass index or alcohol consumption and fatigue. ${ }^{\prime}$ Of course, crasssectional associations, particularly the relationship between physical activity and fatigue, are difficult to interpret for direction of influence. To our knowledge, prospective relations between lifestyle factors and fatigue in the working population are not yet established. For the development of preventive measures, however, it is important to examine the etiological role of potentially modifiable lifestyle factors in the onset of fatigue.

In the Maastricht Cohort Study, fatigue was fairly well associatled with psychological distress, as expressed by a correlation of $0.62 .^{12}$ This finding. which is consistent with observed correlations in other studies, ${ }_{s}^{3,7,13}$ has led to questions such as: Is fatigue conceptually and etiologically distinct from psychological distress? Or is the overlap between the two constructs so large as to throw in doubt the usefulness of having two separate concepts? In the research literature on prolonged fatigue, several recent studies have addressed operational and conceptual issues regarding fatigue and different psychiatric disordiers. ${ }^{14.4 \pi}$ While discussing competing hypotheses about the temporal relationship and differences between fatigue and psychiatric disorder in the literature, Addington et al. ${ }^{17}$ concluded that the findings further substantiate the idea that fatigue is etiologically heterogeneous from psychiatric disturbances. At present, longitudinal analyses suggest some differential predictive effects of psychosocial work characteristics in the etiology of fatigue versus psychological distress, measured with the Checklist Individual Strength and the General Health Questionnaire, supporting the notion of two distinct concepts. With respect to lifestyle factors, little is known about differential etiological effects regarding fatigue and psychological distress.

In the present study, we used the data of the Maastricht Cohort Study to prospectively explore the role of lifestyle factors (smoking, alcohol consumption, physical activity during 
leisure time, and the associated variable of body mass index), measured at baseline, in the onset of fatigue and psychological distress after 1-year follow-up in the working population, thereby further elucidating the concepts of fatigue and psychological distress.

\section{Methods}

\section{Study population at baseline and follow-up}

The large-scale prospective Maastricht Cohort Study of "Fatigue at work" was set up to examine the onset and natural history of fatigue and psychological distress in the working population. ${ }^{13.19}$ In May $1998,26,978$ employees, aged 18 to 65 years, from 45 companies and organizations received an introductory letter at home and the baseline questionnaire. This self-administered baseline questionnaire included items on psychosocial work characteristics, demographic, work-family, lifestyle, and health factors and on fatigue and psychological distress. A total of 12,161 employees completed and refurned the questionnaire. The overall response rate was $45 \%$. Written consent was obtained from all participants. Sixty-six questionnaires were excluded from the analysis because the age criterion was not met or because of technical reasons. The baseline cohort consisted of 8840 men $(73 \%)$ and 3255 women $(27 \%)$. Full details of the sampling, the nonresponse, and the baseline characteristics of the study population have been reported elsewhere. ${ }^{12}$

In May 1999, those employees ( $(n=11,272)$ who had completed the baseline questionnaire and at least one of the two short questionnaires, which were sent in September 1998 and January 1999, were approached again to complete the follow-up questionnaire. Overall, 9625 employees, 7025 men $(73 \%)$ and 2600 women $(27 \%)$, completed and returned the follow-up questionnaire (response rate of $80 \%$ ). In the present analysis, those employees who reported themselves at baseline absent from work or reported working under modified conditions related to former sickness absence (eg, fewer hours, modified tasks, or other functions) were excluded. Therefore, the final study population on whom follow-up data were available was 8833 employees, 6522 men $(74 \%)$ and 2311 women (26\%).

\section{Baseline lifestyle factors}

The body mass index (BMI) was calculated from information on weight and height (BMI = $\left.\mathrm{kg} / \mathrm{m}^{2}\right)$. The BMI was used as continuous variable and then categorized according to the standardized classification of the National Institutes of Health (BMI $<18.5$, undenweight: BMI " 8.5 to 24.9 , normal; BMI 25 to 29.9, overweight; BMI 30 to 34.9 , obesity I; BMI 35 to 39.9 , obesity $I_{\text {; }}$ BMI $\geq 40$, extreme obesity III). ${ }^{20}$ Because small numbers of employees were observed in the obese subgroups, we recorded BMI into four categories (BM) $<18.5$. underweight BMI 18.5 to 24.9 , normal; BMI 25 to 29.9 , overweight; $B M I \geq 30$, obesity). Alcohol consumption was measured by weekly consumption in glasses and divided into four cattegories (0 glasses, 1 to 14 glasses, 15 to 21 glasses, $\geq 22$ glassesiweek). Smoking slatus was assessed by a single item ("Do you smoke every day?"). Physical activity during leisure time was measured by a single item ("How many times per week are you at least half an hour physically active?"). The response options were (never/once a week, 2 to 7 times a 
week, $>7$ times week). Table 1 shows the distribution of lifestyle factors at baseline for men and women separately.

\section{Baseline psychosocial work characteristics, demographic and health factors}

A validated Dutch wersion of the Job Content Questionnaire was used to measure psychological demands, decision latitude, and social support at work. 21.22 Psychological demands were assessed by the sum of five items. Decision latitude was measured by the sum of two subscales: skill discretion and decision authority. Social support was assessed by two scales, each consisting of four items: supervisor support and coworker support. Emotional demands at work were measured by the sum of five items, which were derived from a Dutch questionnaire on Work and Health, ${ }^{23}$ a Dutch questionnaire on Perception and Judgement of Work ${ }^{24}$ and self-formulated. To assess whether employees perceive their work as physically demanding, a single item from the Dutch questionnaire on Work and Health ${ }^{23}$ was used. Three items from the Dutch questionnaire on Perception and Judgement of Work $^{24}$ were used to measure job insecurity, conflicts with supervisor, and conflicts with coworkers. Employees provided information on age, educationall level, living alone, status of employment (permanent or temporary contract), and the presence of disease. Detalls of these measures, which are considered in the analyses as confounding factors, have been reported elsewhere.

\section{Baseline and follow-up fatigue}

The 20-item self-report Checklist Individual Strength (CIS), which was originally developed for hospital studies of chronic fatigue syndrome, was used to measure fatigue. ${ }^{25.26}$ The CIS covers several aspects of fatigue, such as severity, concentration, motivation, and physical activity level. The instrument was extensively tested in the clinical setting ${ }^{27,26}$ and was validated in the working population. ${ }^{29}$ Subjects are instructed to indicate how they felt during the past 2 weeks. The response to each statement is scored on a seven-point Likert scale (1) $=$ "Yes, that is true" to $7=$ "No, that is not true"). Higher scores indicate a higher level of fatigue, more concentration problems, reduced motivation, or low levels of activity. In the Maastricht Cohort Study, the responses to the individual items were summed to generate a CIS total score, ranging from 20 to 140 . A cutoff point for case classification of CIS total $>76$ was established in a separate pilot study by means of defined samples with differences in fatigue levels. ${ }^{1 /}$ All employees scoring $>76$ were designated as probable fatigue cases.

\section{Baseline and follow-up psychological distress}

The 12-item version of the General Health Questionnaire (GHQ-12) was used to assess psychological distress. ${ }^{30.31}$ The GHQ-12 was developed as a screening instrument for detecting minor psychiatric disorders in the generall population. Two scoring systems were used for the four-point response scale. The Likert scoring method $(0,1,2,3)$ summed the respamses of the 12 items to generate a continuous distribution, ranging from 0 to 36 . The traditional $\mathrm{GHQ}$ scoring method $(0,0,1,1)$ is designed to identify individuals reporting sufficient psychological distress to be classified as probable cases of minor psychiatric disorder. In the present study, the threshold for case classification was 4 or higher, given a 
possible rangle of scores from 0 to 12 , which means that employees scoring 4 or more of the 12 items were considered to represent probable cases of psychological distress. The threshold for case classification is high but identical to the threshold used in other workplace studies. ${ }^{3,32}$

\section{Data analytic procedure}

All analyses were performed separately for men and women because of the observed gender difference regarding psychological distress ${ }^{12}$ and because our earlier reports of results ${ }^{2+2}$ were gender-specific. Differences in the prevalence of fiatigue and psychological distress between categories of lifestyle factors were assessed by chi-squared statistics. Pearson intercorrelations were computed for all study variables. After exclusion of either fatigue cases ( $\mathrm{CIS}>76$ ) or psychological distress cases (GHQ $\geq 4$ ) at baseline, the cumulative 1-year incidence of fatigue and psychological distress was determined. To examine the role of lifestyle factors, measured at baseline, in the onset of fatigue and psychological distress after 1-year follow-up, the data were analyzed using multiple logistic regression analysis. Statistical analyses were performed using the Statistical Package for the Social Sclences, release $9.0 .^{33}$

Multiple logistic regression was conducted in four steps for each lifestyle factor separately. Because a simple incidence analysis ignores the issue that those close to the CIS cutoff and making only small changes will be counted as incident cases, we introduced the refinement that they also must have an increase of a certain size. The size was determined by calculating the mean within-person variance for baseline and follow-up CIS measurement (eight points). Then the delta CIS score, which is the follow-up CIS score minus the baseline CIS score, was calculated for all employees. Those employees who crossed the predefined CIS cutoff of $>76$ at follow-up and had a delta CIS $\leq 8$ were excluded from the analysis. Therefore, after exclusion of prevalent fatigue cases and additional 66 incident cases (53 men and 13 women) with a small change, 5036 men and 1787 women remained for the analysis. After exclusion of the prevalent cases, the results presented here for psychological distress are based on 5243 men and 1785 women.

In the first step of the logistic regression analysis, we adjusted for age, educational level, living alone, employment status, and presence of disease; in step two, we controlled for the other lifestyle factors. In the third step, we adjusted for those psychosocial work characteristics that were identified as risk factors for fatigue or psychological distress. In addition: we controlled for all psychosocial work characteristics together. Because fatigue and psychological distress are fairly well associated, in the fourth step we controlled for the continuous baseline GHQ-12 or CIS score, when subsequent fatigue or psychological distress was considered as a dependent variable, respectively. ORs and their $95 \% \mathrm{Cls}$ were calculated for each lifestyle factor. 


\section{RESULTS}

\section{Prevalence of fatigue and psychological distress by different categories of lifestyle factors at baseline}

The distribution of lifestyle factors and the corresponding prevalence of fatigue and psychological distress can be seen in Table 1 . In both genders, those employees who smoked and reported nolonce a week physical activity had a significantly higher prevalence of fatigue and psychological distress. Obesity and overweight compared with nomal weight were related to fatigue and psychological distress in men only. Employees of both genders who reported no alcohol consumption had a significantly higher prevalence of fatigue compared with those who reported 1 to 14 glasses of alcohol per week.

Table 1 Lifestyle factors and prevalence of fatigue an psychological distress at baselinea

\begin{tabular}{|c|c|c|c|c|c|c|c|c|}
\hline & \multicolumn{4}{|c|}{ Men $(n=8840)$} & \multicolumn{4}{|c|}{ Women $(n=3255)$} \\
\hline & $n$ & $\%$ & $\% \mathrm{~F}$ & $\% \mathrm{PO}$ & $n$ & $\%$ & 晚F & $\% \mathrm{PD}$ \\
\hline Overall prevalence & & & 21.7 & 21.8 & & & 22.5 & 25.9 \\
\hline BMI & & & * & * & & & & \\
\hline Underweight $(<18.5)$ & 33 & 0.4 & 27.3 & 24.2 & 83 & 26 & 28.8 & 325 \\
\hline Nommal $(18.5-249)$ & 4212 & 49.2 & 20.6 & 21.5 & 2156 & 68.9 & 21.3 & 25.7 \\
\hline Owerweight $(25-29.9)$ & 3722 & 43.5 & 22.1 & 21.6 & 695 & 22.1 & 23.5 & 25.0 \\
\hline Obesity $(30 \times 34.9)$ & 509 & 5.9 & 27.0 & 26.9 & 474 & 5.5 & 28.4 & 29.0 \\
\hline Obesily $\| 1 \mid(35-39.9)$ & 60 & 0.7 & 23.3 & 25.0 & 34 & 1,1 & 18.2 & 23.5 \\
\hline Obesity & 21 & 0.2 & 23.8 & 28.6 & 7 & 0.2 & 42.9 & 57.1 \\
\hline Alcatol & & & ** & & & & * & \\
\hline No alcohol & 1797 & 20.3 & 24.7 & 23.9 & 1425 & 44.0 & 24.8 & 24.9 \\
\hline 1-14 glasses/week & 5757 & 65.1 & 20.7 & 21.3 & 1691 & 52.2 & 20.3 & 26.5 \\
\hline 15-21 glasses/week & 891 & 10.1 & 21.3 & 20.8 & 109 & 3.4 & 25.9 & 26.6 \\
\hline$\geq 22$ glasses/week & 338 & 3.8 & 23.2 & 220 & 13 & 0.4 & 38.5 & 38.5 \\
\hline Smoking daly & & & * & wh & & & wis & wis \\
\hline No & 6388 & 727 & 20.8 & 20.6 & 2320 & 71.7 & 20.1 & 232 \\
\hline Yes & 2396 & 273 & 24.0 & 24.7 & 916 & 28.3 & 29.6 & 32.6 \\
\hline Physical activity & & & $*$ & $w *$ & & & $*$ & $*$ \\
\hline 0-1 fimehweok & 2953 & 33.6 & 30.3 & 25.1 & 1032 & 32.0 & 30.3 & 30.6 \\
\hline $2-7$ times/week & 5203 & 59.2 & 17.6 & 20.3 & 2006 & 62.0 & 19.0 & 23.2 \\
\hline$>7$ timesiweek & 633 & 7.2 & 15.3 & 18.7 & 195 & 6.0 & 172 & 26.9 \\
\hline
\end{tabular}

a F, prewalence of fatigue; PD, prevalence of psychological distress; BMI, body mask indax.

* $p<0.05$ for differences in proportions by chi-squared statistics.

* $p<0.01$ for differences in proportions by chirsquared slatistics. 


\section{Intercorrelations of study variables}

In both genders, the highest correlation was found between smoking and education ( $\mathrm{r}=$ $-0.22, N=7959, p<0.01$ in men; $r=-0.22, N=2682, p<0.01$ in women). Overall, the study variables were rather weakly correlated with each other (specific data not shown).

\section{Lifestyle factors at baseline predicting fatigue after 1-year follow-up}

The cumulative incidence of fatigue during 1-year follow up was $9.7 \%(n=492)$ in men and $13.5 \%(n=241)$ in women. Because ORs after adjustment for those psychosocial work characteristics that were previously identified as risk factors for fatigue did not vary meaningfully from ORs after adjustment for all psychosocial work characteristics (see description of step 3 in data analytic procedure above), we present only the ORs adjusted for identified risk factors.

Tabie 2 Prospective associations between lifestye factiors at baseline and onset of faligue after $\|$-year follow-up in men $(n=5036$; incident cases, $n=492)$, adjusted for potential confounders and baseline General Health Questionnaire score"

\begin{tabular}{|c|c|c|c|c|}
\hline Factor & OR1 $(95 \% \mathrm{Cl})$ & OR2 $(95 \%$ Cl) & OR3 (95\% Cl) & OR4 ( $95 \% \mathrm{Cl})$ \\
\hline \multicolumn{5}{|l|}{ Body mess index } \\
\hline Undenweight ( $<18.5$ ) & $1.46(0.33-6.54)$ & $1.36(0.30 \times 6.12)$ & $1.29(0.28-5.96)$ & $1.70(0.37-7.83)$ \\
\hline Normal $(18.5 .24 .9)$ & $\|$ & 41 & $1 t$ & 11 \\
\hline Ovenweight (25-29.9) & $1.24(1.01-1.52)$ & $1.24(1.01-1.53)$ & $1.23(1.00-1.53)$ & $1.33(1.07-1.66)$ \\
\hline Obesity $(\geq 30)$ & $1.45(0.99-2.11)$ & $1.30(0.88-1.91)$ & $1.08(0.72-1.62)$ & $1.48(0.76-1.76)$ \\
\hline \multicolumn{5}{|l|}{ Alconol } \\
\hline No alcohol & $1.37(1.09 .9 .73)$ & $1.33(1.05 \times 1.68)$ & $1.27(0.98-1.61)$ & $1.29(1.00-4.66)$ \\
\hline 1-14 glasses/meek & $\|$ & 11 & $1 t$ & 11 \\
\hline 15-21glasses/week & $1.15(0.83-1.57)$ & $1.11(0.81-1.53)$ & $1.12(0.81-1.57)$ & $1.09(0.78-1.53)$ \\
\hline 222 glassesiweek & $0.96(0.56-1.64)$ & $0.91(0.53-1.56)$ & $0.94(0.53-1.56)$ & $0.94(0.56-1.63)$ \\
\hline \multicolumn{5}{|l|}{ Smoking/dally } \\
\hline No & $\|$ & 1 & $1 \uparrow$ & 1 \\
\hline Yes & $1.27(1.02-1.57)$ & $1.22(0.98-1.52)$ & $1.20(0.96-1.50)$ & $1.20(0.95-1.52)$ \\
\hline \multicolumn{5}{|l|}{ Physical Activity } \\
\hline a-1 timewnek & $1.44(1.18-1.77)$ & $1.36(1.11-1.68)$ & $1.37(1.10-1.70)$ & $1.33(1.07-4.66)$ \\
\hline $2-7$ limes/weok & 4 & 11 & it & $1 \hat{t}$ \\
\hline$>7$ timestweek & $0.78(0.52-1.18)$ & $0.79(0.52-1.19)$ & $0.79(0.52-1.22)$ & $0.88(0.57-1.35)$ \\
\hline
\end{tabular}

"OR1, adjusted for age, education, living alone, employment status, and presence of disease; OR2, adjusted for stèp $1+$ other lifestyle factors (body mass index continuous); OR3, adjusted for step $2+$ psychosocial work characteristics (psychological demarids, decision latiltude, physicaly demanding work, emotional demands); OR4, adjusted for step 3+ baseline General Heallh Questionnaire score. OR, adds ratio; $\mathrm{Cl}$, confidence interval.

tReference category.

As presented in Table 2, in men, all studied lifestyle factors except smoking were significantly associated with fatigue when controlling for demographics, presence of disease, and other lifestyle factors. After adjustment for psychosocial work characteristics, a strong inverse 
association was found between physical activity and fatigue, whereas the ORs for no alcohol consumption and being owerweight were reduced in size and were marginally significant. When also controlling for baseline $\mathrm{GHQ}$ score, being overweight $(\mathrm{OR}, 1.33 ; 95 \% \mathrm{Cl}, 1.07$ to 1.66) and not being physically active (OR, $1.33 ; 95 \% \mathrm{Cl}, 1.07$ to 1.66) were predictive for the onset of fatigue after 1-year follow-up. Although other categories of body mass index and physical activity were found to be nonsignificant (eg, being obese or being physically active $>$ seven times per week), the direction of the observed associations, positive or inverse was as expected. Furthermore, no alcohol consumption (OR, $1.29 ; 95 \% \mathrm{Cl}_{1} 1.00$ to 1.66 ) was predictive of fatigue after adjustment for baseline $\mathrm{GHQ}$ score. In women, only being underweight (OR, $3.16 ; 95 \% \mathrm{Cl}, 1.56$ to 6.39 ) was a strong predictor for the onset of fatigue after 1 -year follow-up, even after adjustment for potential confounding variables and baseline GHQ score (Table 3). Although being physically active was not significantly associated with the development of fatigue, the direction of the associations was as expected.

Table 3 Prospective associations beiween lifestyle factors at baseline and onset of fatigue alter i-yaar tollow-up in women $(n=1787$; incident cases, $n=241)$, adjusted for potential confounders and baselime General Health Questionnaire score* $^{*}$

\begin{tabular}{|c|c|c|c|c|}
\hline Factor & OR1 $(95 \% \mathrm{C})$ & OR2 $(95 \% \mathrm{Cl})$ & OR3 $(95 \% \mathrm{CI})$ & OR4 $(95 \% \mathrm{Cl})$ \\
\hline \multicolumn{5}{|l|}{ Body mass index } \\
\hline Underweight $(<18.5)$ & $3.14(1.57-6.28)$ & $3.10(1.55-6.22)$ & $320(1.58 \times 6.47)$ & $3.16(1.56-(9.39)$ \\
\hline Normal $(18.5-24.9)$ & it & 11t & 1 & 11 \\
\hline Ovenweight $(25-29.9)$ & $1.10(0.80-1.67)$ & $1.16(0.80 \cdot 1.68)$ & $1.16(0.80-1.68)$ & $1.22(0.84-1.78)$ \\
\hline Obesilly $(\leq 30)$ & $1.50(0.85-2.67)$ & $1.51(0.85-2.68)$ & $1.62(0.90-2.89)$ & $1.66(0.93-2.98)$ \\
\hline \multicolumn{5}{|l|}{ Alcohol } \\
\hline No alcohol & $1.02(0.76-1.37)$ & $1.01(0.75-1.36)$ & $0.99(0.73-1.33)$ & $0.99(0.73-1.34)$ \\
\hline 1-14 glasses/week & $\uparrow \uparrow$ & it & 11 & 11 \\
\hline 15-21glasses/week & $0.72(0.28-1.86)$ & $0.67(0.26-1.74)$ & $0.65(0.25-1.71)$ & $0.68(0.26-1.79)$ \\
\hline$\geq 22$ glasses/week & $0.05(0.00$ & $0.05(0.00$ & $0.05(0.00$ & 0.0510 .00 \\
\hline \multicolumn{5}{|l|}{ Smoking/daily } \\
\hline No & it & $1 \uparrow$ & it & 11 \\
\hline Yes & $1.34(0.97-1.86)$ & $1.37(0.98-1.91)$ & $1.38(0.99-1.92)$ & $1.33(0.95-1.86)$ \\
\hline \multicolumn{5}{|l|}{ Physical Activity } \\
\hline $0-1$ limelweek & $1.22(0.90-1.65)$ & $1.13(0.82-1.54)$ & $1.10(0.80-1.51)$ & $1.05(0.76-1.44)$ \\
\hline 2-7 tmesweek & $1+$ & if & it & 1 \\
\hline$>7$ timesweek & $0.73(0.37-1.45)$ & $0.73(0.37-1.46)$ & $0.75(0.38 \cdots 1.50)$ & $0.74(0.37-1.48)$ \\
\hline
\end{tabular}

"OR , adjusted for age, education, liwing alone, employment status, and presence of disease; OR2, adjusted for step 1 * other lifestyle factors (body mass index conthnuous); OR3, adjusted lor step $2+$ psychosocial wotk characterishics (coworker social support); ORA, adjusted for step 3+baseline General Heallh Questionnalre score. OR, odds ralio; Ch, confidence interval.

Teference cattegory. 


\section{Lifestyle factors at baseline predicting psychological distress after 1-year follow-up}

The 1-year cumulative incidence of psychological distress was $12.6 \%$ ( $n=657$ ) in men and $18.2 \%$ ( $n=321)$ in women. The presented ORs were adjusted onlly for psychosocial work characteristics, which were identified as risk faclors for psychological distress, because these ORs did not wary meaningfully from those controlled for all psychosocial work characteristics: In contrast to fatique, the consumption of 15 to 21 glasses of alcohol per week (OR, 1.36 ; $95 \% \mathrm{Cl}, 1.04$ to 1.79) was a predictor for the onset of psychological distress in men, even after adjustment for all potential confounding variables and the baseline CIS score (Table 4). Not being physically active, however, was no longer associated with the onset of psychological distress when controlled for baseline CIS score. As shown in Table 5, in women, no lifestyle factor was found to be predictive for the onset of psychological distress after 1 -year follow-up.

Table 4 Prospectiwe associations between lifeslyle factors at baseline and onset of psychological distress after 1-year follow-up in men ( $n=5243$; incident cases, $n=657$ ), adjusted for potential confounders and baseline Checklist Individual Strength score*

\begin{tabular}{|c|c|c|c|c|}
\hline Factor & ORH $195 \% \mathrm{Cl}$ & OR2 $(95 \% \mathrm{Cl})$ & OR3 $(95 \% \mathrm{Cl})$ & OR4 $(95 \%$ Cll) \\
\hline \multicolumn{5}{|l|}{ Body mass index } \\
\hline Undewweight $(<12.5)$ & $0.38(0.05-2.90)$ & $0.37(0.05-2.79)$ & $0.36(0.05-2.77)$ & $0.43(0.06-3.30)$ \\
\hline Normall (18.5-24.9) & 14 & 11 & 11 & 11 \\
\hline Overweight $(25-29.9)$ & $1.07(0.90-1.28)$ & $1.07(0.89-1.28)$ & $0.98(0.82-1.18)$ & $0.98(0.81 \cdot 1,19)$ \\
\hline Obesity $(\geq 30)$ & $0.90(0.62-1.32)$ & $0.85(0.58-1.24)$ & $0.69(0.46-1.04)$ & $0.68(0.45-4.02)$ \\
\hline \multicolumn{5}{|l|}{ Alconol } \\
\hline No alcohol & $1.21(0.98-1.50)$ & $1.19(0.96-1.48)$ & $1.14(0.92-1.43)$ & $1.14(0.9(1 \cdot 1.44)$ \\
\hline 1-14 giasses/week & $1 甘$ & 11 & 11 & 11 \\
\hline 15-21 glasses/week & $1.39(1.07 \times 4.80)$ & $1.34(1.02-1.75)$ & $1.36(1.04-1.78)$ & $1.36(1.04-1.79)$ \\
\hline 222 glassesiweek & 1. $13(0.73-4.73)$ & $1.13(0.73-1.74)$ & $1.08(0.70-1.68)$ & $1.00(0.64 \times 1.56)$ \\
\hline \multicolumn{5}{|l|}{ Smoking/daily } \\
\hline No & 1 & 1t & $1 \pi$ & $1 t$ \\
\hline Yas & $1.10(0.91 * 1.34)$ & $1.03(0.84-1.26)$ & $1.00(0.81-1.22)$ & $1.02(0.83-1.26)$ \\
\hline \multicolumn{5}{|l|}{ Physsical Activity } \\
\hline 0-1t timelweek & $1.32(1.11-1.58)$ & $1.28(1.07 \cdot 1.54)$ & $1.24\left({ }^{4} .03-1.50\right)$ & $1.06(0.87 \times 1.29)$ \\
\hline 27 timeshweek & 11 & it & it & $4 \uparrow$ \\
\hline$>7$ timesiweok & $1.00(0.72 \cdot 1.40)$ & $0.99(0.71-1.39)$ & $0.97(0.69-1.36)$ & $4.02(0.72-1.44)$ \\
\hline
\end{tabular}

* OR1, adjusted for age, education, living alone employment status, and presence of disease; OR2, adjusted for step 1+ other lifestyle factors (body mass index continuous); OR3, adjusted for step $2+$ psychosocial work characteristics (psychalogical demands, physically demanding work, emotional demands, contlict supervisor, conflict coworker); OR4,

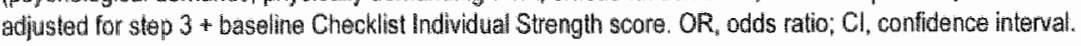

tReference category. 


\section{Discussion}

The findings of this prospective, longitudinal study showed that several modifiable lifestyle factors were significant risk factors for the onset of fatigue and psychological distress in the working population. The identified lifestyle factors were still predictive of fatigue or psychological distress after controlling for other lifestyle factors, psychosocial work characteristics, and baseline outcome measures. In addition, our study suggests same differential effects of lifestyle factors in the onset of fatigue and psychological distress and revealed differences between men and women.

We found evidence for a strong relationship between the lowest level of physical activity during leisure time and fatigue in men, which is consistent with a finding among male industrial employees reported in a cross-sectional study by Kristal-Boneh et al. ${ }^{1}$ In contrast to Kristal-Boneh ef al ${ }^{4}$ our study revealed that overweight and no alcohol consumption are risk factors for the onset of fatigue, whereas smoking was not prospectively associated with fatigue in men. With respect to psychological distress, Stansfield et al ${ }^{10}$ also reported in a cross-sectional study that the proportion of GHQ cases increased with alcohol intake in men (and in women). In the same study, Stansfeld et al ${ }^{10}$ showed that smoking habit, which was not predictive of distress in our study, was found to be related to psychiatric morbidity in men

Table 5 Prospective associations between iffestyle factors at baseline and onset of psychological distress after 1-year follow-up in women ( $n=1785^{;}$incident cases, $\left.n=321\right)$, adjusted for potential confounders and baseline Checkilist Individual Strength score ${ }^{*}$

\begin{tabular}{|c|c|c|c|c|}
\hline Factor & $\mathrm{OR} 1(95 \% \mathrm{Cl})$ & OR2 $(95 \% \mathrm{Cl})$ & OR3 $(95 \% \mathrm{Cl})$ & ORA $(95 \% \mathrm{Cl})$ \\
\hline \multicolumn{5}{|l|}{ Body mass index } \\
\hline Underwaight ( $<18.5$ ) & $1.60(0.76-3.37)$ & $1.53(0.72-3.23)$ & & $1.32(0.60-2.91)$ \\
\hline Nomal $(18.5-24.9)$ & 11 & 11 & $*$ & 11 \\
\hline Overweight (25-29.9) & $1.15[0.84-1.57)$ & $1.15(0.84-1.59)$ & & $1.14(0.82-1.58)$ \\
\hline Obesity $(\geq 30)$ & $1.39(0.82-2.34)$ & $1.42(0.84-2.41)$ & & $1.43(0.84-2.45)$ \\
\hline \multicolumn{5}{|l|}{ Alcohol } \\
\hline No alcolnal & $0.86(0.66-1.12)$ & $0.86(0.66-1.12)$ & & $0.83(0.63-1.09)$ \\
\hline $1-14$ glasses/week & 11 & 1 & ii & 11 \\
\hline 15-21glasses/week & $0.92(0.45-1.88)$ & $0.85(0.41-1.74)$ & & $0.83(0.40-1.71)$ \\
\hline$\geq 22$ glasses/week & 0.0310 .00 & 0.0310 .00 & & 0.0110 .00 \\
\hline \multicolumn{5}{|l|}{ Smokingidailly } \\
\hline No & 18 & 11 & *\# & $\|$ \\
\hline Yes & $1.30(0.97-1.74)$ & $1.27(0.94-1.72)$ & & $1.20(0.88-1.64)$ \\
\hline \multicolumn{5}{|l|}{ Physical Activity } \\
\hline 0.1 time'week & $1.15(0.88-1.52)$ & $1.13(0.85-1.49)$ & & $1.01(0.76 \times 1.35)$ \\
\hline 2.7 timeshweek & $\| T$ & 1 & $*$ & $1+$ \\
\hline$>7$ times/week & $0.81[0.44 \times 1.50)$ & $0.82(0.44-1.52)$ & & $0.89(0.47-1.67)$ \\
\hline
\end{tabular}

"OR1, adjusted for age, education, living alone, employment status, and presence of disease; OR2, adjusled for step 1 + other lifestyle factors (body mass index continuous); OR4, adjusted for step 2 * baseline Checklist Individual Strength score: $\mathrm{OR}_{\text {, }}$ odds ratio; $\mathrm{Cl}$, confidence intervall.

TReference category.

\# OR3, no adjustment for psychosocial work characteristics.s. 
only. A comparison of these cross-sectional results with our prospective findings, however, is hampered because of a different definition of lifestyle factors, fatigue and psychological distress, a different nature of designs, different time spans, and different settings in which the studies were performed. Regarding differential etiological effects of lifestyle in fatigue and psychological distress. we should acknowledge that our results suggest distinct factors in both health outcomes and in bath genders.

When interpreting the results of the present study, several methodological issues must be considered. One issue concerns a possible misclassification of exposure and the measurement of the examined lifestyle factors. If misclassification has occurred, we expect this to be nondifferential, and estimates are most likely biased toward the null value. The body mass index was categorized according to the standard classification of the National Institutes of Health. ${ }^{20}$ Although small in sample size, underweight employees were neither excluded from the present study nor classified as reporting a normal weight. Nevertheless, we must recognize that it is not impossible that, for instance, an underlying disease can account for the established causal relation with fatigue in women. Daily smoking, alcohol consumption per week, and engagement in physical activity of at least half an hour per week (eg, exercise, biking. walking) were assessed by a single item. The items, however "had response categories that can easily be interpreted and can be used directly to develop measures and actions to prevent, or at least reduce, the risk of fatigue and psychological distress in the working population.

Following on this issue, a possible misclassification of fatigue or psychological distress cases cannot be exclluded, because both outcome measures were dichotomized. However, the Cis cutoff point of $>76$ for fatigue, which was empirically derived in a separate pilot study, had a high sensitivity and specificity $\left(73 \%\right.$ and $90 \%$ respectively), ${ }^{19}$ thereby restricting misclassification. Moreover, in the present study, we also applied an additionall conservative strategy by introducing a refinement of a minimum amount of increase on crossing the cutoff; thereby excluding those employees who are close to the cutoff and cause only a small change. With respect to psychological distress, the threshold for case classification (GHQ $\geq$ 4 ) is high but likely to indicate very symptomatic employees as probable cases of minor psychiatric disorder, and in that way, minimize possible misclassification.

Whereas in men and women different lifestyle factors were observed to be predictive of falligue, no significant predictors albeit trends were found for future psychological distress in women. Whether this gender difference can be attributed to a small sample size or a different time course of lifestyle factors in affecting health cannot yet be determined and requires further exploration.

Another issue concerns the follow-up period of 1 year between the assessment of lifestyle factors and fatigue and psychological distress. However , because we identified several lifestyle factors as risk factors for the development of fatigue and psychological distress, it is unlikely that with the two outcomes studied, the follow-up period of 1 year was too short. Moreover, it has been argued that different stressors follow different exposure time courses in longitudinal studies on work stress. ${ }^{34}$ Accordingly, we should acknowledge that the impact of each lifestyle factor on fatigue and psychological distress may follow a different time course. Although in some factors a high prevalence of fatigue and psychological distress was observed, the cumulative incidence of fatigue and psychological distress after 1-year followup was rather low (egl, smoking). Given the cross-sectional association, the question is raised whether causal dynamics have played themselves out, ie, there is no continued 
impact of continued exposure. Hence, to explore the exposure lime concept of each lifestyle factor and to clarify the impact of changes in lifestyle factors on the onset of fatigue and psychological distress, repeated measurements during a longer follow-up period, different time frames, or both, are required.

Given the considerable impact of fatigue and psychological distress on socioeconomic costs and the high prevalence of potentially modifiable lifestyle factors within our large. heterogeneous working population "it is important to note that the prospective results suggest causal associations. Although prevention of mental health problems is difficult, these findings are extremely valuable and provide a sound basis for the development of recommendations and interventions for improving mental health, either on an individual or a group level (eg, at the workplace). For instance, being physically inactive during leisure time, a prevalent and modifiable lifestyle factor, was found to be a strong, independent predictor of fatigue after 1 year follow-up in men, even after the adjustment for psychosocial work characteristics. Thus, the benefits of increased physical activity during leisure time are strongly suggested. Nevertheless, it should be remembered that if a cross-sectional association but no association over time (eg, smoking) exists, the benefits of changing the risk factor cannot be ruled out.

To conclude, this prospective study revealed that potentially modifiable lifestyle factors are predictive of fatigue and psychological distress in men and women. These effects are independlent of other lifestyle factors, psychosocial work characteristics, and baseline measures of psychological distress and fatigue. Moneover, it suggests some differential effects of lifestyle factors in the etiology of fatigue and psychological distress, supporting the motion of distinct concepts. Notably, from the viewpoint of developing measures to prevent or at least reduce the risk of fatigue and psychological distress in the working population, the study revealed modifiable risk factors. Therefore, the results can be used to design interventions, either individually tailored or at the group level in the workplace. Nevertheless, to completely understand the multifactorial etiology of fatigue and psychological distress and to obtain conclusive evidence for distinct concepts, future research should further elucidate the role of work-family factors and individual characteristics and their interplay with lifestyle factors and psychosocial work characteristics.

\section{ACKNOWLEDGEMENTS}

The Maastricht Cohort Study is part of the Netherlands concerled research action on "Fatigue at Work" granted by the Netherlands Organization for Scientific Research. The present study was and is currently supported by a grant from the Netherlands Organization for Scientific Research (NWO grant no. 580-02.251).

\section{REFERENCES}

1. Kristal-Boneh $E$, Froam $P$, Harari $G$, Ribak J. Fatigue among Israeli industrial employees. J Occup Environ Med. 1996;38: 1145-50.

2. Meijman T, Schaufeli W. Psychische vermaeidheid en arbeid. Ontwikkelingen in de A\&: psychologie [Fatigue at work. Developments in $1 / 0$ psychology]. De Psycholoog. 1996; June:23641. 
3. Hardy GE, Shapiro DA, Borrill CS. Fatigue in the workforce of National Health Service Trusts: levels of symptomatology and links with minor psychiatric disorder, demographic, occupational and work role factors. J Psychosom Res. 1997;43:83-92.

4. Mounstephen $A$, Sharpe M. Chronic fatigue syndrome and occupational health. Occup Med (Oxf.) $1997: 47: 217-27$

5. Schirer CAP. De toeriame van arbeidsongeschiktheid wegens psychische aandoeningen IThe increalse of work disability due to mental disorders]. TBV. 1997:5:16-23.

6. Lewis $G$, Wessely $S$. The epidemiology of fatigue: more questions than answers. J Epidemion Community Health. 1992;46:92-7.

7. Pawlikowska $T_{*}$, Chalder $T$, Hirsch SR, Wallace $P_{n}$ Wright D., Wessely SC. Population based study of fatigue and psychological distress. BMJ. 1994;308:763-6.

8. Bultmann U, Kant IJ, Van Amelsvoort LGPM, Van den Brandt PA, KasI SV. Differences in fatigue and psychological distress across occupations: Resulfs from the Maastricht Cohort Study of Fatigue at Work. J Occup Environ Med. 2001:43:976-983.

9. Bultimann U, Kani WJ, Van den Brandt PA, Kasi SV. Psychosocial work characteristics as risk factors for the onset of fatigue and psychological distress: Prospective results from the Maastricht Cohort Study. Psychol Med. In press.

10. Stansfeld SA, Smith GD, Marmat M. Association between physical and psychological morbidity in the Whitehall II Study. J Psychosom Res. 1993; 37:227-38.

11. Lasser K, Boyd JW, Woolhandler S, Himmelstein DU, McCormick D, Bor DH. Smoking and mental illness: A population-based prevallence study. JAMA. 2000;284:2606-2610.

12. Buttmann U, Kant 1 $\downarrow$, Kasi S, Beurskens A, Van den Brandt P. Fatigue and psyelhological distress in the working population: Psychometrics, prevalence, and correlates. J Psychosom Res. In press.

13. Hickie IB, Hooker AW, Hadzi Pawlovic D, Bennett BK, Wilson A.J, Lloyd AR. Fatigue in selected primary care settings: sociodemographic and psychiatric correlates. Med J Aust. 1996;164:585-8.

14. Hickie I $_{2}$ Koschera A, Hadzi-Pavlovic D, Bennett B, Lloyd A. The temporal stability and comorbidity of prolonged fatigue: a longitudinal study in primary care. Psychol Med. 1999;29:855-61.

15. Van der Linden $G$, Chalder $T$, Hickie I, Koschera A, Sham P, Wessely S. Fatigue and psychiatric disorder; different or the same? Psychol Med. 1999; 29:863-8.

16. Koschera A, Hickie I, Hadzi-Pavlovic D, Wilson A, Lloyd A. Prolonged faligue, anxiety and depression: exploring relationships in a primary care sample. Aust $N Z$ J Psychiatry. 1999;33:54552.

17. Addington $A M$, Gallo JJ, Ford DE, Eaton WW. Epidemiology of unexplained fatigue and major depression in the community: the Baltimore ECA follow-up, 1981-1994. Psychol Med. $2004: 31: 1037-44$

18. Kant U., Beurskens A, Schrber C, Nijhuis F, van Schayck C, Swaen G. De Maastrichtse Cohort Studie nabar langdurige psychische vermoeidheid in de arbeidssituatie [The Maastricht Cohort Study of prolonged Fatigue at Work]. TBV. 2000;8:226-232.

19. Bültmann U, De Vries M, Beurskens AJHM, Bleijenberg G, Vercoulen JHMM, Kant IJ. Measurement of prolonged fatigue in the working population: Determination of a cutoff point for the Checklist Individual Strength. J Occup Health Psychol. 2000;5:411-416.

20. National Institutes of Health. Clinical Guidelines on the Identification, Evaluation, and Treatment of Overweight and Obesity in Adults - The Evidence Report. Bethesda, MD: US Department of Health and Human Services; 1998. NIH Publication no.98-4083.

21. Karasek RA. Job Content Questionnaire and Users's Guide. Las Angeles: University of Southerr California, Department of Industrial and Systems Engineering: 1985

22. Houtman I. Reliability and Validity of the Dutch Version of the Karaselk Job Content Questionnaire: Proceedings of the NIOSH/APA Conference on Stress, Work, and Health. Washington, DC: NIOSHIAPA; 1995.

23. Gründemann R, Smulders P, de Winter $C$. Handleiding Vragenlijst Arbeid en Gezondheid [Questionnaire on Work and Health. Manual]. Lisse: Swets \& Zeitlinger; 1993. 
24. Van Veldhoven $M$ : Meijman $T$. Het meten van psychosociale arbeidsbelasting met een vragenlijst: De Vragenlijst Beleving en Beoordeling van de Arbeid (VBBA) [Questionnaire on Perception and Judgement of Work]. Amsterdam: Nederlands Instituut voor Arbeidsomstandigheden; 1994.

25. Vercoulen JH, Swanink CM. Fennis JF, Galama JM, wan der Meer JW, Bleijentierg G. Dimensional assessment of chronic fatigue syndrome. J Psychosom Res. 1994:38:383-92.

26. Vercoulen JHHM, Alberts M, Bleijenberg G. De Checklist Individuele Spankracht (CIS) IThe Checklist Individual Strength (CIS)]. Gedragstherapie. 1999;32:131-136.

27. Vercoulen $\mathrm{JH}_{3}$, Hommes $\mathrm{OR}$, Swanink $\mathrm{CM}_{n}$ et ol. The measurement of fatigue in patients with multiple sclerosis. A multidimensional comparison with patients with chronic fatigue syndrome and healthy subjects. Arch Neurol. 1996; 53: 642-9.

28. Vercoulen JH, Swanink CM "Fennis JF, Galama JM, van der Meer JW, Bleijenberg G. Prognosis in chronic fatigue syndrome: a prospective study on the natural course. J Neural Neurosurg Psychiatry. 1996;60:489-94.

29. Beurskens AJ, Bültmann U, Kant IV, Vercoulen JH, Bleijenberg G, Swaen GM. Fatigue among working people: validity of a questionnaire measure. Occup Environ Med. 2000;57:353-7.

30. Goldberg DP. Williams P. A User's Guide to the General Health Questionnaire. Windsor: NFERNelson; 1988.

31. Koeter MWJ, Ormel J. General Health Questionnaire, Handleiding Nederlandse bewerking [General Health Questionnaire, Manual Dutch version]. Lisse: Swets \& Zeitlinger; $199 \%$.

32. Wall TD, Bolden RI, Borrill CS, et al. Minor psychiatric disorder in NHS trust staff: occupational and gender differences. Bir J Psychiatry. 1997;171:519-23.

33. Statistical Package for the Social Sciences. SPSS for Windows, release. 9.0. Chicago: Statistical Products and Service Solutions; 1998.

34. Frese M, Zapf D. Methodological issues in the studly of work stress: Objective vs subjective measurement of work stress and the question of langitudinal studies. In: Cooper CL, Payne R, eds. Causes, Copingis and Consequences of Stress at Work. Chichester: Wiley: 1988: $375-411$. 


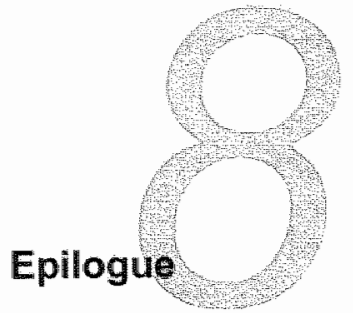


The primary objective of this epilogue is to reflect, rather than to elaborate in detal, on the main findings of the study described in the previous chapters of this thesis. In view of both. the study purposes formulated in the introduction (Chapter 1) and the growing interest in prolonged fatigue within the field of occupational (mental) health research, the main topics covered in this chapter include the concept and prevalence of fatigue and psychological distress in the working population and the etiological role of work and lifestyle, thereby considering some general methodological issues. At the end, the chapter addresses implications for occupational (mental) health research and prevention, and recommendations. for further research.

\section{CONCEPT AND PREVALENCE}

In the first part of the thesis the concept and prevalence of fatigue and psychological distress in the working population were addressed. A prerequisite of a questionnaire-based study of fatigue in the working population is, of course, a valid instrument to measure fatigue. At the beginning of the Maastricht Cohort Study, however, information about such a validated fatigue instrument for use in the working population was lacking. In this study, fatigue was measured with the Checklist Individual Strength (CIS), which covers several aspects of fatigue, such as fatigue severity, concentration, motivation, and physical activity. The CIS is a 20-item, easy to administer, self-report questionnaire, which was originally developed for hospital studies of chronic fatigue syndrome. ${ }^{1,2}$ The CIS was extensively tested in the clinical setting, and has been frequently used in patients with chronic fatigue syndrome and other chronic illnesses. ${ }^{1,3,4}$ Furthermore, the CIS was used to determine the prevalence of symptoms in veterans who had been deployed in the UNTAC peacekeeping operation during 1992 and $1993 .^{5}$ In the above-mentioned studies, the subscale fatigue severity was used as one criterion among others to identify cases. In line with the understanding of fatigue in the Maastricht Cohort Sudy, this study used the total CIS, comprising all subscales.

Since there was neither information about the use of the CIS in the working population "nor about a criterion to identify cases based on the CIS total score, a pilot study was conducted by means of defined samples with differences in fatigue level. The aim of this pilot study was twofold: 1) to validate the Checklist Individual Strength in the working population, and 2) to define a cutoff point for fatigue for use in the working population. To recapitulate the main findings, the Checklist Individual Strength was ablle to differentiate between samples with different fatigue levels, and seemed to be a suitable instrument to measure fatigue in the working population (Appendix). Notwithstanding the potential limits of defining a cutoff point for fatigue, the determined cutoff point for case classification of CIS total $>76$ was found to be appropriate for use in fatigue studies in the working population (Chapter 2). This information about the use of the Checklist Individual Strength in the working population was not only important for the present study and for other projects conducted within the Maastricht Cohort Study, but will also be helpful for future fatigue studies within working populations.

With respect to the magnitude of fatigue, it was shown that a total of $2595(22 \%)$ employees scored above the predefined cutoff for fatigue, with no observed difference between men and women (Chapter 3). When compared with the prevalence reported in community and primary care studies, a prevalence of fatigue of $22 \%$ in this working sample cannot be regarded as 
unusual. In view of the possible consequences of fatigue, ie, affecting the employees" performance and ability to function in the work and home settings, and probably leading to sickness absence and work disability, however, this prevalence can pose a considerable problem. In advance of the longitudinal results (Chapter 5), the cumulative 1-year incidence of fatigue was found to be around $11 \%$, indicating a mean duration of fatigue of approximately 2 years, which underlines the magnitude and impact of fatigue in the working population, and consequently. supports an earlier plea for preventive measures.

However, when interpreting these findings, it has to be kept in mind that the overall response rate was $45 \%$. Though reasonable for a survey in the working population, this response rate raised the question of a selective participation of employees, which may have biased the findings. It must be acknowledged, that a slight overestimation of fatigue cannot be ruled out, since a nonresponse analysis showed that nonrespondents were less likely to report fatigue and sickness absence. Another related issue concerns the composition of the study population. Although a total of 12,095 employed men and women with a large number of different occupations were inciuded, the study population cannot be regarded as a truly representative sample of the Dutch workforce, since participation in the Maastricht Cohort Study was restricted to $100+$ companies and organizations. It should be emphasized, however, that this working sample covered almost all sectors of the Dutch workforce. Moreover, it should be noted that this unique working sample provided sufficient new fatigue cases during the follow-up period and made it possible to identify pulative risk factors for the onset of fatigue and psychological distress. Also, it has to be carefully considered that the prevalence and incidence of fatigue strongly depend on the predefined CIS cutoff point on the one hand, and on the study population and the response rate on the other hand. Admittedly, the use of a cutoff point for fatigue, while rather continuously distributed, ${ }^{6.19}$ is a troublesome issue. Therefore, the limitations regarding the setting of a cutoff point were extensively discussed in Chapter 2. Nevertheless, while explicitly demonstrating the process of decision making, a cutoff point for fatigue was determined by means of defined samples with differences in fatigue level during pilot work. In short, the determination of this cutoff point was based on high specificity, thereby restricting the number of false-positively classified healthy working employees.

Alongside the magnitude of fatigue in the working population, the relationship between fatigue and psychological distress was explored. Psychological distress was measured with the General Health Questionnaire $(G H Q-12){ }^{10,11}$ With a cutoff likely to indicate very symptomatic employees as probable cases of minor psychiatric disorder, the prevalence was $22 \%$ and $26 \%$ in men and women, respectively (Chapter 3 ). In line with the findings of earlier fatigue studies conducted across different populations, ${ }^{7,12,13}$ fatigue was demonstrated to be fairly well associated with psychological distress. Of particular interest was therefore to learn whether the existing measures, ie, the CIS and $6 H Q-12$, assess highly similar or sufficieritly different underlying concepts in the working population. In an attempt to cast more light on these operational and conceptual issues, different strategies were utilized. Although a principal component analysis appeared to be useful in separating fatigue items from those describing psychological distress, it was not possible to separate the concepts by means of different associations with demographic or health factors. Obviously, these findings warrant further research in order to more specifically disentangle the relationship between fatigue and psychological distress. Nevertheless, in spite of the observed correlation, the results of 
the study do suggesi that fatigue and psychological distress may be separate concepts. As a consequence of the considerable magnitude of fatigue and psychological distress in the working population, which both represent a challenge for the field of occupational (mental) health, the need to further elucidate the concepts of fatigue and psychological distress, and the observed gender difference for psychological distress, the present study addressed both health outcomes, fatigue and psychological distress, in men and women separately.

While a link between psychosocial work characteristics and fatigue has generally been assumed, only very few studies have actually examined this proposed relationship in the working population. In contrast, many studies have accumulated evidence which suggests that psychosocial factors at work, such as psychological job demands, decision latitude and social support, were associated with a wariety of mental health outcomes, eg, psychological distress or other forms of psychiatric disorders. ${ }^{\text {4-19. }}$ In an attempt to overcome the lack of information concerning fatigue, this study addressed the relationship between a wide range of psychosocial work characteristics and fatigue and psychologicial distress (Chapter 4). To measure psychosocial work characteristics, not only the main factors of the widely ackmowledged Demand-Control-Support model ${ }^{14,15,20}$ but also additional factors, such as emotional demands, job insecurity, conflicts with supervisor and conflicts with coworker, were used. Despite limitations related to the cross-sectional nature of its design, the study provided strong support for associations between psychosociall work characteristics and fatigue in men and women. A comparison of the associations between psychosocial work characteristics and fatigue and psychological distress "respectively suggested some differential effects, even after the adjustment for the other dependent variable. Even though the broad spectrum of psychosocial work characteristics allowed a more comprehensive insight into the work environment, still other work-related factors (eg, working hours, shift work) and orglanizational aspects may be considered as related to fatigue and psychological distress. It is important to note that the observed relations between psychosocial work characteristics and either fatigue or psychalogical distress are not readily interpretable as cause-effect associations. The possible etiological role of psychosocial work characteristics in the onset of fatigue and psychological distress in the working population; and the question as to whether fatigue is etiologically distinct from psychological distress, should be clarified in the longituidinal setting.

\section{THE ETIOLOGICAL ROLE OF WORK AND LIFESTYLE}

In the second part of the thesis possible risk factors for the onset of fatigue and psychologicall distress in the working population were examined. Although the likely multifactorial etiology of fatigue is stressed in the literature, ${ }^{21}$ and psychosocial reasons are most often mentioned as explanations for feeling fatigued, there is barely any knowledge on the role of work, home life, and individual characteristics in the onset of fatigue in the working population. To begin to disentangle the likely multifactoriall etiology of fatigue, and in order to identify factors which could be targeted for future preventive measures, this longitudinal study primarily focuses on the possible etiological role of psychosocial work characteristics and lifestyle factors.

As reported in Chapter 5, a wide range of psychosocial work characteristics was found to be related to the onset of fatigue during 1-year follow-up in the working population. It is: 
interesting to note that after the adjustment for baseline fatigue, clear differential effects of psychosocial work characteristics on fatigue were observed between men and women. To summarize the main findings, coworker social support had a strong protective effect on future fatigue in women. In men, psychological, emotional, and physical demands were predictive of fatigue, whereas decision latitude had a protective effect on fatigue. Whether these observed gender differences may be partly explained by differences in the structure of occupations and work characteristics for men and women, ${ }^{22}$ by differences in the perception of or vulnerability to work conditions, ${ }^{23}$ or probably emerge due to a different time course of work-related factors in the onset of fatigue, cannot yet be determined. Certainly, these gender differences merit a further exploration, in which the impact of demands in home life should receive special attention. Since it cannot be ruled out that a disease might influence the reporting of either psychosocial work characteristics or fatigue, the presence of a disease at baseline was taken into account as a confounding variable. The findings of this study. however, showed that the associations between psychosocial work characteristics and fatigue remained significant after control for potential confounding variables and were independent of baseline fatigue and psychological distress. Notably, good interpersonal relationships at work and high decision latitude, especially high decision authority, were demonstrated to be important aspects that should be addressed in preventive measures.

With respect to lifestyle factors, not being physically active during leisure time and being overweight in men, and underweight in women, were identified as potentially modifiable risk factors for the onset of fatigue in the working population (Chapter 7). The longitudinal associations remained significant even when adjusted for potential confounding variables, including the presence of a disease and earlier identified psychosocial work characteristics, other lifestyle factors, as well as psychological distress. In particular it seems advisable to stimulate physical activity during leisure time. Not being physically active during leisure time. a prevalent and modifiable lifestyle factor, was found to be a strong, independent risk factor for fatigue. Thus, the benefits of increased physical activity during leisure time are strongly suggested. Nevertheless, it should be recognized that if a cross-sectional relation but no rellation over time (eg, smoking) exists, the benefits of changing the risk factor cannot be ruled out.

In an effort to examine whether the effects found for fatigue differed from those for psychological distress, ie, to learn whether fatigue is etiologically distinct from psychological distress, the observed longitudinal associations were compared. This studly found partly similar and partly different effects for psychosocial work characteristics as well as for lifestyle factors on psychological distress. For example, with respect to psychosocial work characteristics it was shown that conflicts at work increased the risk for future psychological distress, but not for fatigue, whereas low decision latitude was related to fatigue but not to psychological distress. Moreover, there was no effect of physical activity during leisure time and body mass index on future psycholagical distress, while alcohol consumption was found to be related to psychological distress, but not to fatigue. Although this study suggests some differential effects of psychosocial work characteristics and lifestyle factors in the onset of fatigue and psychological distress, it should be recognized that these findings are not strong enough to provide conclusive evidence for the existence of two distinct concepts. However, the findings do support the notion of different underlying concepts and further substantiate the idea that fatigue might be etiologically heterogeneous from psychological distress. 
Given the broader. multufactorial etiology which has been generally assumed, it is possible that other factors, for example demands in home life or coping. may also play an independent role in the onset of fatigue and psychological distress or may affect the associations found in this study. However, these relationships have not yet been examined and should be explored in further research. Nevertheless, the longitudinal findings from this study provided suggestive evidence for the etiological role of psychosocial work characteristics and lifestyle factors in the onset of fatigue and psychological distress.

When interpreting these findings, some general methodological issues have to be considered. One issue concerns the assessment of both exposure and outcome, particularly, the potential limitations related to seif-report measures in terms of common method variance. ${ }^{24,25}$ in this study, all data were obtained by means of self-administered questionnaires, which may have resulted in an overestimation of the associations. Another issue related to the assessment of exposure and outcome concerns the potential underlying effects of negative affectivity (NA) on the relationship between self-reported measures. ${ }^{26}$ it is argued that individuals with negative affectivity may perceive their work environment more negatively, thereby creating spurious associations between work characteristics and the reports of adverse health outcomes, which are also influenced by negative affectivity. Recently, the probable substantive role of negative affectivity in employees reactions to work characteristics and the related issue of controling for negative affectivity in occupational (mental) health research has again been debated ${ }^{27.28}$ In the study described in this thesis negative affectivity is not measured. However, in longitudinal analyses which control for baseline values of the outcome variable, the possible influence of NA is reduced. It is important to note that the longitudinal associations between work-related factors and fatigue and psychological distress remained significant after adjustment for potential confounding variables and either baseline fatigue or baseline psychological distress, thereby controlling for the influence of NA on baseline values, strengthening the findings which are based on self-report data.

Another important issue to consider is the (non)-response at follow-up. Although an overall response rate of $80 \%$ after $\|$-year follow-up is reasonable for a questionnaire-based study withim the working population, it must be recognized that nonrespondents were likely to report thigher fatigue levels at baseline than respondents, which may have led to a slight underestimation of the cumulative 1-year incidence of fatigue. However, a selective nonresponse within sectors, trades, and companies participating within the Maastricht Cohort Study was not observed.

Finally in this study the follow-up period between the assessment of work and lifestyle. which reflect the condition at baseline, and the assessment of fatigue and psychological distress is 1 year. It should be emphasized, however "that several work-related factors and lifestyle factors were identified as risk factors for the onset of fatigue and psychological distress. Therefore, it is unlikely that with the two outcomes studied, the follow-up period of 1 year was too short. With respect to changes in exposure, it should be acknowledged that most work characteristics and lifestyle factors were assumed to be relatively stable, while others, like social support and conflicts at work, could have changed during follow-up, so that the associations between these factors and either fatigue or psychological distress would be attenuated. In addition, it should be kept in mind that different exposure variables as well as different outcomes of ill-health may follow different time courses. ${ }^{29}$ In this 1-year follow-up 
study, different exposure time courses (ie, immediate, delayed or cumulative effects) have not been explicitly addressed. Hence, the time course of exposure and outcome variables as well as the impact of exposure changes in the onsel of fatigue and psychological distress should be more specifically explored by means of repeated exposure and outcome measurements during shorter and longer follow-up periods.

\section{IMPLICATIONS FOR OCCUPATIONAL (MENTAL) HEALTH}

The findings described in this study clearly showed that fatigue and psychological distress are common problems in the working population. Given the prevalence and incidence of fatigue and psychological distress on the one hand and the possible consequences, ie, the social and economic costs for employees, employers, and the society on the other, the findings underscore the need for preventive measures for fatigue and psychological distress in the working population.

This study contributes to the field of occupational (mental) health by providing valuable insight into the etiological role and distribution of risk factors in the onset of fatigue and psychological distress in the working population. However, irrespective of this useful information which might facilitate the development of preventive measures, it must be emphasized that prevention of fatigue and psychological distress in the working population is difficult. In view towards the design of effective preventive measures, not only the magnitude but also the prevalence of a given risk factor should be taken into account. For example, no physical activity and low decision latitude were found to be strong and prevalent risk factors for the onset of fatigue in men, and should therefore be considered in the design of preventive measures. Other, probably even more important issues concern the modifiability of a given risk factor and, of course, the susceptibility for change of an individual employee. Considering the design of preventive measures, it is interesting to note that in this study several, more or less modifiable work-related factors and lifestylle factors were identified as related to the onset of fatigue and psychological distress in the working population. Unfortunately, it was in this study not possible to develop a risk profile of factors associated with fatigue and psychological distress. Consequently, it was neither possible to pinpoint specific groups at risk nor to identify individuals at risk.

In Chapter 6. differences in fatigue and psychological distress were examined across occupations, since it is generally assumed that occupations might help to identify specific risk groups and, in particular, might be an easy entree for intervention. Earlier, it was argued ${ }^{30}$ that "paying attention to job titles is a minimal strategy of using objective data and is often quite informative." Occupation or job title is measured separately from the perceptions of the job occupant and can be viewed as a rather crude proxy index for the objective work environment. Although considerable occupational differences regarding the prevalence of fatigue and psychological distress were found, occupation added relatively little explanatory information beyond the perceived measures of the psychasocial work environment. Therefore, the use of occupation exclusively seems to be an inadequate entree for intervention; instead, it is probably more appropriate to use supplementary information about the work environment as perceived by the job occupant.

Thus, despite the suggestive evidence for the etiological role of work-related factors and lifestyle factors in the onsel of fatigue and psychological distress in the working population, it 
should be recognized that the findings are not readily translatable into adequate measures and effective strategies for prevention. However, for the field of occupational (mental) health, this study offered valuable insight and useful indications for the development of future preventive measures. Clearly, the findings warrant further research on fatigue and psychological distress in the working population in order to provide a sound basis for the development of effective preventive measures and adequate strategies for intervention.

\section{FURTHER RESEARCH}

For a greater understanding of fatigue and psychological distress in the working population, future studies should further disentangle the multifactorial etiology of fatigue and psychological distress, should more specifically examine the time course of cause and effect, and should pay special attention to the temporal relationship between fatigue and psychological distress during follow-up.

Certainly, what is needed, is to evaluate the etiological role of other factors, such as domestic and social factors (eg, home life responsibilities, leisure time activities) as well as individual characteristics (eg, coping, negative affectivity), ${ }^{3-33}$ which may also be considered as related to the onset of fatigue and psychological distress in the working population. In addition, specilal attention should be paid to the probably complex interplay between the currently known, ie, work-related factors and lifestyle factors, and the still unknown risk factors for fatigue and psychological distress. For example, interactions between work life and home life responsibilities, ${ }^{34,35}$ and the potential underlying effects of negative affectivity on the relationship between work environment and health outcomes. ${ }^{31}$

Consequently, further research should be directed towards the development of an integrated model for the onset of fatigue and psychological distress in the working population, Such a proposed model should incorporate possible risk factors from all domains, ie, work environment, domestic and social life, and individuall characteristics, as well as fatigue and psychological distress, and should be embedded in a longitudinal setting. Notably, the integrated model may be helpful to clarify the role and impact of different risk factors in the onset of fatigue and psychological distress in more cletall, to identify specific groups at risk, and subsequently, to design adequate preventive measures and strategies for intervention. either tailored for individuals of for specific risk groups. For the development of this integrated model, follow-up data on a wide range of possible risk factors and health outcomes, collected within the framework of the Maastricht Cohort Study, can be used.

Another aspect, which should be addressed in future research, concerns a more detailed investigation of the time course of cause and effect. In order to clarify the exposure time concepts of different risk factors (eg, immediate, delayed or cumulative effects), to specify the impact of exposure changes on future fatigue and psychological distress, and to evaluate the time course of fatigue and psychological distress, longitudinal studies using repeated exposure and outcome measurements during shorter and longer follow-up periods should be conducted. Specifically, future investigations should utilize designs in which effects of transitions, eg, the start of a new job or unexpected changes in job demands, can be detected, so that the onset of exposure as well as short-term and long-term effects of exposure changes can be estimated. 
In addition, further research should explore the temporal relationship between fatigue and psychological distress during a longer follow-up period and should compare associations between possible risk factors and either fatigue or psychological distress. This will not only provide more insight into the directions of causality and into etiologically distinct factors for fatigue and psychological distress, but will probably also lend more weight to the argument of the existence of two distinct undertying concepts, fatigue and psychological distress.

With a complete understanding of the multifactorial etiology of fatigue alnd psychologicai distress in the working population, a greater insight into the complex interplay of risk factors involved in the onset of fatigue and psychological distress, and more detaled information about the temporal relationship between fatigue and psychological distress, adequate prewentive measures and strategies for interventions can be developed for fatigue and psychological distress in the working population.

\section{REFERENCES}

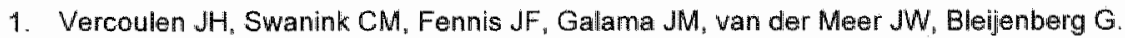
Dimensional assessment of chronic fatigue syndrome. J Psychosom Res 1994; 38:383-92.

2. Vercoulen JHHM, Alberts M, Bleijenberg $G$. De Checklisi Individuele Spankracht (CIS) The Checklist individual Strength (CIS)]. Gedragstherapie 1999;32:131-6.

3. Vercoulen $J H$, Hommes $O R_{n}$ Swanink $C M$, Jongen $P J$, Fennis $J F$, Galama JM, et al. Themeasurement of fatigue in patients with multiple sclerosis. A multidimensional comparison with patients with chronic fatigue syndrome and healthy subjects. Arch Neurol 1996;53:642-9.

4. Vercoulen $\mathrm{JH}_{\mathrm{H}}$, Swanink CM, Fenmis. JF, Galama JM, van der Meer JW, Bleijenberg G. Prognosis in chronic fatigue syndrome: a prospective study on the natural course. J Neurol Neurosurg Psychiatry 1996;60:489-94.

5. De Vries M, Soetekouw PMMB, Bleijenberg G, Wan der Meer JWM. Het Post-Cambodja Klachlen Onderzoek fase I: een inventariserend onderzoek naar aard, omvang en ontstaanswijze [The Post Cambodia Symptom Research Phase I: an inventory of the nature, the magnitude, and the etiology]. Nijmegen: AZN; 1998.

6. David A, Pelosi A, McDonald E, Stephens D, Ledger D, Rathbone R, et al. Tired, weak, or in need of rest: fatigue among general practice attenders. BMJ 1990;301:1199-202.

7. Pawlikowska T, Chalder T, Hirsch SR, Wallace P, Wright DJ. Wessely SC. Population based study of fatigue and psychological distress. BMU 1994:308:763-6.

8. Loge $\mathrm{JH}$, Ekeberg $\mathrm{O}$, Kaasa $\mathrm{S}$. Fatigue in the general Norwegian population: normative data and associations. I Psychosom Res 1998:45:53 65.

9. Dwyer CA. Cut scores and testing: Statistics, judgment, fruth, and error. Psychol Assess $1996 ; 8: 360-2$.

10. Goldberg DP, Williams P. A User's Guide to the General Health Questionnaire. Windsor: NFERNelson; 1988.

11. Koeter MWJ "Ormel J. General Health Questionnaire "Handleiding Nederlandse bewerking [General Health Questionnaire, Manual Dutch version]. Lisse: Swets \& Zeittinger; 1991.

12. Hickie IB, Hooker AW, Hadzi Pavtovic D. Bennett BK, Wilson A.l, Lloyd AR. Fatigue in selected primary care settings: sociodemographic and psychiatric correlates. Med J Aust 1996; 164:58:5-8.

13. Hardy GE, Shapiro DA, Borrill CS. Fatigue in the workforce of National Health Service Trusts: levels of symptomatology and links with minor psychiatric disorder, demographic, occupational and work role factors. J Psychosom Res 1997;43:83-92.

14. Karasek RA. Jab demands, job decision latitude, and mental strain: implications for job redesign. Adm Sci Q 1979;24:285-309.

15. Karasek $R$, Theorell $T$. Healthy Work: stress, productivity, and the reconstruction of working life New York: Basic Books: 1990. 
16. Landsbergis PA, Schnall PL, Deitz D, Fredman R. Pickering $T$. The patterning of psychological attributses and distress by "Job strain" and soclal suppont a sample of working men. J Behaw Med $1992: 15: 379 \times 405$

17. Stansfeld S, Feeney A, Head J, Canner Ri, North F, Marmot M. Sickness absence for psychiatric ilmes: the Whitehall II Study. Soc. Sci Med 1995:40:189-97

18. Stansfld SA, Fuhrer $\mathbb{R}$, Head d, Ferrie J., Shipley M. Work and psychtatric disorder in the Whitehall II Study. J Pisychosom Res $1997 ; 43: 73-81$.

19. Boubonnats $\mathrm{R}$, Brisson $\mathrm{C}$, Moisan J. Vezina M. Job strain and psychological distress in whitecollar workers. Scand 3 Work Environ Health $1996,22: 13945$.

20. Johnson JV. Hall EM. Job strain, work place social support and cardiovascullar disease: A crosssectional study of a random sample of the Swedisch working population. Am $\downarrow$ Public Health $1988,78: 1336-42$

21. Lewis $\mathrm{G}$, Wessely $S$. The epidemiology of fatigue: more questions than answers. J Epidemiol Community Health 1992;46:92-7.

22. Lennon MC. Work conditions as explanations for the relation between socioeconomic status, gender, and psychological disorders. Epldemiol Rew 1995;17:120-7.

23. Roxburgh S. Gender differences in work and well-being: Effects of exposure and vulnerability, $J$ Heallth Soc Behav $1996 ; 37: 265-77$

24. Spector PE. Method valiance as an artifact in self-reported affect and perceptions at work: Myth or significant problem? J Appl Psychol 1987:72:438-43

25. Williams Lu, Cote JA, Buckley MR. Lack of method variance in self-reported affect and peirceptions at work: Reality or artifact? Appl Psychol 1989:74:462-8.

26. Watson D, Clark LA, Telleglen A. Development and validation of brief measures of positive and neglative affect: the PANAS scales. J Pers Soc Psychol 1988;54:1063-70.

27. Spector PE, Zapf D, Chen PY, Frese M. Why negative affectivity should not be controlled in job stress research: Don't throw out the baby with the bath water. J Organ Behav 2000;21: 79-95.

28. Payne RL. Comments on "Why negative affectiwity should not be controlled in job stress research: Don't throw out the baby with the bath water" J Organ Behav 2000;21:97-9.

29. Frese M. Zapf D. Methodological issues in the study of work stress: Objectiwe vs subjective measurement of work stress and the question of longitudinal studies. In: Cooper CL, Payne R, editors, Causes, Coping and Consequences of Stress at Work. Chichester: Wiley; 1988. p. 375411.

30. Kasl SV. Measuring jab stressors and studying the health impact of the work environment: An epidemiologic commentary. J Occup Health Psychol 1998,3:390-401.

31. Watson D, Clark LA. Negative affectivity: the disposition to experience aversive emotional states. Prycthol Bull 1984;96:465-90

32. Parkes. KR. Personallity and coping as moderators of work stress processes: Models, methods and neasulles. Work Stress 1994;8:110-29.

33. Kas SV, Rapp SR. Stress, Heath, and Well-being: The Role of Individual Diferences. In: Cooper CL. Paym $R$, editors. Personality and Stress: Individual Differences in the Stress Process. Chichester: Willy: 1991. p. 269-284.

34. Grearthaus JH, Beutell NJ. Sources of conflict between work and family roles. Acad Manage Rew $1985 ; 10: 76-88$

35. Alleri TD, Herst DEL, Bruck CS, Sutton M. Consequences associated with work-to-family conflict: A rewiew and agenda for future research. J Occup thealth Psychol $2000 ; 5,278-308$. 


\section{SUMMARY}

Fatigue is a common symptom of ill-health. In recent years, fatigue in the working population has attracted attention in occupational (mental) health research, because it may interfere with an individual's performance and functioning in the occupational as well as in the thome setting. Moreover, because fatigue may also lead to sickness absenteeism and work disability, it is not only a social problem but also an economic problem calling for preventive action. This need for preventive measures and the absence of data about risk factors for the onset of fatigue has prompted the establishment of the Netherlands" concerted research action on "Fatigue at Work", granted by The Netherlands Organization for Scientific Research (NWO). This multidisciplinary, 6-year national research program was initiated in 1996 and includes medical and psychological research on acute and prolonged fatigue among employees. In 1998, as part of the Netherlands' concerted research action, the largescale epidemiological Maastricht Cohort Study of "Fatigue at Work" was set up 1) to gain insight into the prevalence and incidence of fatigue, 2) to examine risk factors involved in the onset and natural course of fatigue, and 3) to investigate the effectiveness of different treatments fatigue. The purpose of the study described in this thesis was to determine the prevalence and incidence of fatigue and psychological distress in the working population. and to identify risk factors for the onset of fatigue and psychological distress in the working population.

The rationale of the study presented in this thesis, the concept of fatigue, and the design of the Maastricht Cohort Study of "Fatigue at Work" are described in Chapter 1. In 1998, the large-scale prospective Maastricht Cohort Study of "Fatigue at Work" was started in the Netherlands. During the 3-year follow-up period, data on demographic factors, work-rellated factors, domestic and social factors, individual characteristics, and (mental) health outcomes. were obtained yearly by means of an extensive "mailed self-administered questionnaire. In addition to the yearly collection, follow-up data on (mental) health outcomes were gathered twice a year by a short, mailed self-administered questionnaire. In May 1998, a total of 26,978 male and female employees, aged 18 to 65 years, from 45 companies and organizations received a letter at home inviting participation and the self-administered baseline questionnaire. Altogether, 12,161 employees completed and returned the baseline questionnaire (response rate of $45 \%$ ). The final study population at baseline consisted of 12,095 employees: $8840(73 \%)$ men and $3255(27 \%)$ women. According to the Netherlands Standard Classification of Occupations 1992, a total of 687 different occupations were assigned to the study population at baseline.

Within the Maastricht Cohort Study of "Fatigue at Work", fatigue is measured with the Checklist Individual Strength (CIS), which was originally developed for hospital studies of chronic fatigue syndrome. The CIS is a 20 -item, easy to administer, self-report questionnaire and covers several aspects of fatigue, such as severity, concentration, motivation and physical activity. Because information about the use of the CiS in the working population and about a criterion to identify cases based on all subscales of the CIS was lacking, a pilot study was conducted by means of defined samples with differences in fatigue level. The validation of the CIS in the working population is described in the Appendix. The CIS was able to differentiate between samples with different fatigue levels, and seemed to be a suitable 
insitrument to measure fatigue in the working population. In Chapter 2, the detemination of a cis cutoff point for use in the working population is presented. A cutoff point for case classification of CIS $>76$ was defined, with a specificity of $90 \%$ and a sensitivity of $73 \%$. The determination of this cutoff point was based on high specificity, considering a minimum of false-positively classified healthy working employees, It was concluded that the defined cutoff point for fatigue seens to be appropriate for use in the working population.

Chapter 3 describes the relationship between fatigue and psychological distress in the working population. The chapter focuses on 1) the psychometric properties of the Checklist Individual Strength and the General Health Questionnaire (GHQ-12); which was used to assess psychological distress, 2) the prevalence of fatigue and psychological distress, and 3) the associations with demographic and health factors. In this study, we used the baseline data from 12,095 employees (8840 men, 3255 women), who participated in the Maastricht Cohort Study. Analyses revealed that fatigue was continuously distributed in the working population. Moreover, fatigue was fairly well associated with psychological distress $(r=0.62)$. In a principal component analysis, a separation between fatigue items and those describing psychological distress was shown. A total of $2595(22 \%)$ employees scored above the predefined cutoff point for fatigue. No difference between men and women was observed. For probable cases of psychological distress, however, a significant difference between men $(22 \%)$ and women $(26 \%)$ was found. No clear, distinct patterns of associations were observed for fatigue versus psychological distress regarding demographic and health factors. These findings indicate that fatigue and psychological distress are common in the working population. In addition, the findings suggest that fatigue and psychological distress, although closely associated, may be different conditions, which can be measured independently. As a consequence of the magnitude of fatigue and psychological distress, the need to further elucidate the concepts of fatigue and psychological distress, and the observed gender difference for psychological distress, it was decided to conduct subsequent anallyses for both health outcomes, fatigue and psychological distress, in men and women separately.

While the likely multifactorial etiology of fatigue is emphasized in the literature, with psychosocial (eg. work, family, and lifestyle) being the commonest reason for feeling fatigued, only very few studies have actually examined the relationship between psychosocial work characteristics and fatigue. In Chapter 4, cross-sectional associations between a wide range of psychosocial work characteristics and fatigue and psychological distress are presented. All information on psychosocial work characteristics was obtained from the baseline questionnaire. Psychological job demands, decision latitude, and supervisor/coworker support were measured with a Dutch version of the Job Content Questionnaire; emotional demands at work, physical demands at work, job insecurity, and conflict with supervisor/coworker were assessed with items from existing Dutch questionnaires. After exclusion of employees who reported themselves at baseline absent from work due to iliness or reported working under modified conditions related to former sickness absence, the analyses were based on 11,020 employees. Low decision latitude and low social support at work were associated with fatigue in men and women, even after adjustment for psychological distress. Associations were also observed between high emotional demands, job insecurity, physical demands, and conflict with supervisor and fatigue in men; and between high psychological job demands and canflict with coworker and 
Hatigue in women. In addition, analyses revealed some differential effects of psychosocial work characteristics on fatigue and psychological distress, which might lend weight to the argument that they are two different constructs. Although the present study has limitations related to the cross-sectional nature of its design, it was concluded that psychosocial work characteristics are associated with fatigue in both genders. For the development of effective preventive measures, however, it is important to identify the psychosocial lactors at work involved in the onsel of fatigue and psychological distress.

Chapter 5 describes the relationship between psychosocial work characteristics at baseline and the onset of fatigue and psychological distress after 1-year follow-up. The study population of the linear regression analyses consisted of 6522 men and 2311 women. In men, when controlled for baseline fatigue, psychological, physical and emotional demands at work, as well as conflict with coworker were significantly related to higher fatigue scores, whereas decision latitude was significantly associated with lower fatigue scores In women, only coworker support was significantly related to lower fatigue scores. The prospective associations between psychosocial work characteristics and psychological distress showed partly similar and partly distinct effects compared to fatigue. The cumulative incidence for fatigue during 1-year follow-up was $9.7 \%$ in men and $13.5 \%$ in women (for psychological distress $12.6 \%$ in men and $18.2 \%$ in women). After exclusion of fatigue cases at baseline, additional logistic regression analyses revealed that low decision latitude (OR (Odds ratio) 1.59 in men; OR 1.51 in women) and low coworker support (OR 1.45 in men; OR 1.78 in women) increased the risk for fatigue. The results also showed that conflict with coworker (OR 2.12) was strongly related to future fatigue in women. Moreover, high emotional demands (OR 1.47) were found to be related to the onset of fatigue in men. These associations were independent of baseline psychological distress. Our longitudinal findings provide support for the etiological role of psychosocial work characteristics in the onset of fatigue and psychological distress. The findings also suggest some differential effects of psychosocial work characteristics in the onset of fatigue versus psychological distress. It was concluded that good interpersonal relationships at work and high decision latitude might be relevant aspects that should be targeted in workplace interventions.

From the standpoint of developing preventive measures, occupations/job titles might help identify specific groups at risk and, in particular, might be an entree for intervention. In Chapter 6, differences in fatigue and psychological distress are presented across occupations. A total of 131 occupations, comprising 8521 employees $(77 \%$ of the baseline population), were studied. Additional information about the psychosocial work environment as perceived by the job occupant was incorporated. The analyses revealed considerable occupational differences regarding the prevalence of fatigue and psychological distress. Our results also showed that occupation, as a proxy index of the objective work environment. explained only $3.6 \%$ and $2.6 \%$ of the observed differences in fatigue and psychological distress, respectively. Overall, accupation addled relatively little explanatory information beyond the percelved measures of the work environment. It was concluded that the use of occupation exclusively seems to be an imadequate entree for intervention; instead, it is probably more appropriate to use supplementary information about the work environment as perceived by the job occupant. 
Besides the influence of the work environment, we explored the relationship between lifestyle factors at baseline and the onset of fatigue and psychological distress after 1-year follow-up (Chapter 7). Lifestyle factors included smoking, alcohol consumption, physical activity during leisure time, and the with lifestyle associated variable of body mass index. After exclusion of prevalent cases at baseline, the analyses were based on 5036 men and 1787 women for fatigue (5243 men and 1785 women for psychological distress). After adjustment for demographic factors, presence of disease, other lifestyle factors, psychosocial work characteristics, and baseline psychological distress, the results showed that being overweight (OR 1.33) and being physically inactive during leisure time (OR 1.33) were related to the onset of fatigue in men, whereas being underweight (OR 3.16) was associated with fatigue in women. For psychological distress in men, the odds ratio of the consumption of 15-21 glasses of alcohol per week, compared to the consumption of 1-14 glasses of alcohol per week, was 1.36. No relationship was found between lifestyle factors and the onset of psychological distress in women. It was concluded that some potentially modifiable lifestyle factors are independently related to the onset of fatigue and psychological distress in the working population. In particular, it seems advisable to stimulate physical activity during leisure time.

Chapter 8 reflects on the main findings of the preceding chapters and addresses some general methodological issues concerning the assessment and follow-up of exposure and outcome variables. At the end of this chapter, implications for occupational (mental) health and recommendations for further research are presented. It was concluded that the studies described in this thesis provide valuable insight into (the onset of) fatigue and psychological distress in the working population and offer useful indications for the development of preventive measures. However, our findings are not readily translatable into adequate preventive measures. To provide a sound basis for the development of adequate preventive measures and effective strategies for intervention, future research should further disentangle the multifactorial etiology of fatigue and psychologicall distress in the working population and should pay special attention to the complex interplay between psychosocial work characteristics, domestic and social factors, lifestyle factors, and individual characteristics. 


\section{SAMENVATTING}

Het onderzoek naar langdurige vermoeidheid in de arbeidssituatie wint de laatste jaren aan belangstelling amdiat vermoeidheid niet alleen het persoonlijk functioneren in de werksituatie en de privé-situatie beinwloedt maar ook kan leiden tot ziekteverzum en arbeidsongeschiktheid. Daarmee is langdurige vermoeidheid zowel een knellend sociaalmedisch probleem als een economisch probleem dat om preventieve maairegelen vraagt. De behoefte aan wetenschappelijk gefundeerde preventiestrategieën en het ontbreken van inzicht in risicofactoren voor het ontstaan en beloop wan vermoeidheid hebben in 1996 geleid tot de start van een Prioriteit Programma 'Psychische vermoeidheid in de arbeidssituatie' door de Nederlandse Organisatie voor Wetenschappelijk Onderzoek (NWO). In dit multidisciplinaire Prioniteit Progiramma worden medische en psychologische aspecten van acute en langdurige vermoeidheid bestudeerd. Als onderdeel van dit programma starte de Universiteit Maastricht in 1998 een grootschalig prospectief cohortonderzoek naar 'Langdurige vermoeidheid in de arbeidssituatie'. Dit cohortonderzoek is opgezet om inzicht te verkrijgen in 1) de omvang. 2) de risicofactoren in het ontstaan en beloop en 3) de diagnostiek en behandeling van langdurige vermoeidheid (verder in deze samenvatting aangeduid met vermoeidheid). Het uiteindelijke doel is te komen tot preventieve maatregelen. De studie beschreven in dit proefschrift is uitgevoerd in het kader van dit cohortonderzoek en heeft de volgende doelen: het onderzoeken van de prevalentie an incidentie van vermoeidheid en psychische klachten in een werkende populatie en hel identificeren van risicofactoren voor het ontstaan van vermoeidheid en psychische klachten in de arbeidssituatie.

In Hoofdstuk 1 staat het rationele van de studie, het concept van vermoeidheid en de opzet van de prospectieve Maastrichtse Cohort Studie naar "Vermoeidheid in de arbeidissituatie" centraal. Bij de beginmeting in mei 1998 werden 26.978 werknemers van 18 tot 65 jaar. afkomstig uit 45 verschillende bedrijven en instellingen, met een persoonlijke brief en een vragenlijst via de post woor deelname benaderd. In totaal retoumeerden 12.161 werknemers de eerste vragenlijst, een respons vain $45 \%$. De onderzoekspopulatie omvatte uiteindelijk 12.095 werknemers: 8840 (73\%) mannen en 3255 (27\%) vrouwen. De deelnemers werden drie jaar lang gevolgd. Gegevens over werk, privé-situatie, persoonskenmerken, vermoeidheid en de geestelijke gezondheid werden jaarlijks door middel van wragenlijsten op individueel niveau verzameld. Daarnaast werden vermoeidheid en andere uitkomstmaten met een korte vragenlijst om de vier maanden gemeten. Het beroep van de onderzoeksdeeinemers werd bij de beginmeting volgens de Nederlandse Standaard Beroepenclassificatie 1992 gecodeerd. In het cohort waren 687 verschillende beroepen vertegenwoordigld.

In het cohortonderzoek is vermoeidheid gemeten met de Checkllist Individuele Spankracht (CIS), een vragenlijst die oorspronkelijk ontwikkeid is voor het bestuderen van het Chronische Vermoeidheidssyndroom. De zelfgerapporteerde CIS omvat 20 vragen over verschillende aspecten van vermoeidheid zoals de emst van vermoeidheid, concentratie. motivatie en lichamelijke activiteit. Omdal bij de start van het cohortanderzoek geen ervaring aanwezig was met het gebruik wan de CIS in de beroepsbevolking en er geen afkappunt bestond voor het classificeren van vermoeide werknemers, werd een pilotstudie uitgevoerd. 
De Appendix bevat de resultaten wan het onderzoek naar de validiteit van de CIS in de beroepsbevolking. De pillotstudie toont aan dat de CIS in staat is vermoeide werknemers van miet vernoeide werknemers te onderscheiden. De belangrijkste conclusie is dat de CiS een geschikt instrument is voor het meten van vermoeidheid in de arbeidssituatie. In Hoofdstuk 2 wordt de bepaling van een CIS afkappunt voor gebruik in een werkende populatie gepresenteerd. Voor het classificeren van vermoeide werknemers is een afkappunt van CIS $>76$, met een specificiteit van $90 \%$ en een sensitiviteit van $73 \%$, vastgesteld. Dit afkappunt is bepaald op basis van een hoge specificiteit teneinde het aantal foutpositief geclassificeerde gezonde werknemers te beperken. Het vastgestelde afkappunt voor vermoeidheid is geschikt voor gebruik in de werkende bevolking.

Hoofdstuk 3 beschrifft de relatie tussen vermaeidheid en psychische klachten in een werkende populatie. In dit hoofdstuk worden de volgende aspecten belicht: 1) de psychometrische eigenschappen van de ClS en de General Health Questionnaire (GHQ-12), een instrument voor het meten van psychische klachten, 2) de prevalentie van vermoeidheid en psychische klachten en 3) relaties met demografische kenmerken en gezondheidsvartabelen. Analyses van de gegevens uit de beginmeting van het Maastrichtse cohortonderzoek tonen aan dat de relatie tussen vermoeidheid en psychische klachten aanzienlijk is $(r=0.62)$. In een principale componentenanalyse zijn vermoeidheidswragen onderscheiden van vragen betreffende psychische klachten. In totaal scoort $22 \%(n=2595)$ van de werknemers boven het afkappunt voor vermoeidheid. Er is geen significant verschil in prevalentie van vermoeidheid gevonden tussen mannen en vrouwen. Met betrekking tot psychische klachten blijkt wel een significant verschil in prevalentie tussen mannen $(22 \%)$ en vroumen $(26 \%)$ aanwezig te zijn. De relatie van demografische kenmerken en gezondheidswariabelen met vermoeidheid verschilt weinig van de relatie met psychische klachten. Op basis van deze resultaten is geconcludeerd dat vermoeidheid en psychische klachten veel voorkomen in de werkende bewolking. Daarnaast zijn er aanwijzingen gevonden voor het feit dat vermoeidheid en psychische klachten, ondanks hun duidelijke relatie, twee verschillende concepten zijn die onafhankelijk van elkaar kunnen worden gemeten. Daarom is besloten navolgende analyses apart voor vermoeidheid en psychische klachten uit te woeren.

Volgens de literatuur kent vermoeidheid een ontstaansgeschiedenis waarin verschillende risicofactoren kunnen worden onderscheiden. Psychosociale factoren (bijwoorbeeld werk, prive-situatie en leefwizze) worden vaak als reden voor vermoeidheid genoemd. Echter "de relatie tussen psychosociale werkkenmerken en vermoeidheid is nog weinig bestudeerd. Hoofdstuk 4 presenteert de resultaten van een cross-sectioneel onderzoek naar de relatie tussen een grote verscheidenheid aan psychosociale werkkenmerken en vermoeidheid en psychische klachten gemeten bij de beginmeting. Psychosociale werkkenmerken zoals taakeisen, regelmogelijkheden en ondersteuning van dagelikse leiding en collega"s zijn gemeten met een Nederlandse wersie van de Job Content Questionnaire. Voor het vaststellen van emotionele en lichamelijke belasting in het werk, toekomstonzekerheid en conflicten met dagelijkse leiding en collega's zijn vragen uit Nederlandse vragenlijsten gebruikt. De onderzoekspopulatie bestaat uit 11.020 werknemers (werknemers die bij de beginmeting verzuimden of aangepast werk vanwege eerder verzuim rapporteerden zijn uitgesloten). De analyses tonen, na correctie voor het hebben van psychische klachten, aan 
dat weinig regelmogelijkheden en weinig ondersteuning in het werk gerelateerd zijn aan vermoeidheid. De relatie tussen verschillende psychosociale werkkenmerken en vermoeidheid is anders voor mannen en vrouwen. Een hoge emotionele belasting. toekomstonzekerheid, lichamelijke belasting in het werk en conflicten met de dagelikse leiding laten bij mannen een relatie met vermoeidheid zien. Bij vrouwen zijn verbanden tussen hoge taakeisen en conflicten met collega's en vermoeidheid gevonden. Bovendien zijn tussen vermoeidheid en psychische klachten verschillen in de relatie met psychosocialle werkkenmerken vastgesteld. Dil geeft meer steun aan de hypothese dat vemoeidheid en psychische klachten twee verschillende concepten zijh. Hoewel dit voorliggende crosssectionele anderzoek zijn beperkingen kent, kan worden geconcludeerd dat psychosociale werkkenmerken een relatie hebben met vermoeidheid bij zowel mannen als vrouwen. Voor het ontwikkelen van preventieve maatregelen is echter meer inzicht in de risicofactoren voor het ontstaan van vermoeidheid en psychische klachten nodig.

Hoofdstuk 5 beschrijft de relatie in de tijd tussen psychosociale werkkenmerken. gemeten bij de beginmeting, en het ontstaan van vermoeidheid en psychische klachten gedurende een follow-up periode van een jaar. De cumulatieve 1-jaars incidentie van vermoeidheld is $9.7 \%$ bij mannen en $13.5 \%$ bij vrouwen (wan psychische klachten is dit $12.6 \%$ bij mannen en $18.2 \%$ bij vrouwen). Logistische regressie analyses onder werknemers, die bij de beginmeting geen vermoeidheid rapporteerden, laten een duidelijke relatie zien tussen weinig regelmogelijkheden in het werk (OR (odds ratio) 1.59 voor mannen; OR 1.51 voor vrouwen) en weinig ondersteuning van collega's (OR 1.45 voor mannen; OR 1.78 voor vrouwen) en het ontstaan van vermoeidheid. Bovendien is een sterke relatie gevonden tussen het rapporteren van conflicten met collega's en vermoeidheid bij vrouwen (OR 2.12); en tussen een hoge emotionele belasting in het werk en vermoeidheid bij mannen (OR 1.47). Deze relaties worden niet beinvloed door het hebben van psychische klachten bij de beginmeting. Bij een vergelijking van risicofactoren voor het ontstaan van vermoeidheid en het ontstaan van psychische klachten zijn deels gelijke maar deels ook andere factoren gevonden. Op basis van deze resultaten kan worden geconcludeerd dat regelmogelijkheden en ondersteuning in het werk belangrijke aspecten zijn in het ontstaan van vermoeidheid. Toekomstige interventies zouden zich hier meer op moeten richten.

In Hoofdstuk 6 worden verschillen in de prevalentie van vermoeidheid en psychische klachten tussen 131 beroepen, met daarin 8521 werknemers (77\% van de beginmeting). onderzocht. In de analyses is naast de variabele 'beroep' ook additionele informatie over psychosociale werkkenmerken, gemeten bij de beginmeting, meegenomen. De resultaten laten grote verschillen zien in de prevalentie van vermoeidheid en psychische klachten tussen de verschillende beroepen. De variabele 'beroep', die beschouwd kan worden als een index voor de objectieve werkomgeving, verklaarde $3,6 \%$ van de waargenomen verschillen in vermoeidheid en $2.6 \%$ van de waargenomen verschillen in psychische klachten. De resultaten tonen verder aan dat het beroep weinig extra verkiarende informatie geeft naast de belewingsmaten betreffende de werkomgeving. Er kan worden geconcludeerd dat informatie over het beroep alleen niet voldoende is voor het ontwikkelen van adequate interventies. Dit zou daarom moeten worden aangevuld met informatie over de beleving van de werkomgeving. 
Naast de invloed van psychosociale werkkenmerken is ook de relatie in de tijd wssen leefwilze, gemeten bij de beginmeting, en het ontstaan van vermoeidheid en psychische klachiten gedurende een follow-up periode van een jaar bestudeerd (Hoofdstuk 7). Het begrip 'leefwijze' omwat roken, alcohol consumptie, lichamelijke activiteif buiten het werk en de, aan de leefwijze gerelateerde, Quetelet-index. De onderzoekspopulatie voor deze analyses bestaat uit werknemers die bij de beginmeting geen vermoeidheid "respectievelijk geen psychische klachten, rapporteerden. Na correctie voor o.a. gezondheid, psychosociale werkkenmerken en psychische klachten bij de beginmeting, laten de resultaten bij mannen een duidelijke relatie tussen zowel overgewicht (OR 1.33) als het rapporteren van geen lichamelijke activiteit buiten het werk (OR 1.33) en het ontstaan vain vermoeidheid zien. Bij vrouwen is een sterke relatie gevonden tussen ondergewicht (OR 3.16) en het ontstaan van vermoeidheid. Daamaast laat de consumptie van 15-21 glazen alcohol per week (OR 1.36), vergeleken met de consumptie van 1-14 glazen alcohol per week, een relatie zien met het ontstaan van psychische klachten bij mannen. Bij vrouwen zijn geen relaties tussen leefwijze en het ontstaan van psychische klachten gevonden. Op basis van deze resultaten kan worden geconcludeerd dat bepaalde aspecten valn de leefwijze risicofactoren zijn voor het ontstaan van vermoeidheid en psychische klachten. Het stimuleren van lichamelijke activiteit buiten het werk kan daarom een belangrijk aspect zijn waaraan in toekomstige interventies aandacht moet worden besteed.

In Hoofdstuk 8 worden de resultaten van de studies in het kader van de doelstellingen van dit proefschrift nader beschouwd. Er wordt ook aandacht besteed aan algemene methodologische kwesties betreffende het meten en de follow-up periode van expositie- en uitkomstmaten. Bovendien worden implicaties voor de praktijk en aanbevelingen voor toekomstig onderzoek gepresenteend. Samenvattend wordt geconstateerd dat de studies hier beschreven een waardevol inzicht verschaffen in (het ontstaan van) vermoeidheid en psychische klachten in een werkende populatie en er worden aanknopingspunten geboden voor het ontwikkelen van preventieve maatregelen. Er moet echter worden opgemerkt dat deze bevindingen niet direct kunnen worden vertaald in adequate preventieve maatregelen. Voor het ontwikkelen van adequate preventieve maatregelen en effectieve interventiestrategieen zal in toekomstig onderzoek de multifactoriële ontstaansgeschiedenis van vermoeidheid en psychische klachten verder bestudeerd moeten worden. Daarnaast zall er aandacht moeten worden geschonken aan de complexe interacties tussen werk, privésituatie, leefwijze en individuele kenmerken. 


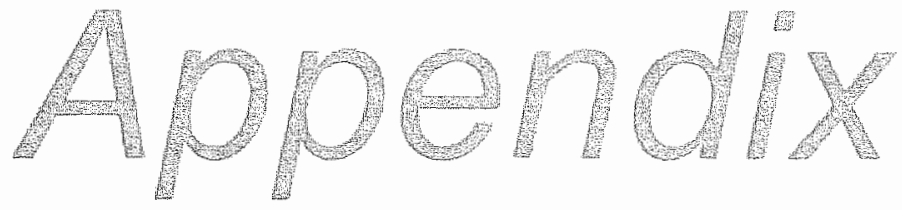

Fatigue among working people: validity of a questionnaire measure

Anna J.H.M. Beurskens ${ }^{\mathrm{a}}$, Ute Bültmann ${ }^{\mathrm{a}}$, I.Jmert Kant ${ }^{\mathrm{a}}$, Jan H.M.M. Vercoulen ${ }^{\mathrm{b}}$; Gijs Bleijenberg'; Gerard M.H. Swaen ${ }^{\text {th }}$

aDepartment of Epidemiology, Maastricht University, Maastricht, the Netherlands ${ }^{b}$ Department of Medical Psychology, University Hospital Nijmegen, Nijmegen, the Netherlands

Occupational and Environmental Medicine 2000;57:353-357 


\section{ABSTRACT}

Objectives: To evaluate the validity of the Checklist Individual Strength questionnaire (CIS) in the working population. This 20 item self reported questionnaire has often been used in patients with chronic fatigue. To date, no research has focused on the validity af the CIS in occupational groups. Methods: To evaluate the discriminant validity the CIS was filled out by five groups of employees with expected differences in fatigue. The convergent validity was evaluated by comparing the results of the CIS with the results of three related measures: unidimensional measured fatigue, bumout, and need for recovery. Results: The CIS was able to discriminate between fatigued and non-fatigued employees in occupational groups. The expected agreement between the results of the CIS and related measures was confirmed. Conclusions: The CIS seems to be an appropriate instrument for measuring fatigue in the working population. 


\section{INTRODUCTION}

Fatigue at work is a normal everyday experience. However, in the case of severe fatigue it may affect the person's performance in the occupational as well as the home setting. Moreover, severe long term fatigue may lead to sick leave and work disability.

In The Netherlands about one in every three recipients of work disability benefit is classified as occupationally disabled on mental grounds. "They have an "exogenous reaction" "which is the official diagnosis that includes chronic job stress and burnout - that is, a mental state closely related to mental fatigue. In 1996 a large scale national concerted research action on fatigue at work was initiated in The Netherlands. This multidisciplinary research programme includes psychological and medical research and is supported by grants from the Netherlands Organisation for Scientific Research (NWO), universities, occupational health services, private research institutes, trade unions, and business. ${ }^{3}$

Within the research programme fatigue is defined as: "The change in the psychological control mechanism that regulates task behaviour, resulting from preliminary mental and/or physical efforts which have become bothersome to such an extent that the individual is no longer able to adequately meet the demands that the job requires on his or her mental functioning, or that the individual is able to meet these demands only at the cost of increasing mental effort and the surmounting of psychic resistance ${ }^{\text {m }} .^{3}$

We see fatigue, in line with Lewis and Wessely, ${ }^{4}$ as a subjective sensation with emotional, behavioural, and cognitive components. There is an essential difference between acute fatigue and long term fatigue. Acute fatigue is characterised by reversibility, task specificity, and the functional use of compensation mechanisms. Acute fatigue is a normal phenomenon that disappears after a period of rest, when tasks are switched, or when particular strategies are used-for example, working at a slower pace. By contrast, long term fatigue is irreversible, not task specific, and the compensation mechanisms that were useful in reducing acute fatigue are no longer effective.

To gain more insight in the aetiology and prognosis of long term fatigue at work one of the research programmes within the national concerted research action studies is the epidemiology of long term fatigue. A large scale longitudinal prospective cohor study was started in May 1998. The cohort study surveys a heterogeneous population of over 12000 employees from different companies and organisations. The follow up is 3 years. Data on work related, psychological, social, physical and behavioural factors, as well as on the health outcomes fatigue, bumout, need for recovery, and sick leave were collected by means of self administered questionnaires and sick leave administrations systems.

Instruments available to assess fatigue can be divided into unidimensional instruments and multidimensional instruments. According to Smets et af the use of unidimensional instruments excludes the possibility of a more complete description of fatigue. The wording of a single question can introduce substantial difference and may emphasise only one dimension of fatigue. Within the cohort study we have chosen for a multidimensional assessment of fatigue.

The multidimensional Checklist Individual Strength questionnaire $(\mathrm{CIS})^{7-11}$ was used to measure chronic fatigue (see appendix). The CIS was designed to measure several aspects of fatigue which is in line with our definition of fatigue. It consists of four dimensions: the subjective experience of fatigue and reduction in motivation, reduction in activity and reduction in concentration. The CIS was tested thoroughly in the clinical setting among 
patients with chronic latigue syndrome and other chronic diseases and healthy controls. ${ }^{7-11}$ The internal consistency of the CIS seemed to be good: Chronbach's a for the total CIS was 0.90 and for the scaies the a ranged from 0.83 to 0.92 . $^{11}$ The ClS was able to discriminate between patients with chronic fatigue syndrome, patients with multiple sclerosis, and healthy controls and the conwergent validity was also satisfying. ${ }^{3}$

There is, however, no work to date that focuses on the validity of the CIS in the working population. For that reason, a validity study was conducted. The aim of this study was to evaluate the ability of the multidimensional CIS in classifying employees according to their level of fatigue. The cis was filled out by five groups of employees with expected differences in fatigue: two groups of healthy employees, two groups of employees with a somatic reason for fatigue, and one group with a mental reason for fatigue. Also, the scores on the CIS in the working groups were compared with a reference group of patients with chronic fatigue syndrome. Our hypotheses were that the employees with a mental reason for fatigue and the employees wilh a somatic reason for fatigue would score higher on all dimensions of the CIS than the healthy employees. The convergent validity of the CIS was evaluated by comparing the results of the CIS with the results of three related measures: fatigue measured on a unidimensional five point Likert scalle, burnout, and need for recovery. Burnout is a mental state which can be regarded as an extreme expression of long term fatigue. ${ }^{12}$ The employees' need for recovery ${ }^{\prime 3}$ can be considered as a mediating or moderating characteristic in the aetiology of fatigue.

\section{SUBJECTS AND METHODS}

\section{Study population}

To evaluate the ability of the CIS to discriminate between fatigued and non-fatigued subjects we formed five sets of employees with expected differences in fatigue: two sets of healthy employees, two sets of employees with a somatic reason for fatigue, and one set with a mental reason for fatigue. All employees were employed for $\geq 20$ hours a week.

The first group of employees consisted of 37 healthy white collar workers with mental work, mostly working at a university. The second group consisted of 38 healthy blue collar workers with industrial work. These employees performed heavy, dirty work in an iron foundry. We asked the healthy employees to fill out the questionnaire. The third group compared 38 patients who had an operation for low back pain hernia. The physiotherapists in attendance asked the patients to fill out the questionnaire 5-7 days after the operation. The fourth group of employees were pregnant women $(n=47)$. The median duration of the pregnancy was 27 weeks. Their midwives asked if they wanted to participate in the study. The third and fourth groups had a somatic reason for fatigue. Company doctors and insurance doctors selected the fifth group with a mentall reason for fatigue. We asked the doctors to select employees with a mental reason for fatigue and to exclude employees with psychiatric illness. The doctors asked eligible patients to fill out the questionnaire. In total, 59 employees with a mental reason for fatigue returned the questionnaire. For privacy reasons we do not know the exact diagnosis of these subjects. 
Table I Characteristics of the amployees

\begin{tabular}{|c|c|c|c|c|c|}
\hline & $\begin{array}{l}\text { Whilse } \\
\text { colltar }\end{array}$ & $\begin{array}{l}\text { Blue } \\
\text { collat }\end{array}$ & $\begin{array}{c}\text { Somatic after } \\
\text { hernia }\end{array}$ & $\begin{array}{l}\text { Somiatic } \\
\text { pregnant }\end{array}$ & Mental \\
\hline Age (mean (SD) & $35(6.4)$ & $35.8(8.9)$ & $43(7.4)$ & $31(2.7)$ & $44(0.1)$ \\
\hline Sex (\% female) & $51 \%$ & $3 \%$ & $37 \%$ & $100 \%$ & $46 \%$ \\
\hline Supervisor (\% yes) & $24 \%$ & $16 \%$ & $32 \%$ & $23 \%$ & $14 \%$ \\
\hline Education level" (mediam) & 7 & 2 & 3.5 & 6 & 6 \\
\hline Sick leave $(\%)$ & $0 \%$ & $0 \%$ & $100 \%$ & $13 \%$ & $68 \%$ \\
\hline Hours wark & 40 & 41 & 39 & 32 & 35 \\
\hline
\end{tabular}

* Scored on a 7 point scale: lowest education is primary school (1), highest educatoon is uniwetsity (?)

Table 1 shows the characteristics of the five groups of employees. The groups were different on some characteristics but most differences were related to the selection of the groups - for example, sex in the group of pregnant women. However, the education level in the fifth group was high. This can be explained by the fact that the employees in this group were mainly white collar workers.

\section{Questionnaire}

All 219 employees received a self administered questionnaire which contained questions about demographic factors, fatigue, burnout, need for recovery, and sick leave. The CIS was used to measure fatigue, it consists of 20 statements for which the person has to indicate on a 7 point scale to what extent the particular statement applies to him or her. ${ }^{7}$ The statements refer to aspects of fatigue experienced during the previous 2 weeks. The number of items per dimension varies. The dimension "subjective fatigue" has eight items - for example, I feel tired - "reduction in motivation" four items - for example, I feel no desire to do anything -.. "reduction in activity" three items - for example, I don't do much during the day - and "reduction in concentration" five items - for example, My thoughts easily wander. Also, by adding the four dimensions a CIS total score can be calculated. Higher scores indicate a higher degree of fatigue, more concentration problems, reduced molivation and less activity. Fatigue was also measured on a unidimensional five point Likert scale. Employees were asked to rate their perceived fatigue during the previous 2 weeks, ranging from "very often" to "rarely or never".

Burnout was measured with the Maslach Burnout Inventory-General Survey (MBI-GS). The Maslach Burnout Inventory was originally developed to measure burnout in human service providers. ${ }^{2}$ Recently, a measure of burnout was developed which can be used also in other occupations, the MBI-GS. ${ }^{12.15}$ This MBL-GS has three subscales that parallel the MBI: exhaustion, cynicism and professional efficacy. The exhaustion items are generic, without the MBl's emphasis on emotions and without direct reference to service recipients. The items include references to both emotional and physical fatigue. The items of the subscale cynicism reflect indifference or a distant attitude toward work itself. A strong degree of exhaustion, cymicism and a low degree of professional efficacy are indicative for the syndrome burnout. ${ }^{15}$ The need for recovery was measured with six items from a validated 
Dutch questionnaire about psychosocial job demands on job stress. ${ }^{13}$ The questions asked about the situation at the end of a working day - for example, if the employees still feel fresh after supper or if they are able to relax only on a second day off.

\section{Analyses}

All data analyses were done with SPSS statistical software. ${ }^{16}$ To gain insight in the discriminant validity, differences among the five groups of employees for the four dimensions of the CIS were calculated with univariate analyses of wariance (ANOVA). Because we are especially interested in the differences between the healthy employees and the employees with a somatic reason for fatigue on the one hand and the mental group on the other, we evaluated whether these differences were significant with a Bonferroni correction (a 0.05). One way analyses of cowariance (ANCOVA) was used to adjust for differences in age, sex, and education of the employees.

To evaluate the convergent validity, the differences among the five groups of employees for the three related measures was compared with the discriminant results of the CIS. We expected that the agreement between the dimensions of the CIS and the scale exhaustion of the MBI-GS would be better than with the scales cynicism and professional efficacy, because these scales measure other aspects of work. Also, to evaluate the relation between CIS total and the scale exhaustion of the MBI-GS in the group of employees with a mental reason for fatigue we made a scatterplot and calculated the Pearson correlation coefficient.

\section{RESULTS}

\section{Discriminant validity}

Table 2 shows the mean (SD) of the groups of employees on the dimensions of the CIS. Figure 1 shows the distribution of the scores graphically. The employees with a mental reason for fatigue scored systematically higher on all dimensions of the CIS. Also, the employees with somatic reasons for fatigue had higher scores than the healthy employees. For the dimensions reduction in motivation and concentration, and for the total CIS the differences between the group with a mental reason for fatigue and all the other groups were significant.

Table 2 Scores on the dimensions of the CIS (means (SDY) in the groups of employees and pualues ior the differences with the mental group (Bonteironi correction)

\begin{tabular}{|c|c|c|c|c|c|c|c|c|c|}
\hline & $\begin{array}{l}\text { White collar } \\
(n=37)\end{array}$ & p Value & $\begin{array}{l}\text { Blla collar } \\
(n=38)\end{array}$ & p Valle & $\begin{array}{l}\text { After hemia } \\
(n=38)\end{array}$ & p Value & $\begin{array}{l}\text { Pregnarit: } \\
m=47\end{array}$ & p Value & $\begin{array}{l}\text { Mential } \\
(n=59)\end{array}$ \\
\hline Subj. latigute & $20.3(10.1)$ & 0.00 & $21.9(11.4)$ & 0.00 & $329(11.7)$ & 0.07 & $339(130)$ & 0.14 & $39.6(12.1)$ \\
\hline Activity & $60(27)$ & 0.00 & $5.6(3.0)$ & 0.00 & $9.4(5.2)$ & 0.26 & $8.9(5.0)$ & 0.04 & $11.6(5.7)$ \\
\hline Motivation & $93(4.8)$ & 0.00 & $9.9(5.1)$ & 0.00 & $11.2(5.5)$ & 0.00 & $(3.3(6,0)$ & 0.00 & $17.8(6.6)$ \\
\hline Concentration & $120(5.0)$ & 0.00 & $9.9(5.4)$ & 0.00 & $14.4(5.8)$ & 0.00 & $44.6(6.8)$ & 0.00 & $20.7(8.3)$ \\
\hline CIStotal & $473(198)$ & 0.00 & $47.3(18.9)$ & 0,00 & $67.7(23,5)$ & 0.00 & $70.7(24.9)$ & 0.00 & $89.7(26.2)$ \\
\hline
\end{tabular}

Subjective fatigue (8 items), Activity (3 items), Motivalion (4 items), Concentration (5items), Cis total (20 items) 


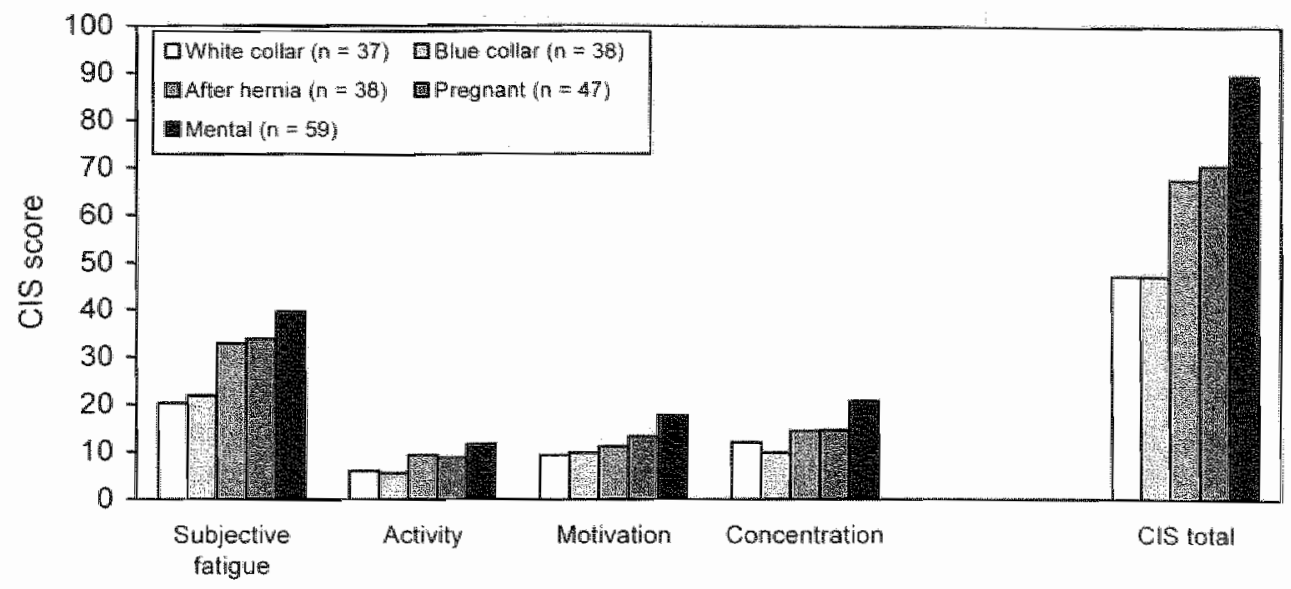

Figure 1. CIS scores in different groups of the working population.

The scores on the CIS in the working groups were compared with a reference group of 748 patients with chronic fatigue syndrome from a sfudy of Vercoulen et al. ${ }^{7}$ The mean scores of patients with chronic fatigue syndrome were for subjective fatigue 51.7 , reduction in activity 16.9, reduction in motivation 17.0, reduction in concentration 27.5 , and for CIS total 113.1. ${ }^{7}$ These scores were substantially higher than the scores of healthy employees and employees with a somatic reason for fatigue. Except for the dimension reduction in motivation, these scores were also higher than the scores of the employees with a mental reason for fatigue. Table 1 shows that the education level of the employees in the group with a mental reason for fatigue was high. We corrected for the effect of education, age, and sex with ANCOVA. However, the adjustments were not significantly different and only slightly changed the CIS scores.

Table 3 Scores on the dimensions of the MBH-GS, meed for reconery and fatigue (mean (SD)] in the chroups of enployeses and $p$ walues for the differences with the mental group (Bonferronil correction)

\begin{tabular}{|c|c|c|c|c|c|c|c|c|c|}
\hline & \multicolumn{2}{|l|}{ White collar } & \multicolumn{2}{|l|}{ Btwe collar } & \multicolumn{2}{|l|}{ After lyornia } & \multicolumn{2}{|l|}{ Prognani } & \multirow{2}{*}{$\begin{array}{l}\text { Mentat } \\
(n=59)\end{array}$} \\
\hline & $(n=37)$ & p Value & $(n=38)$ & pivalue & $n=38$ & pratue & $(n=47)$ & p Value & \\
\hline MDI-GS Exhaustion & $9.7(1.0)$ & 0.00 & $1.7(1.2)$ & 000 & 1.811 .01 & 0.00 & $20(1.3)$ & 000 & $36(1,5)$ \\
\hline MBP-GS Cynicism & $1.4(0.9)$ & 0.00 & $1.7(1.2)$ & 0.18 & $H(B, 1]$ & 0.19 & $1.5(1.1\}$ & 0.00 & $2.3(1.3)$ \\
\hline Ale!-GS Prol. efficacy & $42(0.9)$ & 1.0 & $4.0(1.2)$ & 1.0 & $4.4(1,0)$ & $0.5 \%$ & $4.4(0.8)$ & 0.17 & $4.0(1.0)$ \\
\hline Fatigue, unidimensional & $2.6(0.7)$ & 0.00 & $24(1.1)$ & 0.00 & 3.11 .07 & 0.02 & $3.8(1,0)$ & 1.0 & $3.8(1.0)$ \\
\hline Need for 5ecovery & $0.28(0.28)$ & 0.00 & 0.4 .40 .304 & 0.00 & $0.34(0.31)$ & 0.00 & $0.42(0.33)$ & 0.00 & $0.77(0.27)$ \\
\hline
\end{tabular}

MBI-GS= Maslach Bumout Invenlory-General Survoy 


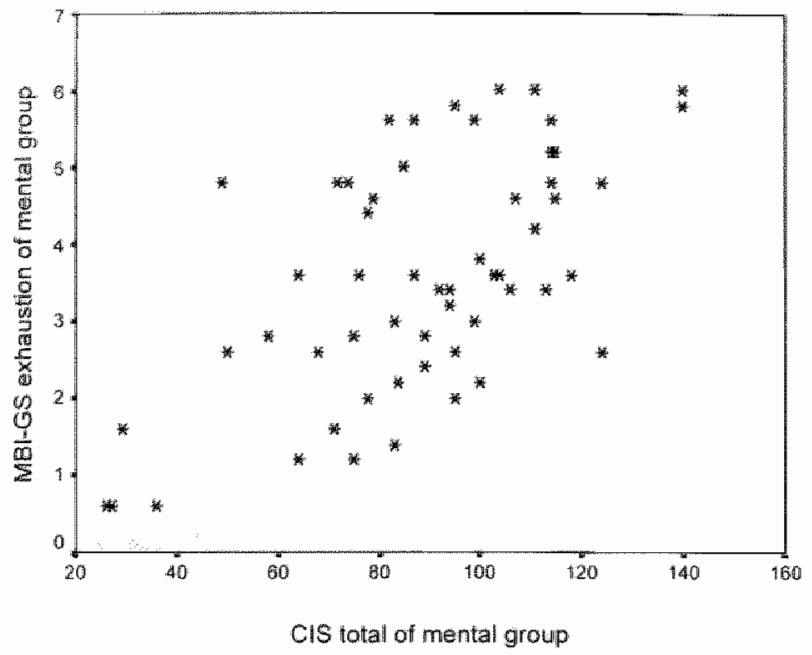

Figure 2. Scatterplot of CIS total and MBI-GS exhaustion of mental group $(n=59)$. Pearsons correiation coefficient $=0.62$

\section{Convergent validity}

Table 3 shows the results of the MBI-GS, unidimenisional fatigue, and need for recovery in the five groups. Except for the scales cynicism and professional efficacy of the MBI-GS, the scores in the mental group were higher than the scores in the other groups. For the scale exhaustion of the MBI-GS and for need for recovery the differences between the mental group and all the other groups were significant. These results correspond to a large extent to the discriminant results of the CIS. Figure 2 shows the scatterplot of CIS total and the subscale exhaustion of MBI-GS in het group of employees with a mental reason for fatigue. The corresponding correlation coefficient was 0.62 .

\section{DISCUSSION}

The aim of this study was to evaluate the ability of the multidimensional CIS to classify study subjects according to their level of fatigue. It seemed that the CIS was able to discriminate adequately between fatigued and non-fatigued employees in occupational groups. The results of the CIS were comparable with the results of three related measures: fatigue measured on a unidimensional five point Likert scale, the scale exhaustion of the MBI-GS, and need for recovery. Also, the correlation between CIS total and the scale exhaustion of the MBI-GS in the mental group was in the expected direction and high.

No gold standard exists for fatigure. Therefore, we will never be able to prove the validity of instruments measuring fatigue. In the absence of a gold standard, direct comparisons of methods of measuring fatigue with related and existing measures are needed. In this study we compared the discriminant ability of the CIS with discriminant abilities of related measures. 
It was noticeable that the group of employees with a mental reason for fatigue scored systematically higher on all dimensions of the CIS than the groups of employees with a somatic reason for fatigue. We do not know how severe the mental reason was or if these subjects also had somatic complaints. However, we noted that the scores of the patients with chronic fatigue syndrome were substantially higher for most of the dimensions than the scores of the employees with a mental reason for fatigue.

The groups of employees with expected differences in fatigue were chosen carefully. The CIS was able to discriminate between these groups. If the CIS had not been able to discriminate between these selective groups then, we anticipated, it would certainly not be able to discriminate between less different groups.

According to Kirshner and Guyatt ${ }^{17}$ questionnaires can be used for three purposes: (a) discriminating among subjects, (b) predicting prognosis, and (c) evaluating change over time. Questionnaires with different purposes require different measurement properties. ${ }^{17}$ In this study we found evidence for a satisfactory discriminating ability of the CIS. In other studies the CIS seemed to be able to measure change in fatigue scores in groups as well as in individuals in randomised controlled trials and over a longer period..$^{9.10}$

We conclude that the $\mathrm{CHS}$ is able to discriminate between groups with expected differences in fatigue. The CIS seems to be an appropriate instrument for measuring fatigue in the working population.

\section{ACKNOWLEDGMENTS}

This project was performed within the National research programme on "Fatigue at Work" supported by The Netherlands Organisation for Scientific Research (NWO). We thank T van Attekum, B Bakx, M Engelen, A Köke, J Slangen, K Schröer, S Verheyen, S Wijnen, and the midwives of Obstetric Center Maastricht for their assistance in data collection.

\section{REFERENCES}

1. Houtman ILD, ed. Trends in arbeid en gezondheid 1996. (Trends in work and health 1996). Amsterdam: NIA/TNO, 1997.

2. Eck MAA van, De diagnosestelling "Categorie $V$ ". (The diagnose "Category V"). In: Bijl $R_{i}$ Bauduin $D$, eds. Categorie $V$ : Arbeidsongeschikt wegens psychische stoornissen. (Category V: disabled because of mental disorders). Utrecht: NoGV, 1991.

3. Meijman T, Schaufeli WB. Psychische vermoeidheid en arbeid. (Fatigue at work). De Psycholoog 1996; june:236-41.

4. Lewis $G$, Wessely $S$. The epidemiology of fatigue: more questions than answers J Epidemiol Community Health 1992;46:92-7.

5. Withdrawn.

6. Smets EMA, Garssen $G$, Bonke $B$, et al. The multidimensional fatigue inventory (MFI) psychometric qualities of an instrument to asserss fatigue. J Psychosom Res 1995;39:315-25

7. Vercouten JHIMMM, Swanink CMA, Fennis. JFM, et al. Dimeinsional assessment of chronic fatigue syndrome. J Psychosom Res 1994:38:383-92.

8. Vercoulen JHMMM, Hommes OR, Swanink CMA, et al. The measurement of fatigue in patients with multiple sclerosis: a multidimensional comparison with patients with chronic fatigue syndrome and healthy subjects. Arch Neurol 1996,53:642-9. 
9. Vercouten JHMM, Swanink CMA, Fennis JFM, el al. Prognosis in chronic fatigue syndrome: a prospective study on the natural course. J Neurol Neurosurg Psychiatry 1996;60:489-94

10. Vercoulen JHMM, Swanink CMA, Zitman FG, et al. Fluoxetine in chronic fatigue syndrome: randomized, double blind, placebo-controlled study. Lancet 1996;347:858-61.

11. Vercoulen JHMM, Alberis M, Bleijenberg G. De Checklist Hndividuele Spankracht (CIS). (The Checklist Individual Strength (CIS)). Gedragstherapie 1999;32:131-6.

12. Schatfeli WE, Leiter MP, Kalimo R. The General Burnout Inventory: a self-report questionnaire to assess burnout at the workplace. In: MP Leiter, ed. Extending the Bumout construct reflecting changing career paths. Symposium. APANNIOSH conference. Work Stress and Health 1995.

13. Veldhoven M van, Meijmam TF. Het meten van psychosocialle arbeidsbelasting met een vragenilist: de Vragenlijst Beleving en Beoordeling van de Arbeid (VBBA) (Questionnaire on psychosocial job demands and job stress). Amsterdam: NIA, 1994.

14. Maslach C. Jackson SE, Leiter MP. Maslach Bumout Inventory manual, 3rd ed. Palo Alto, CA: Consulting Psychologists Press, 1996.

15. Leiter MP, Schaufeli MB. Consistency of the burnout construct across occupations. Anxiety Stress and Coping 1996:9:229443.

16. Norusis MJ. SPSS for windows. Base system user"s Guide Release 7.0. Chicago: SPSS, 1997.

17. Kirshner B, Guyatt GH. A methodological framework for assessing health indices. J Chron Dis $1985 ; 38: 27-36$ 


\section{CIS20R \\ Cherkist Individual Strongth \\ University Hosphat Numegen \\ Department of Medical Psychology}

\section{Instruction:}

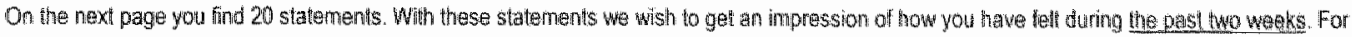
example:

\section{Ileel relaxed}

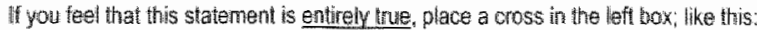

lleed relaxed

yes, that is wue

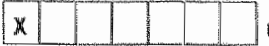

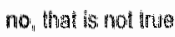

It you leel that this statement is not true at all. place a cross tit the right box: like this:

H teet resared

yes, that is true

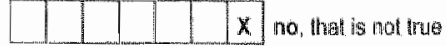
If you feel that this statement is not "yes, that is true", but atso not "no, that is not rue", place a cross in the box that is mast in accordonce willth how you have, fell.

For example, if you feel pelaxed, but not very relaxed, place a cross in one of the boxes close to "yes, that is that: 酸e this:

I feet relaxed

Do not skip any statement and place only one cross for each slatement.

1. feel tired

2. Ileel wery active

3. Thinking requires effort

4. Physicaliyl feel exhausted

5. feel like doing all kind of nice things

6. $\|$ feel fit

7. Ido quile a lot within a day

8. When I am doing someshing, I can concentrate quite well

9. I foel weak

10. Idon't do much during the day

11. I can concentrate well

12. lieet rested

13. I have trouble to concentrate

14. Physically f feel I an in a bad condition

15. I an full of plans

16. I am tifed wery quickly

17. I have a bow output

18. I leet fno desire to co anything

19. Wy thoughts easty wander

20. Physically feel th a good shape yes, that is thie

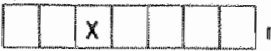
no, Hiat is nou trug yes, that is lowe yes, that is frue yes, that is the yes, that is true yes, that is true yes, that is true yes, that is true yes, that is true yes, that is true yes, that is true yos, that is true yes, that is true yes, that is true yes, that ic true yes, that is true yes, that is trae yes, that is true yes, that is lfue yers, hat is incue yes, that is true

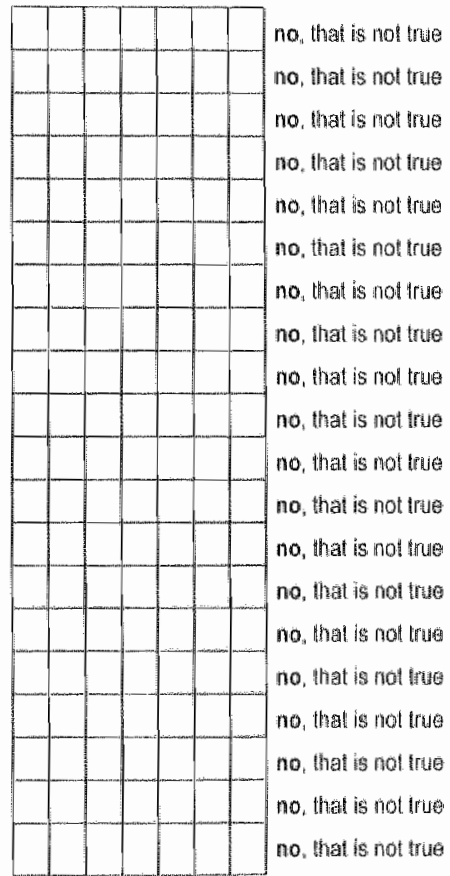

\section{SCORING CIS2OR}

For the iterns, $2,5,6,7,8,11,12,15,20$ is the scoring as follows

For the itens: $1,3,4,9,10,13,14,16,17,18,19$ is the scoing as follows:

yes, that is the \begin{tabular}{|l|l|l|l|l|l|l}
\hline & 2 & 3 & 4 & 5 & 6 & 7 \\
\hline
\end{tabular} yes. that is true \begin{tabular}{ll|l|l|l|l|l|l}
$i$ & 6 & 5 & 4 & 3 & 2 & 1
\end{tabular} no, that hot not the Subseguently the four subscales are calculated by summing the respective items

subscale 1: Subjective feeling of fatigue

subscale 2: Concentration

subscale 3: Hotivation

subscale 4: Physical activity items $1,4,6,9,12,14,16,20$

items $3,4,11,13,19$

Hens $2,5,45,4$,

Hems $7,10,17$ 


\section{ACKNOWLEDGEMENTS}

'The work is done'. Het zal duidelijk zijn dat het uitwoeren van dit onderzoek naal vermoeidheid, zonder daarbij zelf vermoeid te raken, alleen mogelijk was met de huip, 'support' en 'Rat und Tat' van een groot aantal mensen. Daarom wil ik hier ledereen die een bijdrage heeft geleverd aan de uitwoering wan het onderzoek en de totstandkoming van dit proefschrift hartelijk danken.

Een bijzonder woord van dank wil ik richten aan IJmert Kant, mijn co-promotor. Beste IJmert, je hebt jouw rol als begeleider voor mij op een zeer stimulerende en plezierige wijze meer dan waargemaakt. Jouw deskundige en enthousiaste begeleiding bij het onderzoek en het schrijven van dit proefschrift, jouw vertrouwen en jouw steun in goede en in slechte tijden waardeer ik enorm. Mijn dank is groot.

Ook Stanislav $V$. Kasl en Piet van den Brandt, mijn promotoren, wil ik hartelijk danken voor hun bijdragen. I owe my very special thanks to Stanislav $V$. Kasl, who invited me to come to New Haven and work with him at the Department of Epidemiology and Pubiic Health, Vale University School of Medicine. Dear Stan, thank you for the encouragement, inspiration and the valuable discussions in the process of conducting and writing this dissertation. Your critical view towards my work and your transatlantic support have been very important to me. 1 also want to thank you for taking the time to come to Maastricht as a member of the committee. Beste Piet, je zag jouw rol zelf vooral als promotor op de achtergrond maar vanuit die rol heb je een zeer constructieve bijdrage aan de totstandkoming van dit proefschrift geleverd. I $\mathrm{k}$ will je van harte danken voor jouw frisse kijk op het project, jouw vertrouwen en de plezierige samenwerking.

De in dit proefschrift beschreven studies zijn gebaseerd op een grote groep mensen uit de werkende bewolking. Mijn dank gaat dan ook uit naar de meer dan 12.000 werknemers die hebben deelgenomen aan de Maastrichtse Cohort Studie naar 'vermoeidheid in de arbeidssituatie'. Zonder jullie trouwe medewerking gedurende een periode van drie jaar was dit onderzoek in het geheel niet magelijk geweest. Dit geldt natuurlijk ook voor de 45 deelnemende bedrijven en instellingen en hun contactpersonen die hebben bijgedragen aan helt grote aantal deelnemers.

Er moet heel wat werk worden verzet om een grootschalig onderzoek zoals de Maastrichtse Cohort Studie van de grond te krijgen en draaiende te houden. Beste werkgroepleden en onderzoekers, ik dank jullie van harte voor jullie bijdrage en inzet bij dit eerste project uit een hopelijk lange reeks. Sandra Beurskens, jij enthousiasmeerde me woor het onderzoek en jij had altijd een luisterend oor. Danielle Mohren en Nicole Jansen, in de dubbelrol van kameren lotgenoten: bedankt voor al jullie steun en hulp bij problemen birnen en buiten het werk. Jos Slangen, jouw geweldige inzet bij de dataverwerking en jouw hulp bij het voorbereiden wan het werkbezoek zijn onmisbaar geweest. Kees Schröer, als lid van de projectgroep dank ik jou voor jouw waardevol en verfrissend commentaar. Ludovic van Amelsvoort, bedankt voor jouw hulp, niet alleen bij de laatste loodjes. Gerard Swaen, jij gaf me de ruimte om het wetenschapspad internationaal te bewandelen. Marliese Saya en Sanne Imbos, bedankt voor de vele uren die jullie hebben gestoken in het coderen van diagnoses en talloze beroepen. Annemie Mordant en Ron Schellings bedank ik voor hun betrokkentheid bij het project. 
Goede interpersoonlike relaties op het werk, zo toont een van de studies in dit proefschrift aan, zijn een zeer belangrijk aspect van het werk. Zelf heb ik in de afgelopen jaren op mijn thuisbasis, de capaciteitsgroep Epidemiologie van de Universiteit Maastricht, het grote belang van dit psychosociale werkaspect evaren, en niet alleen ter voorkoming van vermoeidheid. Bij deze wil ik mijn collega's en (oud-) collega's hartelijk danken voor de 'social support work" en de plezierige samenwerking. Cobie Martens, ik ben je zeer damkbar woor het zorgvuldige lay-outen van dit proefschrift.

Furthermore, I would like to thank my colleagues from the division of Chronic Disease Epidemiology at the Department of Epidemiology and Public Health, Yale University School of Medicine, for the inspiring and pleasant research environment. In particular, I am indebted to William 'Bill' Gallo and Artyom 'Art" Sedrakyan, my roommates and "brothers", for the lively discussions, all kinds of support and the great time - not only at LEPH. Linda Morrissey and Vicki Ramsay are gratefully acknowledged for their help and support at any time, in any situation. I would also like to thank Jennifer Rusiecki, my Ph.D. companion, for the interesting dialogues about research and the world outside.

Het werkbezoek aan Yale werd mogelijk gemaakt door de inzet en steun van een aantal personen en instellingen. In dit verband wil ik, naast IJmert Kant en Gerard Swaen, in het bijzonder mijn dank uitspreken aan het instituut HEALTH, de Dwarsverbandcommissie van het NWO Prioriteit Programma 'Psychische vermoeidheid in de arbeidssituatie' en Cecile Nijland.

Marjan (ook jouw hulp was groot in mijn afwezigheid), Erik (ik heb vaak naar de slijmbal gelluisterd), Arianne, Gerben, Andrea en de gehele 'Thembi club' wil ik van harte danken voor de interesse die jullie steeds weer toonden in de vorderingen van het onderzoek, de inspirerende gesprekken over "Gott und die Welt" en alle luisterende oren. Allen Freunden und Bekannten möchte ich danken für das Interesse an meiner niederländischen Doktorarbeit in Englisch. Den Yale-DFG Stammtischlern spreche ich meinen herzlichen Dank aus für die geselligen und relaxten Stunden in denen ich mein Forschungsprojekt eben Forschungsprojekt sein lassen konnte. Claus und Christoph, ihren Familien, sowie Anke, Heiner, Anja, Rita und Familie Danner danke ich für die jederzeit bereitwillige Unterstützung und das allzeit offene Ohr bei kleinen und größeren Problemen. In het bijzonder wil ik hier een aantal mensen bedanken die er in de afgelopen periode altijd voor me waren en wiens vriendschap veel voor mij betekent. Edwin "blijf zo enthousiast. Miranda en Raymond, als paranimien, en Marcus, als CEP, ik dank jullie voor de steun 'tot in het laatste uur'.

Nicht zulletzt möchte ich glanz besonders meinen Eltern danken für ihre großartige Unterstützung, ihr fortwahrendes Interesse und das Verständnis, das sie mir stets entgegenbrachten.

Ute Bütmann

Maastricht, Februari 2002 


\section{ABOUT THE AUTHOR}

Ute Bültmann was born on November 11, 1968 in Schuttorf (Gemany). After graduating from the Burg-Gymnasium in Bad Bentheim (Germany) in 1988, she studied the Dutch language and literature in The Hague (the Netherlands) and at the Westfalische Withelms-Universität in Munster (Germany). In 1990 she applied to the Hogeschool Midden Nederland in Utrecht (the Netherlands) to study Physical Therapy and graduated (cum laude) in 1994. In the same year, she enrolled in the Health Promotion and Education program at the Faculty of Health Sciences of Maastricht University, Maastricht (the Netherlands). After obtaining her M.Sc. degree in February 1997, she worked as a physical therapist in primary care. From September 1997 to December 2001 she was appointed as a Ph.D. student at the Department of Epidemiology of Maastricht. University. Her research was focused on risk factors for fatigue and psychological distress in the working population and resulted in the present thesis. Part of her research was conducted in collaboration with the Department of Epidemiology and Public Health, Yale University School of Medicine, New Haven (USA). where she spent nine months as a visiting research scholar. Since January 2002, she has continued her research activities as a post-doctoral fellow at the Department of Epidemiology of Maastricht University. 